\title{
Functional Histology: The Tissues of Common Coleoid Cephalopods
}

\author{
Ramón Anadón
}

\begin{abstract}
The knowledge of the organization of normal tissues and the changes occurring during physiological or pathological processes is basic to interpret the relationship between structure and function. There are numerous microscopic studies focused on different cephalopod organs that are based on the use of high-resolution methods as the transmission electron microscopy. However, there is no comprehensive basic histological guide to the different tissues in common species of cephalopods. To fill this gap, we present a careful description of the normal histological organization of cephalopods. Through 35 plates including 225 photomicrographs and the accompanying text descriptions, this chapter covers the body systems of three common species of European coleoid cephalopods, the cuttlefish (Sepia officinalis), the squid (Loligo vulgaris) and the octopus (Octopus vulgaris). The histology of the three species is presented in parallel, emphasizing those significant between-species differences. Sections used for study and photomicrographs were mostly stained with hematoxylin-eosin (H\&E), a standard light microscopy method widely accessible for most laboratories of histology and pathology. Some sections of octopus were stained the Masson's trichrome or the periodic acid-Schiff (PAS) methods.
\end{abstract}

\section{Keywords}

Cephalopods • Tissues $・$ Comparative histology $・$ Light microscopy $・$ Atlas

\subsection{Introduction}

The microscopic anatomy or histology is based on examination of stained thin sections of the different structures of the body. The knowledge of the organization of normal tissues and the changes occurring during physiological or pathological processes is fundamental to interpret the relationship between structure and function. Most textbooks of histology are dedicated to human or mammalian tissues, and the scant books existing on comparative histology generally do not mention cephalopod tissues at all. There are numerous detailed microscopic studies focused on different cephalopod organs that are based in the use of high-

R. Anadón ( $($ )

Department of Functional Biology, University of Santiago de

Compostela, Campus Vida, Santiago de Compostela, Spain

e-mail: ramon.anadon@usc.es resolution methods such as the transmission electron microscopy, which have been comprehensively presented in a chapter on cephalopods by Budelmann et al. (1997). For ultrastructural data, interested readers are directed to this chapter, which also includes an exhaustive list of references. However, there is no comprehensive histological guide to the different tissues in common species of cephalopods using standard light microscopy methods available in most laboratories of pathology. This chapter covers the "normal" histological organization of three representative coastal species of Coleoidea. The species studied here are two representatives of decapodiformes, the cuttlefish (Sepia officinalis; Sepiida) and the squid (Loligo vulgaris; Teuthida) and a representative of the octopodiformes, the common octopus (Octopus vulgaris).

The anatomy of the cephalopods has been studied for centuries (Swammerdam 1737; Cuvier 1817; Owen 1855; 
Isgrove 1909; Williams 1909; Meyer 1913; Chun 1914). In this chapter, the microscopic anatomy of main systems of the three species is summarily presented in parallel, emphasizing those between-species differences in tissue organization when significant. Photomicrographs were taken of histological sections of four octopus (two adult males and two females, one immature), two squid (a male and an immature female) and three cuttlefish (two adult males and a female).

Previous to histological methods, live specimens were deeply anaesthetized by immersion in seawater containing $1 \% \mathrm{MgCl}_{2}$ and $1 \%$ ethanol (10-15 min) and then euthanized in seawater with $3.5 \% \mathrm{MgCl}_{2}$ followed by immediate mechanical destruction of the brain. After dissection of the various organs and structures, fixation was done in Davidson fluid (formalin, alcohol and acetic acid in tap water). Tissue blocks were embedded in paraffin wax and sectioned on a rotary microtome. Dewaxed sections were routinely stained with hematoxylin-eosin (H\&E). Some sections of octopus were additionally stained using the Masson's trichrome or the periodic acid-Schiff (PAS)-staining methods.

\subsection{Skin (Fig. 4.1)}

The skin of cephalopods has evolved to separate the internal medium from the seawater but also to provide a quick changing way adapted for intra-specific communication, camouflage, or prey attraction (Osorio 2014). The skin covers the outer surface of the body, showing highly different regional specializations, as in the suckers, and is continuous with the inner surfaces of the siphon and the pallial cavity. The skin of the cephalopods consists of a transparent epidermis formed of columnar epithelial cells and interspersed mucous cells, and a dermal layer of varying thickness formed of connective tissue that includes a number of chromatophores, iridophores and reflecting cells. Light microscopy of histological sections shows little detail of the epithelial cells, but ultrastructural studies reveal complex interdigitation of lateral cell surfaces as well as the presence of an apical microvillous layer (see Lee et al. 2014). A thick basal lamina anchors the epidermis to the dermal tissue. The epidermis of the pallial cavity mostly shows flattened epidermal cells and is deeply modified in some regions of the funnel (see below) where it may form extensive thickened glandular surfaces.

The dermis mostly consists of a connective tissue formed of fibroblasts and networks of collagen fibers included in varied amounts of ground substance that exhibit in many places conspicuous chromatophore organs and also other types of pigment cells below. The skin of octopus and cuttlefish, mainly dorsally, contains a number of muscle fascicles that allow rapid changes in the animal appearance of skin papillae and tubercles caused by erector muscles or its disappearance by contraction of depressor muscles. Collagen fibrils are abundant in the skin and muscles of cephalopods, where they form fiber bundles with various orientations. These fibers are eosinophilic in H\&E stains but are better distinguished from muscle fibers with the Masson's trichrome stain, showing a similar affinity for colorants as vertebrate collagen fibers. The thickness and appearance of the dermis vary along the animal surface. In octopus and cuttlefish, the dermis is thick and endowed of various
Fig. 4.1 Sections of the skin of octopus arm $(\mathbf{a}, \mathbf{b})$ and squid mantle (c, d). In a, note the abundant collagen stained in green and the iridophores in pink. In c, goblet cells and secreted mucus appear red-stained. In d, note muscle fibers inserted at both poles of the organ. $\mathrm{Chr}$, chromatophoric organs; Ep, epidermis; Ir, iridophores (reflecting cells). a Masson's trichrome. b, c H\&E stain. Scale bars a, d $100 \mu \mathrm{m}$; b $200 \mu \mathrm{m}$; c $50 \mu \mathrm{m}$
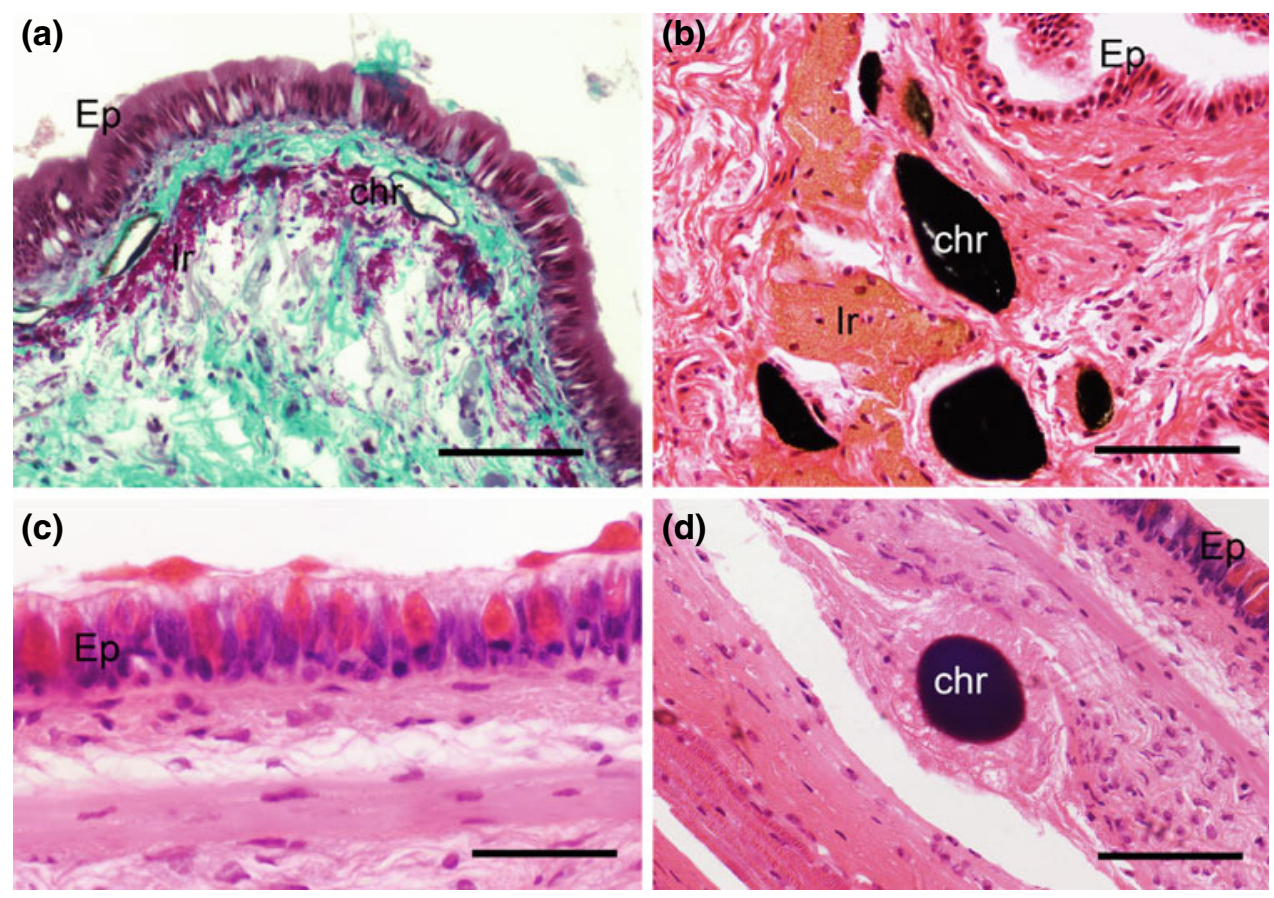
bundles of muscle fibers whose contraction transforms the skin from smooth to papillae or tubercles (papillary erector muscles) or the smoothening of the surface (papillary depressor muscles). This, together with fast changes in pigmentation in an instant, allows animals to adopting flexibly very different appearances for camouflage or communication (Hanlon 2007). The dermis of the inner pallial surface is thin and mostly lacks pigment cells.

\subsection{Chromatophores}

The chromatophore organs are complex pigment-containing structures that consist of a large elastic sac (sacculus) filled of pigment that is contained inside of a chromatophoric cell and a crown of radial muscle fibers that join this cell (Fig. 4.1d). Specialized histological methods and/or transmission electron microscopy reveal that radial muscle fibers are richly innervated by nerve fibers accompanied of glial cells, as well as the unsheathing cells around the chromatophore cell. In live animals, chromatophore organs exhibit changing size and colors that vary from black-brown in melanophores to red or yellow in other chromatophores. The contraction of radial muscle fibers extends the pigment sacculus and its relaxation concentrated pigment showing a small surface. In histological sections of anaesthetized animals, they appear contracted as black organs. The contraction and/or relaxation of different types of chromatophoric organs combined with the reflection of light by other types of pigment cells located below allow the extremely rapid changes of the coloration patterns in the skin of cephalopods (Packard 1995). A number of videos of cephalopods showing fast changes of skin pigmentation patterns are freely available in the Web.

In the skin, eyes and other tissues of cephalopods, there are different types of reflecting cells. In H\&E-stained histological sections, the reflecting cells appear to contain yellowish platelets or granules that are mostly unstained (Fig. 4.1b), but granules appear brightly stained in red with Masson's trichrome method. The internal organization of reflecting cells has been thoroughly studied with transmission electron microscopy. These ultrastructural studies reveal several types of pigment cells named as iridophores, leucophores and reflecting cells with varied structural organizations of reflective structures (see Budelmann et al. 1997). Recent studies show that reflecting platelets contain condensed proteins coded by the reflectin gene family that is specific to cephalopods (Crookes et al. 2004; DeMartini et al. 2015). The regular arrangement of collagen fibers in the dermis may also contribute to the skin appearance and reflectivity.

In many species of pelagic cephalopods, but not in the octopus, squid and cuttlefish species illustrated here, the skin may bear a number of photophores, specialized organs that emit light.

\subsection{Cartilaginous Tissues (Fig. 4.2)}

Cephalopods use cartilaginous tissues in a few locations of the body (Cole and Hall 2009). Chondroid tissues form a part of buccal bolsters contributing to mechanical properties of the buccal mass. In squid, buccal bolsters show an onion-like organization of connective cells around a pulpous-like connective center. The cerebral ganglia are surrounded by cartilage in some respects similar to that of vertebrates, although chondrocytes exhibit thin-branched processes. Isogenic groups of chondrocytes are frequently observed. A dense perichondrium consisting of thin fibroblasts included in an abundant matrix of collagen fibers surrounds some surfaces of cranial cartilages. In the eye, the equatorial and subequatorial scleral regions exhibit a cartilaginous skeleton that reminds the scleral bones or cartilages found in many vertebrate eyes. In squid and cuttlefish, the scleral cartilage shows a single or a double layer of radial columnar chondrocytes embedded in homogeneous cartilaginous matrix. In octopus eyes, the equatorial sclera exhibits a thick cartilagelike tissue with dense accumulation of very thin and long radial cells that are well-stained with the Masson's method. These cells are embedded in scarce matrix, and the inner and outer tissue surfaces are flanked by thin muscle layers (scleral muscles). Connective tissues in the base of the octopus cranium often may show atypical appearances with very thick collagen fibers embedded in an abundant homogeneous unstained matrix containing fibroblasts and lacking blood vessels, which make them difficult to classify. 

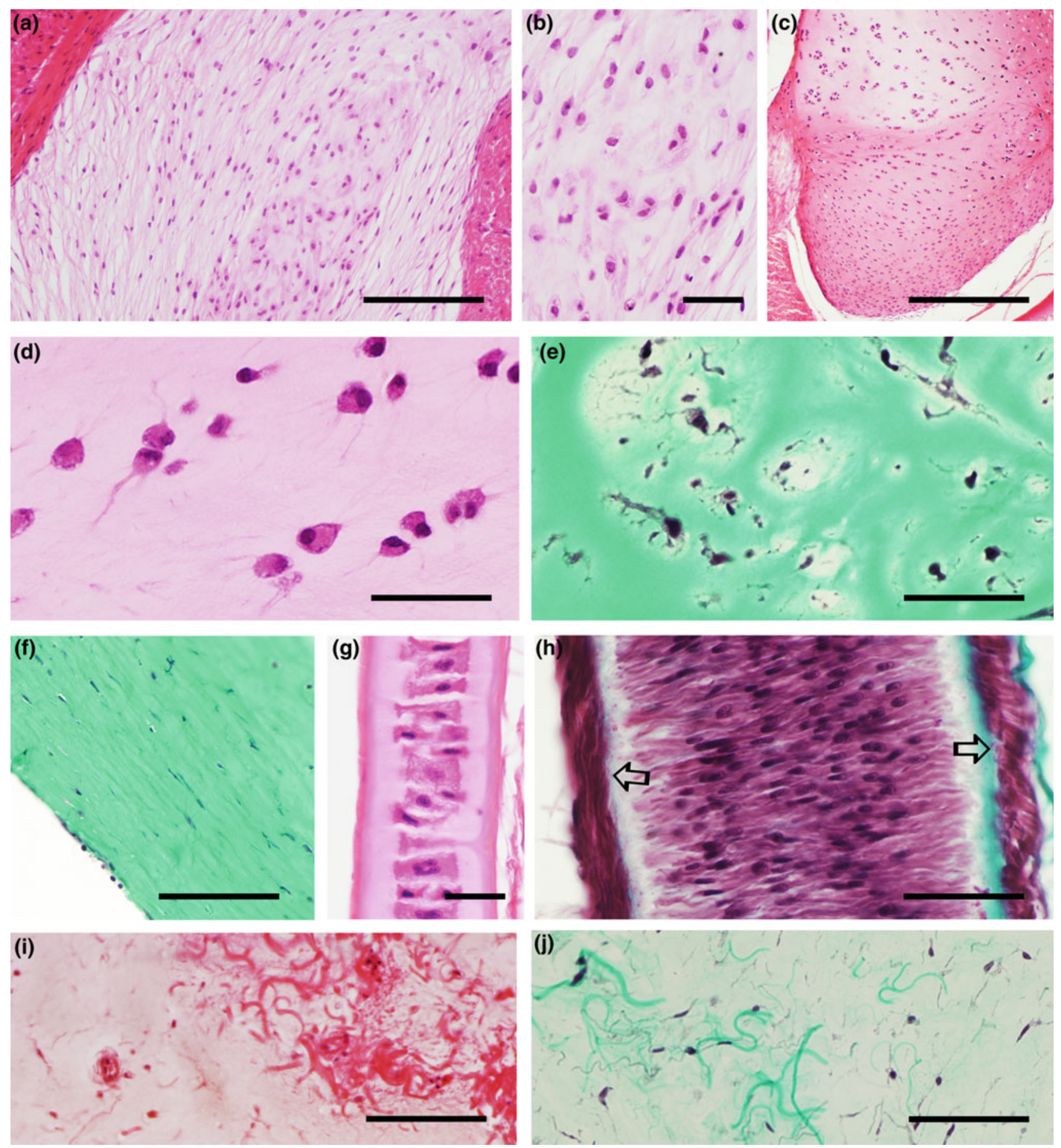

Fig. 4.2 Sections of cartilage and related skeletal tissues. a, b Chondroid tissue of a buccal bolster of squid showing an onion-like organization of connective cells around a pulpous-like connective center. $\mathbf{c}$ Section of the cranial cartilage of squid. $\mathbf{d}$ Detail of processes of chondrocytes. e Section of the cranial cartilage of octopus showing branched chondrocytes. f Dense perichondrium of a cranial cartilage. e Equatorial scleral cartilage of the squid with a single layer of

chondrocytes. f A typical equatorial scleral cartilage-like tissue of the octopus eye showing dense accumulation of thin and long radial cells. The tissue is flanked by thin muscle layers (scleral muscles; outlined arrows). $\mathbf{i}$, $\mathbf{j}$ Sections through connective tissue in the base of the octopus cranium showing thick collagen fibers in a homogeneous matrix. a-d, $\mathbf{g}-\mathbf{i}, \mathrm{H} \& \mathrm{E}$ stain; $\mathbf{e}, \mathbf{f}, \mathbf{h}, \mathbf{j}$ Masson's trichrome. Scale bars $\mathbf{a}$, $\mathbf{f}, \mathbf{h}, \mathbf{i}, \mathbf{j} 100 \mu \mathrm{m} ; \mathbf{b}, \mathbf{g} 25 \mu \mathrm{m} ; \mathbf{d}, \mathbf{e} 50 \mu \mathrm{m} ; \mathbf{c} 200 \mu \mathrm{m}$ 


\subsection{The Shell}

Some cephalopods have a shell that is located within a dorsal sac of the mantle. Two types of shell are found in coleoids, calcified and chitinous. In cuttlefish, the shell (cuttlebone) is calcareous (aragonite) with a dense dorsal region and a chambered ventral part with pillars and lamellae. A siphuncle complex consisting of specialized epithelium below the shell allows the regulated filling of shell chambers with gas, contributing to the regulation of the cuttlefish buoyancy. For further anatomical details of the cuttlebone, see Budelmann et al. (1997) and Checa et al. (2015). In squid, the shell is a chitinous pen (gladius), a feather-shaped plate, included in the dorsal epithelial sac and secreted by the shell gland. The squid pen is thickened in the midline forming a rachis. In octopus, the shell relicts surrounded by mantle muscles are appreciable only at the insertion of retractor muscles of the funnel.

\subsection{Muscular Organs}

Muscular tissues form a major part of the body of cephalopods, which are highly specialized active marine predators. The musculature of cephalopods, as in other mollusks, mostly consists of muscle fibers with contractile material organized in oblique band or oblique striation, which is hardly visible in normal histological sections as those shown here. These fibers are very thin and long cylindrical cells with the contractile material forming an external tubular region around a central cytoplasmic core that can be mitochondria-poor ("white" muscle fibers) or mitochondria-rich ("red" muscle cells) (Mommsen et al. 1981). Fibers bear a single elongated nucleus. Ultrastructural and functional descriptions of the organization of these fibers including the oblique organization of contractile filaments, dense bodies and sarcoplasmic reticulum can be found in Budelmann et al. (1997) and Rosenbluth et al. (2010). These fibers form the basis of the body muscles, which are most often observed in bands or bundles of parallel fibers with different orientations (see below). Based on their biomechanical features, these muscular masses form muscular hydrostats, muscular organs which lack typical systems of skeletal support (Kier and Smith 1985). In addition to the muscle fibers with oblique striation that form most of the cephalopod muscles, thin cross-striated muscle fibers with myofilaments aligned in register have been reported in transverse muscles of tentacles of cuttlefish and squid and in intrinsic eye muscles (Kier 1985).

\subsection{The Mantle and Its Muscle Layers (Fig. 4.3)}

The mantle forms the muscle walls of the large pallial cavity enclosing the gills and the visceral mass. In squid and cuttlefish, lateral extensions joined to the mantle form the fins.
Contractile activity of the mantle provides the water flux for respiration and the water jerks for rapid escape and swimming of the animal, whereas fin contractions mediate "flying." The mantle consists of a complex tubule-like lamina of muscle tissue covered of connective tunics and skin in its outer and inner surface. In octopus, the mantle muscle mainly consists of inner and outer layers of longitudinal muscle fibers sandwiching a thick central region of circular (transverse) muscle fibers. Thin layers of radial muscle fibers separate bundles of fibers in both the circular and longitudinal muscles. In the squid mantle, the muscular region mainly consists of thick bands of circular muscle fibers alternating with thin circular bands of radial muscle fibers. These layers are covered by the inner and outer connective tunics, and oblique lattices of connective fibers are intercalated with muscle fibers. These connective fibers fold or expand with mantle contractions to accommodate strain gradients (Kurth et al. 2014). The organization of the cuttlefish mantle is similar to that of squid.

\subsubsection{Fins}

Squid and cuttlefish have muscular fins attached to the lateral side of the mantle, which is lacking in octopus. Undulations of these fins, together with mantle contractions and water jets, contribute actively to the different phases of swimming. The lateral fins extend along most the mantle in cuttlefish but only in the apical region in squid. They are attached over the mantle musculature to a region originated during development from the shell sac. The central muscular region of the fin is covered of skin similar to that covering the outer mantle surface. The fin musculature forms two opposite bands separated by a connective layer. In each band, there are bundles of muscle fibers with longitudinal (deep region), transverse (superficial) and dorso-ventral orientation arranged in a regular pattern. An intramuscular array of crossed connective fibers probably provides support during gentle fin movements (Johnsen and Kier 1993).

\subsubsection{The Funnel, the Closure Apparatus and Funnel Organ (Fig. 4.4)}

The siphon or funnel is a foot-derived muscular organ that projects from the margin of the mantle between the ventral mantle corners into a conical tube, the siphon that leads from the mantle cavity to the exterior. The extended funnel ventral region allows the free entrance of water in the pallial cavity between the it and the ventral mantle during pallial dilatation, and make the function of a valve (siphonal valves) during mantle contraction, forcing the flow of water through the siphon (water jerks). The muscles of the squid funnel valves are formed of thick inner and outer bands of longitudinal fibers and circular (transverse) fibers, 
Fig. 4.3 Muscle fibers of the mantle of octopus $(\mathbf{a}-\mathbf{c})$ and squid (d-f). a Panoramic view of a transversal section showing bundles of longitudinal fibers in the inner and outer side of the thick central region with circular muscle fibers. b Detail of the central region showing thin layers of radial fibers separating thick bundles of circular fibers. Note also the net of collagen fibers (green stained) among muscle bundles. c Section through the outer bundles of longitudinal fibers showing the net of collagen tissue and thin bands of radial muscle separating circular bundles. d Outer region of the squid mantle musculature showing circular and radial muscles. e Detail of muscle fibers running in parallel. f Inner region of the squid mantle musculature showing bundles of radial, circular and longitudinal fibers and fascias of dense connective tissue. cT, connective tissue; $\mathrm{C}$, circular muscle; iL, inner longitudinal muscle; oL, outer longitudinal muscle; R, radial muscle. In all figures excepting $\mathrm{E}$, the outer surface is at the right. a, d-f H\&E stain. b, c Masson's trichrome. Scale bars a $500 \mu \mathrm{m} ; \mathbf{d}$, f $100 \mu \mathrm{m} ; \mathbf{b}$, c, e $50 \mu \mathrm{m}$
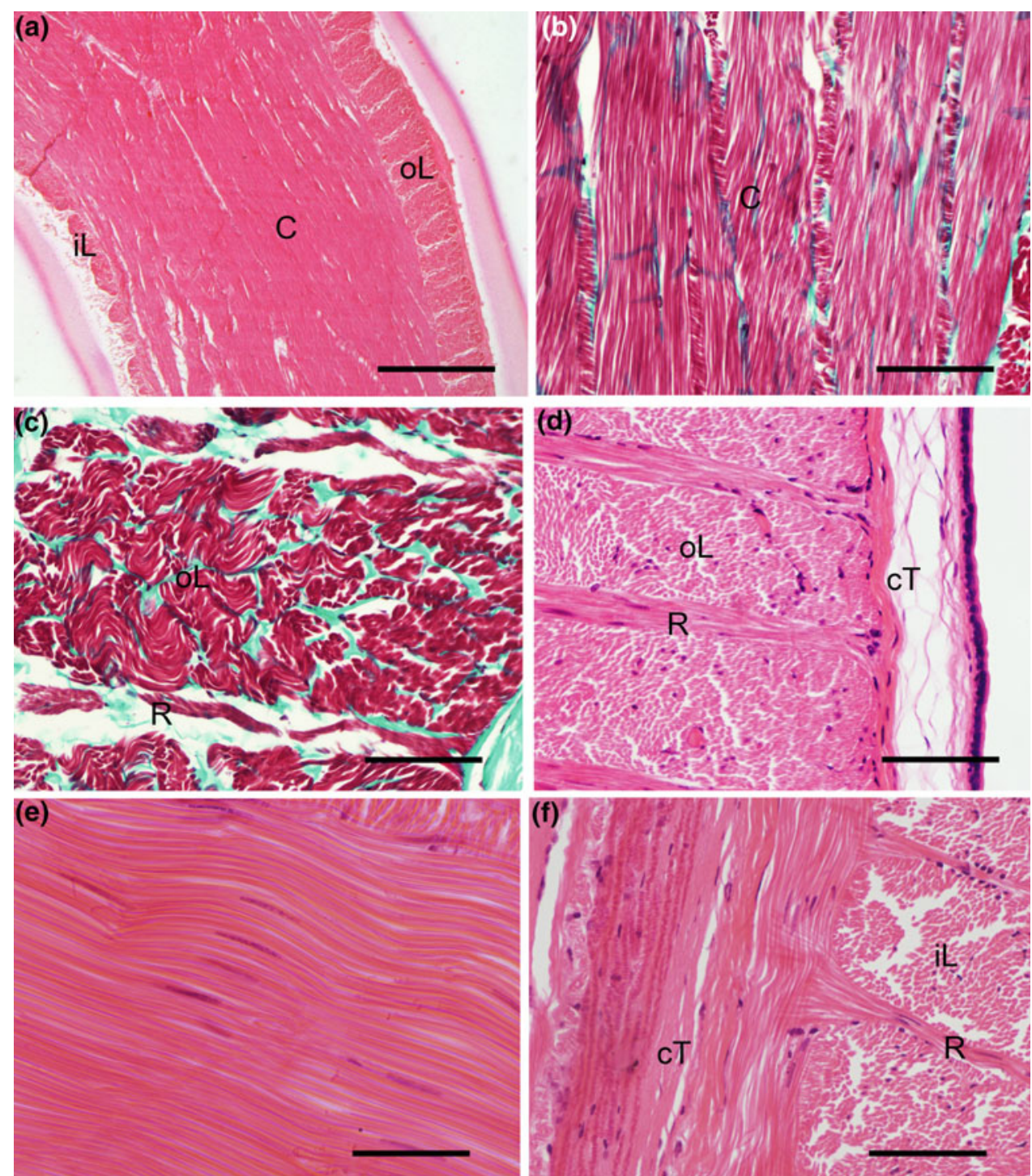

respectively, with thin bands of radial fibers interspersed. The muscles are covered of connective tunics that are continuous with the perichondrium of the funnel cartilage. In squid and cuttlefish, this funnel cartilage is covered of a thin skin and forms a socket for the complementary bouton-like cartilaginous protrusion of the mantle. Thus, the funnel articular cartilage is part of the paired closure apparatus joining the siphonal valves and mantle.

The epidermis of the inner surface of the funnel of squid (and other cephalopods) forms an extensive and very thick intraepithelial gland. It consists of a superficial layer of small epithelial cells of cuboid cylindrical appearance that covers a large mass of tall mucous glandular cells that show nuclei in basal regions and enlarged secretory regions in upper regions. The basal cytoplasm of glandular cells is associated with the fibro-vascular tunic of the epithelial gland. It is thought that the secretion of this gland adds to ink-jets and contributes to minimize water turbulences and facilitate the dynamic of the ink clouds ejected in the water during escape behavior (Derby 2014).

\subsubsection{The Arms and Tentacles (Figs. 4.5 and 4.6)}

Cephalopods bear a characteristic crown of highly mobile elongated fleshy appendages (eight arms and, in squid and cuttlefish, two tentacles). These appendages are arranged around the mouth and are essential for feeding. These cephalopod appendages, together with the siphon, are derived from the embryonic foot. The arms are thicker basally and taper toward the tip. Transverse sections of the arm shaft show a large cylindrical mass of muscle fibers and connective tissue around an axis formed of a ganglionic nerve cord (see below). The large central circular or ovoidal 
Fig. 4.4 a Section of the squid funnel showing the thick muscle layers and the funnel organ. $\mathbf{b}$, c Photomicrographs of the funnel organ showing details of the thick glandular epithelium. Note the large mucous cells basally located and the small non-glandular cells apically. d Section of the funnel passing through the funnel cartilage forming part of the closure organ. H\&E stain. Scale bars a $500 \mu \mathrm{m}$; b $100 \mu \mathrm{m}$; c $50 \mu \mathrm{m}$
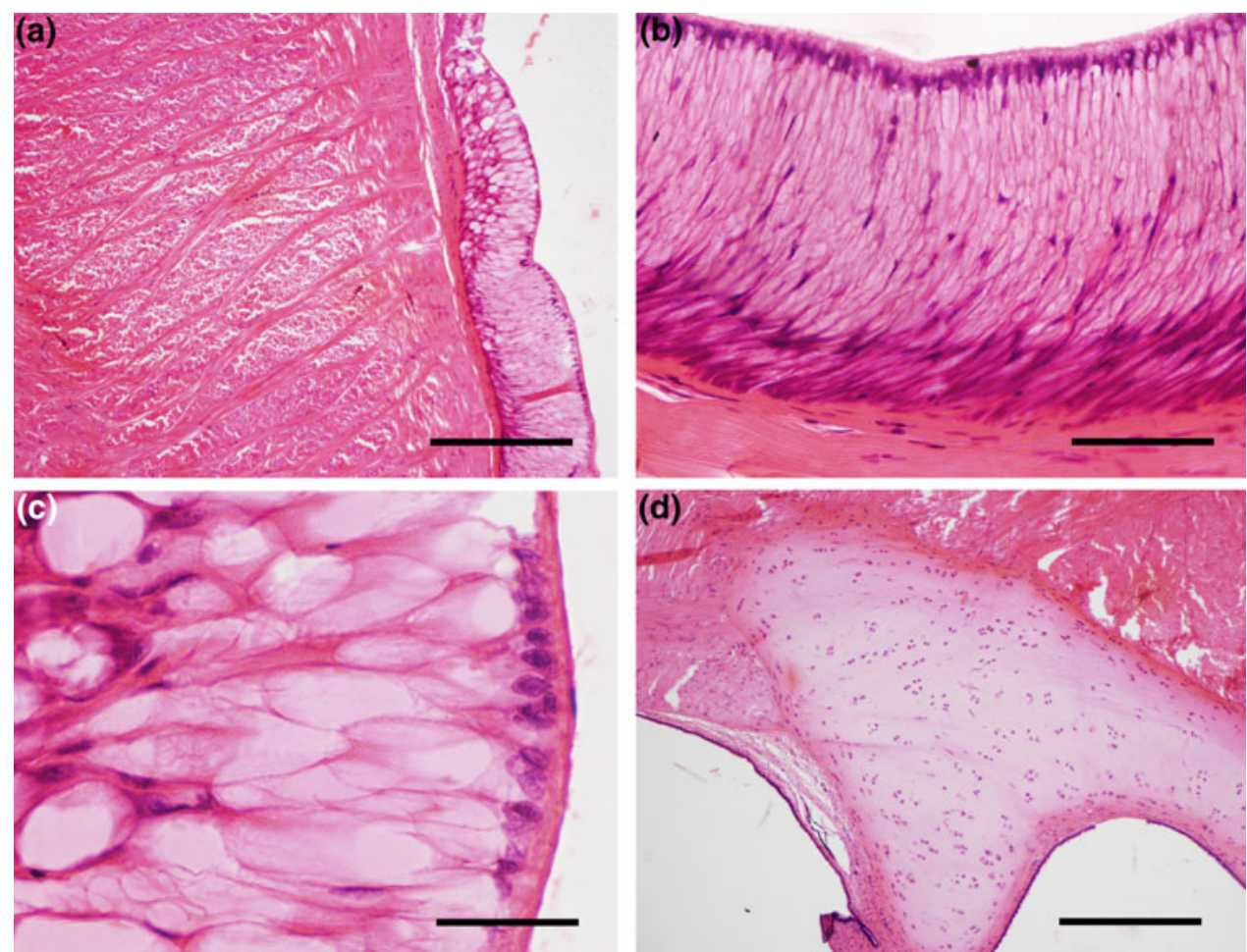

muscle mass of octopus consists of a number of transverse muscular fibers organized in bundles crossed in various directions oriented more or less radially and extending peripherally as muscle trabeculae intercalated with bundles of compact longitudinal muscle fibers arranged in four sectors. This central region is surrounded by thinner bands of oblique (helical) muscle fibers and longitudinal muscle fibers surrounded by a layer of circular muscle fibers. Trabeculae of connective tissue accompany bundles of muscles. For further details of the octopus arm organization, see Kier and Stella (2007). Along the inner side surface (facing toward the mouth), they bear numerous suckers on thin peduncles (decapods) or sessile suckers (two alternate rows in octopus). Muscular bands join these stalked of sessile suckers to the shaft musculature. The shaft is also connected to protective membranes, lateral flaps flanking the sucker region and swimming keels by muscle bands. These lateral membranes contribute to the hydrodynamic properties of squid facilitating arm cohesion and forward or backward swimming and steering. During squid swimming, the arms are pressed together and enclose the tentacles. The fourth ventral pair of arms of cuttlefish bears prominent lateral flaps.

The pair of tentacles found in squid and cuttlefish are modified 4th pair appendages inserted in a pocket between the arm pairs III and IV (the fifth ventral arm of decapods is named as arm IV). Tentacles consist of a long, highly protractible shaft ending in a dilation or club armed with suckers and a terminal region. They are able of considerable fast extension and contraction and are used for prey capture. The shaft shows the axial nerve cord with thick nerve fibers (see below) surrounded by a large mass of crossed bands of transverse muscle fibers, whereas bands of longitudinal muscles in the periphery are small and separated by transverse muscle bands. Thin circular and helical layers of muscle fibers surround the large central muscular mass. Interestingly, the transverse and circular muscle fibers of the tentacular shaft are thin and cross-striated. Unlike oblique-striated fibers, ultrastructural observations reveal that the contractile material is organized in short sarcomeres with thick myosin myofilaments of only about $1 \mu \mathrm{m}$ long, but this is inappreciable with the conventional light microscopy methods used here. The functional properties of these cross-striated fibers differ dramatically from those of oblique-striated fibers and exhibit contraction curves about ten times faster than the other arm muscles. For additional information on the functional organization of muscles of cephalopod arms and tentacles, see Kier and Curtin (2002) and Kier (2016).

The suckers are muscular suction cups on arms and tentacles used in feeding and other functions. The arms and suckers grow continuously, and new suckers are added to the growing apex. The size of suckers decreases toward the arm tip. In octopus, the suckers are symmetrical protrusions and consist of a muscular cup-shaped acetabulum joined to a flattened distal ring, the infundibulum, which is the surface that attaches to the substrate. Suckers are attached to the arm 


\section{(a)}
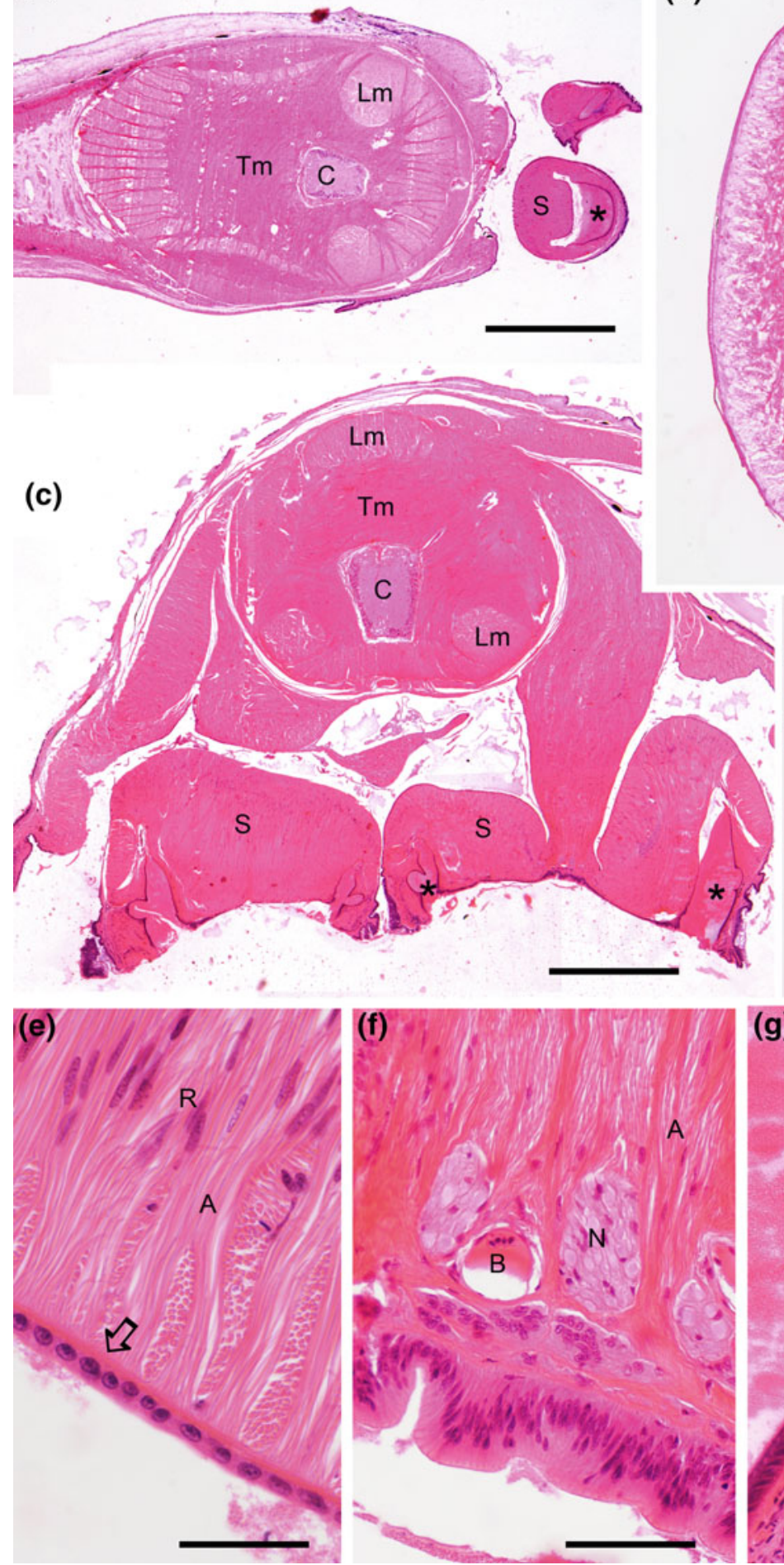

(b)

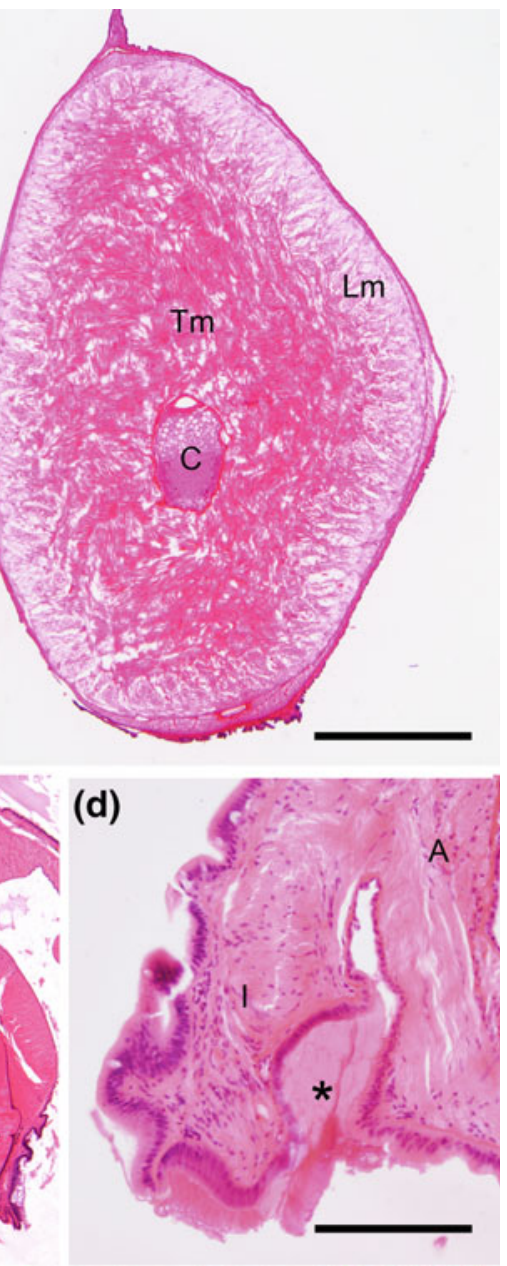

Fig. 4.5 Transverse sections of a squid arm (a), tentacle (b) and tentacle club (c) showing their different appearances. In a and $\mathbf{c}$, suckers ( $\mathrm{S}$ ) are visible. Note in $\mathrm{C}$ the long pedicle joining the suckers to the club and lateral protective membranes. C, nerve cord; Lm, longitudinal muscle; Tm, transverse muscle. $\mathbf{d}$ Detail of the base of the acetabulum (A) separated by a groove from the infundibulum (I) of a club sucker. e Detail of the acetabulum outer surface showing the insertion of radial muscle fibers (R) in the fascia (outlined arrow) that is

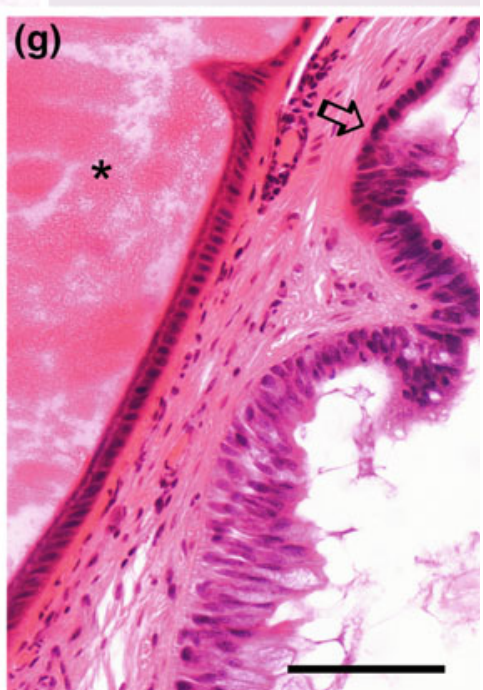

just below the epidermis with cuboid cells. $\mathbf{f}$ Detail of the central region of the acetabulum showing the insertion of pedicular muscles in the fascia below a thickened epithelium. N, nerves; B, blood vessel. g Detail of the border between the acetabulum (A) and infundibulum (I) showing the secretory epithelium producing the ring teeth (star) at left, and the sharp transition between skin zones (outlined arrow). Stars in $\mathbf{a}, \mathbf{c}, \mathbf{d}, \mathbf{g}$ indicate the ring teeth. H\&E stain. Scale bars $\mathbf{a}, \mathbf{b} 1.2 \mathrm{~mm}$; c $1 \mathrm{~mm}$; d $200 \mu \mathrm{m}$; e $50 \mu \mathrm{m} ; \mathbf{f}, \mathbf{g}, 100 \mu \mathrm{m}$ 


\section{(a)}
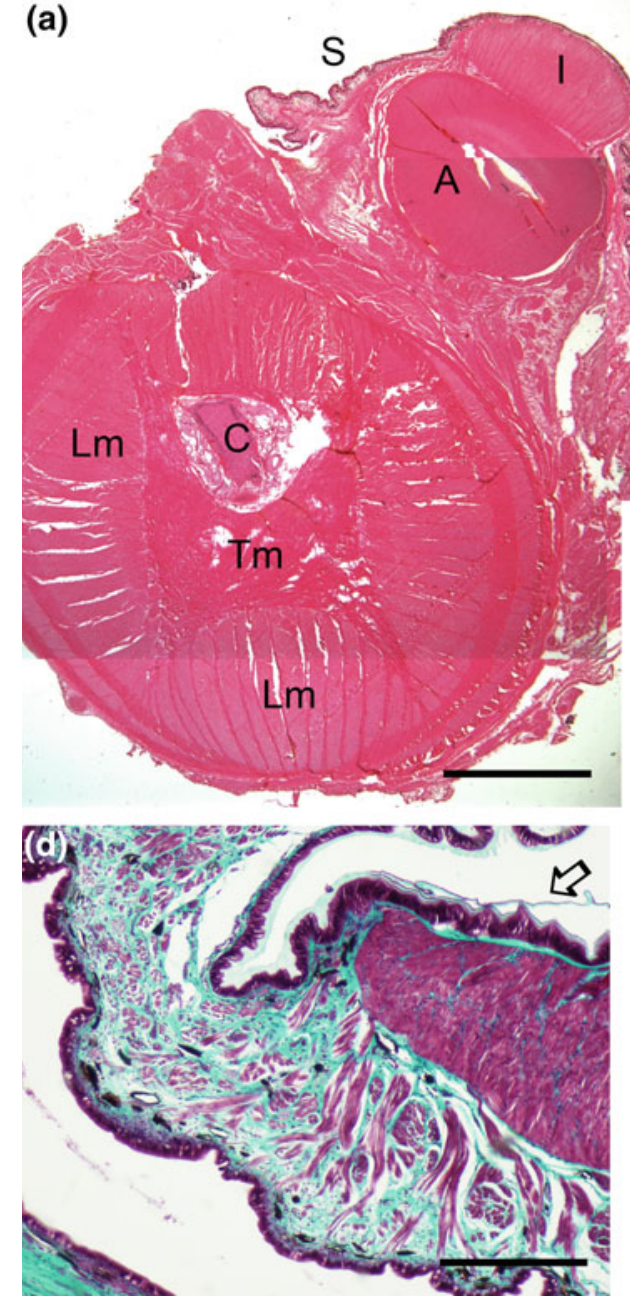

Fig. 4.6 a Transverse sections of an octopus arm showing the core muscles around the nerve cord (C) and the non-stalked base of a sucker (S). The sucker is sectioned marginally showing the thick muscle walls of the acetabulum (A) and infundibulum (I). b Lateral wall of the acetabulum showing the complex fascia between the epithelium and muscles. Only a very thin cuticle covers the acetabular epithelium, which shows occasional papillae. c Section of the infundibulum showing the papillae of the epithelium (outlined arrow). Muscle bands with different orientation (radial, meridional and circular) are also appreciable. The acetabulum is at the left low corner. $\mathbf{d}$ Border of the

\section{(b)}
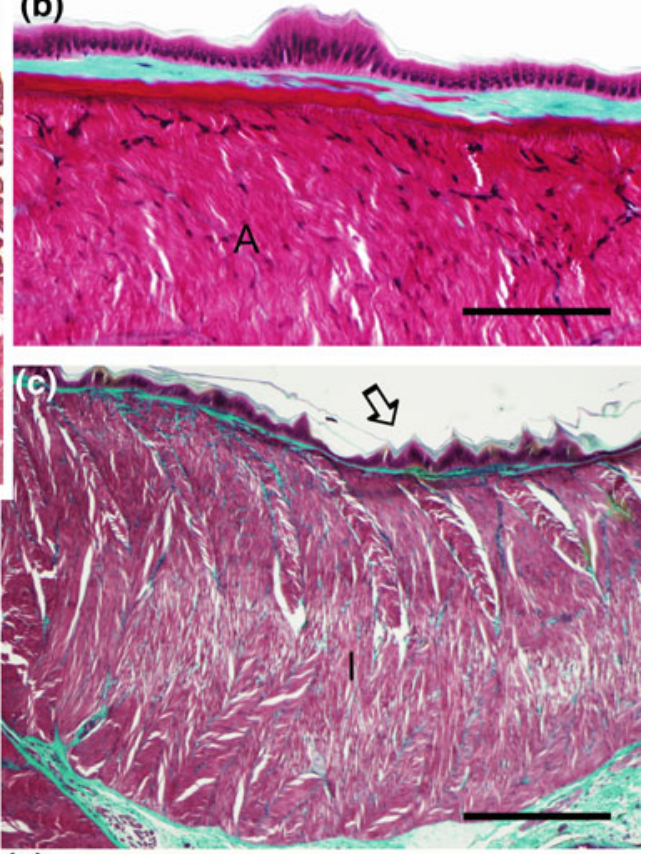

(e)

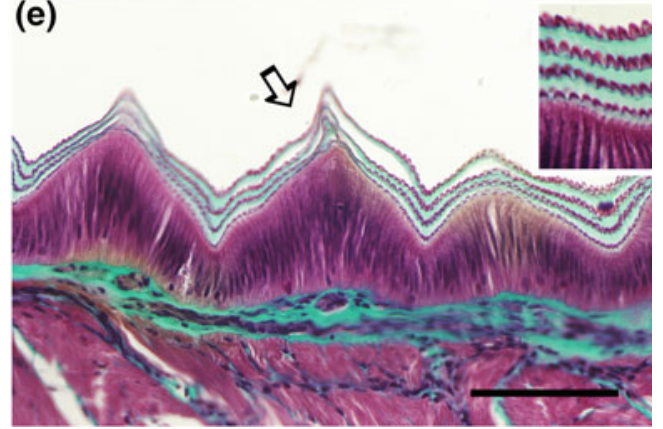

infundibulum showing the transition of the papillae to the normal skin with chromatophores. Note the thick dermis traversed by thin muscle fiber bundles which are in contrast with thick infundibular muscle wall. e Detail of infundibular epithelial papillae covered of a cuticular layer formed of two different types of lamellae. The inset shows a detail of the cuticle showing the relation between apical borders of epithelial cells and the inner lamella with small pegs. Superficial lamellae appear to be seeded out easily (note detached lamellae in $\mathbf{c}$ and d). A, H\&E stain. b-e, Masson's trichrome. Scale bars a $1.2 \mathrm{~mm}$; b $100 \mu \mathrm{m}$; c, d $200 \mu \mathrm{m}$; e $50 \mu \mathrm{m}$

fibers are also visible. After Masson's trichrome staining, a network of oblique collagen trabeculae can be observed in this muscle wall extending between the inner and outer connective membranes and accompanying radial fibers. At the junction with the infundibulum, there are sphincters with numerous circular muscle fibers. In the thick muscle wall of the infundibulum, there are radial, meridional and circular muscle fibers.

In the acetabulum, a poorly specialized cuboidal epithelium bearing scarce small papillae covers the inner connective layer. Instead, the inner surface of the infundibulum is covered by a papillary epidermis consisting of tall epithelial communication with the infundibulum) and circular muscle 
cells arranged in conical papillae or denticles. The epithelial surface is covered of a thick cuticular layer formed of thin alternate laminae of small pegs and amorphous material, which exhibit different staining affinities with the Masson's trichrome stain. Pegs and amorphous material are secreted by tall epithelial cells, and the presence of alternate layers suggests a cyclical renewal of the adhesive surface. At the rim around the papillary surface of the infundibulum, over the end of the thick muscular wall, the papillae and pegs disappear and the surface of the epidermis is only covered of amorphous cuticular material. This cuticle disappears at the transition with the normal epidermis. The suckers are highly specialized for anchoring to a number of substrates and preys. Combined actions of the acetabular and infundibular muscles together with the properties of the infundibular surface provide the basis for the adhesion. For details on the structure and adhesion mechanisms of octopus suckers, see Tramacere et al. (2013, 2014). Below the acetabulum, a musculo-connective region connects the arm and sucker. Numerous muscle bundles of the acetabulo-brachial extrinsic musculature allow the directional extension and retraction of the sucker. A detailed description of the extrinsic acetabulo-brachial muscles of octopus suckers along the arm, arm muscles, and interbrachial muscles is found in Guérin (1908).

In squid and cuttlefish arms and tentacles, the stalked suckers exhibit striking differences with those of octopus. Vertical sections of the sucker show a pedicular muscle that enters through the central roof of the acetabulum and inserts in a thick connective fascia just below the epithelium of the roof, which is unlike the octopus acetabulum (Guérin 1908). The thickened muscle walls of the acetabulum surround this pedicular insertion, being separated by connective tissue. The junction between the infundibulum and acetabulum is wide, unlike in octopus suckers. Moreover, the epithelium of the inner surface of the infundibulum secretes a thick hard annular material known as sucker ring teeth, which lacks in octopus suckers. The ring teeth perform grappling functions during prey capture. Recent studies reveal that the characteristic and mechanically robust ring teeth are formed of a new family of proteins named suckerins, and lack chitin. Suckerins self-assemble into a unique type of supramolecular protein network mechanically reinforced by $\beta$-sheets and are embedded in an amorphous matrix (Guerette et al. 2014; Ding et al. 2014; Hiew et al. 2016). In the outer rim of the infundibulum, there is a toothed cuticular epithelium of tall cells covered of cuticular material that is probably related with sensory neurons. It is followed of a region of folded and thickened epidermis with mucous glandular cells. The external skin of the sucker is mostly formed of a smooth cuboidal or flattened epithelium directly attached to the connective fascia surrounding sucker muscles, without any loose connective tissue separating it from the sucker muscles, which is unlike the complex skin and muscle bundles of the basis of suckers found in octopus. The suckers of decapod arms and tentacles are generally asymmetric. In the tentacular club, numerous and simple small suckers lacking distinction between the acetabulum and infundibulum are found adjacent to the large suckers.

\subsection{The Digestive System (Figs. 4.7, 4.8, 4.9, $4.10,4.11,4.12,4.13$ and 4.14 )}

Cephalopods are highly evolved carnivorous mollusks that pursue and capture prey as crustaceans, fish or other cephalopods using arms and tentacles. Their digestive system (gut) is highly developed and consists of the alimentary canal formed of specialized compartments united by tubular parts. In the coleoids studied in this atlas, the alimentary canal starts in a mouth opening in the large buccal mass. It bears two mandibles or beaks and a radula moved by a complex muscular system and distal parts of salivary glands. The mouth is surrounded by lips (buccal funnel) and the arm apparatus. The arms capture and present prey to feed. A feature of cephalopods is that the esophagus runs through the brain, so the prey must be reduced to fragments by the buccal mass before swallowing. Below the buccal mass, the esophagus allows food to pass to a stomach that is united to a large digestive gland and a caecum, and a thick short intestine continues the system to the anus. Specialized salivary glands accompany the esophagus, their conducts coursing to the buccal mass. Anatomical differences in the digestive system are noted among the three species illustrated here (see Boucaud-Camou and Boucher-Rodoni 1983). For instance, in octopus a crop separates the esophagus into proximal and distal parts, and in cuttlefish, the digestive gland is paired.

\subsubsection{The Buccal Mass (Buccal Bulb, Pharynx)}

The buccal mass is a complex structure surrounded by the buccal and peristomial membranes or lips that comprises a pair of strong, chitinous beaks moved by large muscles, a radular apparatus associated with the buccal cavity, the intrinsic mandibular and radular musculature and nerves, salivary glands and papilla. For a detailed description of the complex anatomy of the buccal mass of squid, including muscles, jaws, radula and glands, the reader is directed to 
Fig. 4.7 MA1. Sections of the buccal mass of cuttlefish and octopus. a Section through the base of a beak wing showing the thick epithelium of beccublasts and the growth of the beak thickness away from this initial region. b Section of a portion of the invaginated radular sac of octopus showing the lamina with radular teeth. c Detail of a radular tooth united to the lamina. d Section showing the tall odontoblasts sinthesizing radular structures. e Section of the buccal mass of an octopus passing through the salivary papilla and the large submandibular salivary gland (star). The arrow points to the salivary duct and the outlined arrow to the subradular ganglion. f Detail of the mucous secretory epithelium of the submandibular gland. a, e, f H\&E stain; bd Masson's trichrome. Scale bars a $100 \mu \mathrm{m} ; \mathbf{b} 0.5 \mathrm{~mm}$; c $200 \mu \mathrm{m}$; d, f $50 \mu \mathrm{m} ; \mathbf{e} 1.2 \mathrm{~mm}$
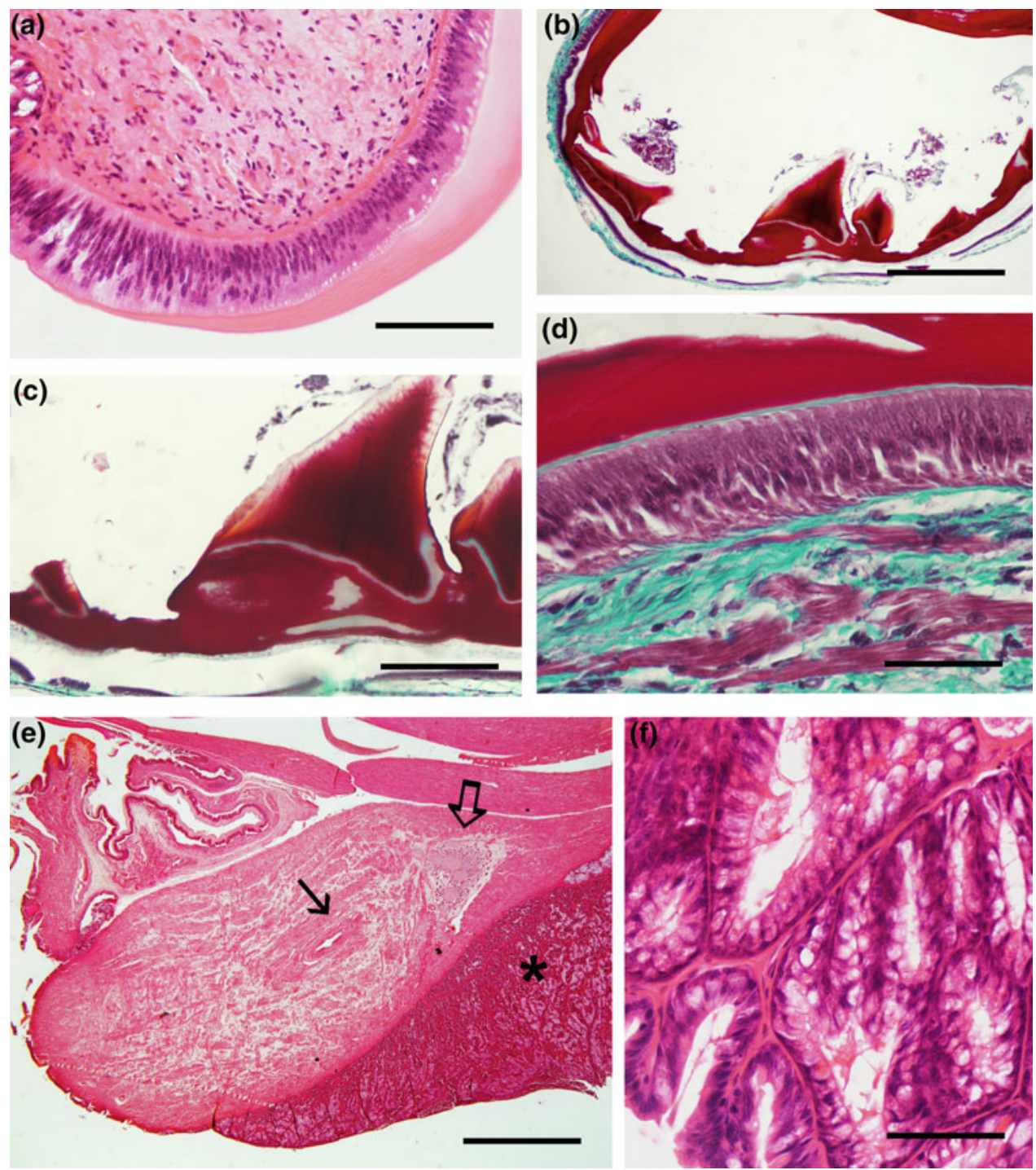

Williams (1909). The functional organization of beak muscles of octopus was studied by Uyeno and Kier (2005). In the following, we only describe the histology of some most characteristic structures including beaks, radula and salivary glands.

\subsubsection{Beaks}

The mandibles, beaks, or jaws resemble a parrot's beak inverted. The upper mandible is longer, straighter, and more compressed than the lower which is strongly convex and closes outside the upper jaw (Williams 1909). Each mandible is formed of two wide and transparent soft chitinous basal plates or wings, which extend apically in a progressively much harder tip or rostrum that forms the cutting edge, where they are generally brownish-black. In histological sections, adult beaks appear frequently broken or separated from the epithelium. The beaks are formed by and lye on a specialized beak-forming epithelium consisting of tall epithelial cells that secrete chitin and proteins, often called beccublasts (Dilly and Nixon 1976). The beccublasts are very tall at the basis of the beak and decrease progressively in height toward apical regions, whereas the beak plate is thin near the basal border and increases considerably its thickness toward the rostrum. The jaws grow constantly by additions to their margins and to their unexposed surfaces. Away from the alar border, the sections of the beak plate (at least in cuttlefish) show two different regions, the distal one that is continuous with that early appearing at the basis and an inner one over beccublasts that shows a different staining with general histological methods. A recent biochemical study in octopus has shown that the hydration, hardening and protein composition of the beak changes from 
Fig. 4.8 D1. Sections of the anterior salivary gland of octopus $(\mathbf{a}-\mathbf{c})$ and the posterior salivary gland of cuttlefish $(\mathbf{d}-\mathbf{f})$. a Panoramic view showing the branched secretory tubules. b and c Secretory portions mainly consist of mucous gland cells that stain pale blue (b) or pink (c) with the Masson's trichrome and the PAS method, respectively. d Panoramic view of the cuttlefish glandular tissue showing its branched tubular organization. e Detail of the mucous cells of glandular tubules. f Section of a glandular duct showing the tall epithelium and the thick musculo-connective wall. a, df H\&E; b Masson's trichrome; c PAS method. Scale bars a $1 \mathrm{~mm} ; \mathbf{b}, \mathbf{c}, \mathbf{e} 50 \mu \mathrm{m} ; \mathbf{f} 100 \mu \mathrm{m}$; d $500 \mu \mathrm{m}$
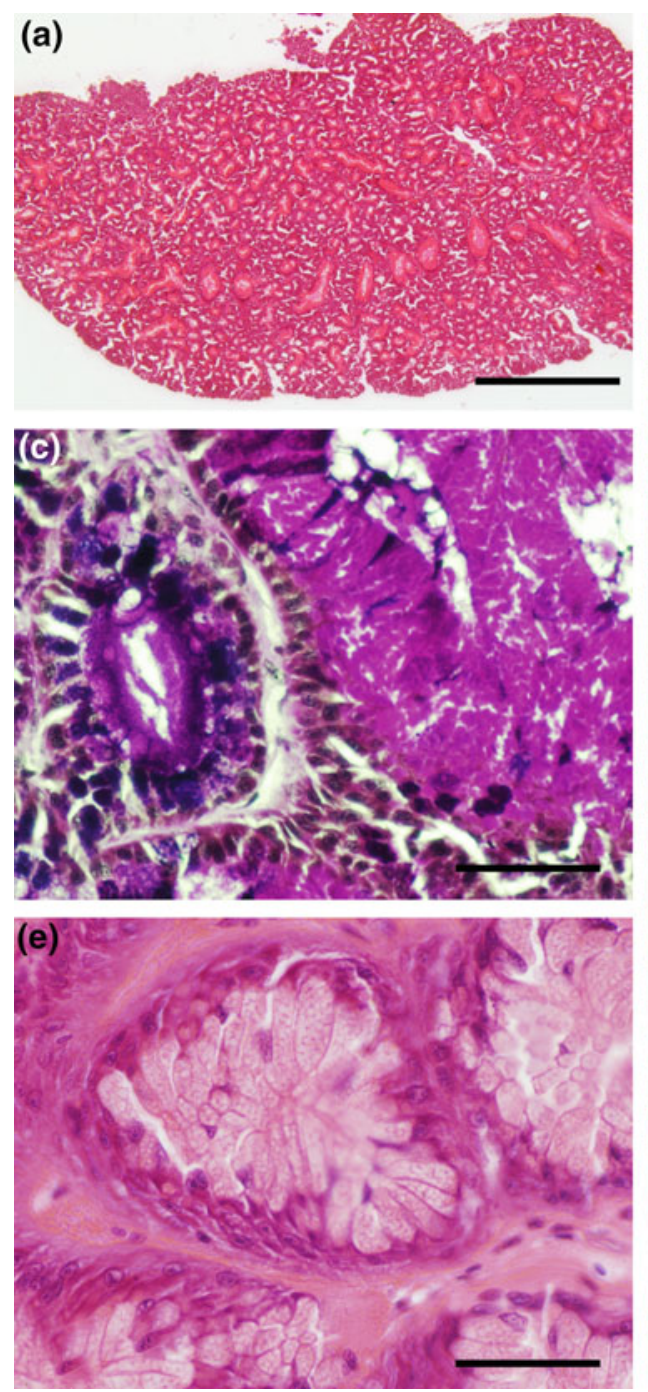
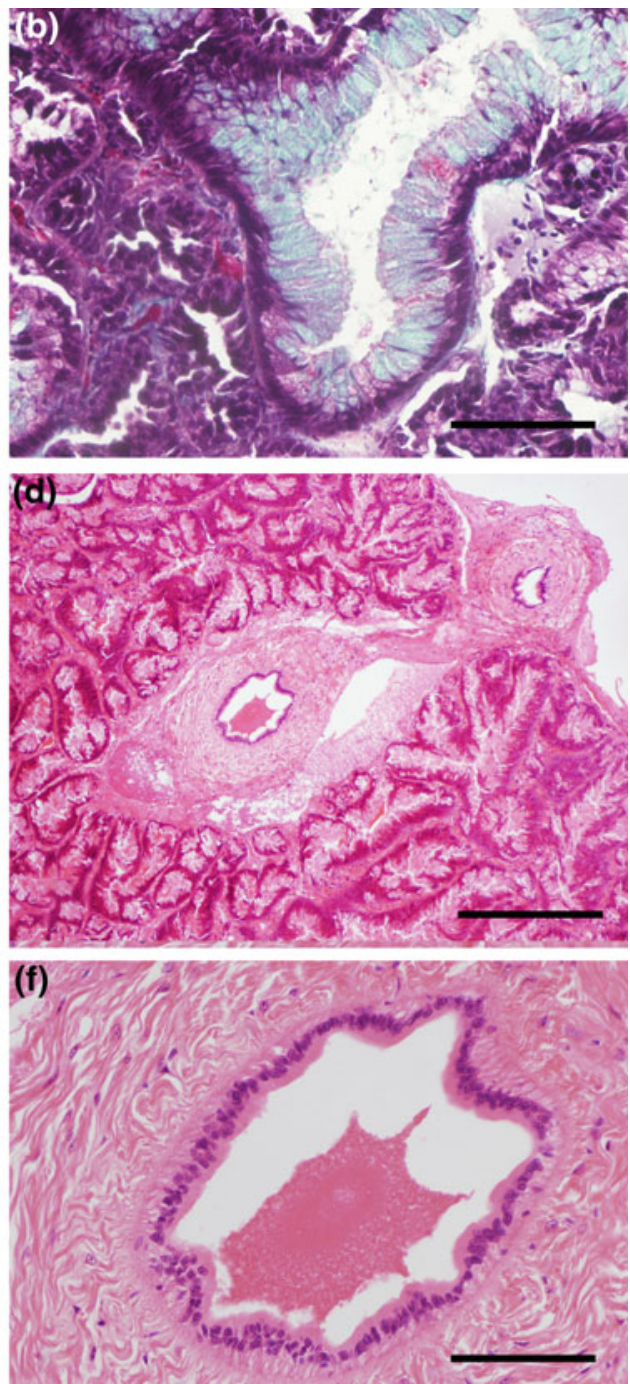

the base to the apex. In soft basal parts, there are proteins belonging to the chitin-binding protein family joined to chitin, whereas in harder apical parts appear proteins of the highly modular histidine-rich protein family (Tan et al. 2015). Mandibular muscles are inserted on the basement connective lamina of the beccublast epithelium (Dilly and Nixon 1976).

\subsubsection{The Radular Apparatus}

The radular apparatus is an eversible buccal structure comprised of the radula and various associated structures. The cephalopod radula consists of a long chitinous membrane with regularly attached teeth arranged in transverse rows, which is better appreciated in dissected and macerated radulas (Messenger and Young 1999). It is lodged in a radular canal that emerges from the radular sac located in the median line. Radular teeth are formed by a set of elongate cells with apical microvilli, the odontoblasts. These cells are organized in two layers, the outer cells producing the radular membrane and the bases of the teeth, and the inner ones producing the cusps. The membrane extends laterally in the hyaline shield covering the cavity in which the retracted radula is lodged. The odontoblasts also secrete the hyaline shield. A subradular connective lamina is intercalated between odontoblasts and muscles. Histological sections of octopus show some details of the radula as the composite origin of teeth, the tall cuticle-secreting odontoblasts and the connective tissue of the subradular membrane. A pair of large protractor muscles (bolster rods), together with the retractor muscles, moves the radula away of and toward the sac allowing to rake food into the pharynx. The radular muscles are innervated by the inferior buccal ganglion (Young 1971). For further details of the anatomy of the radular complex of squid and octopus, the reader is directed to the studies of Williams (1909) and Messenger and Young (1999). 
Fig. 4.9 D2. Sections of the posterior salivary (venom) gland of octopus. a Panoramic view showing the loose organization of branched glandular tubules and striated ducts. b Section showing the transition of the striated duct to the glandular tubule (outlined arrow). Numerous small blood vessels are also observed (thin arrows). c Glandular region showing cells with pale secretion granules and cells with brightly stained granules. Masson's trichrome. d The PAS method stains in purple some glandular cells. e Transverse section of a striated duct showing the characteristic "cistern cells" (thin arrows). f, g Longitudinal sections of a striated duct (f) and one side of a larger duct showing cistern cells (thin arrows) and nerve fibers into the epithelium (outlined arrows). In e-g, stars indicate the duct lumen. a, b H\&E; c, e-g Masson's trichrome; d PAS method. Scale bars a $1 \mathrm{~mm}$; b, c, e-g $50 \mu \mathrm{m}$; d $100 \mu \mathrm{m}$
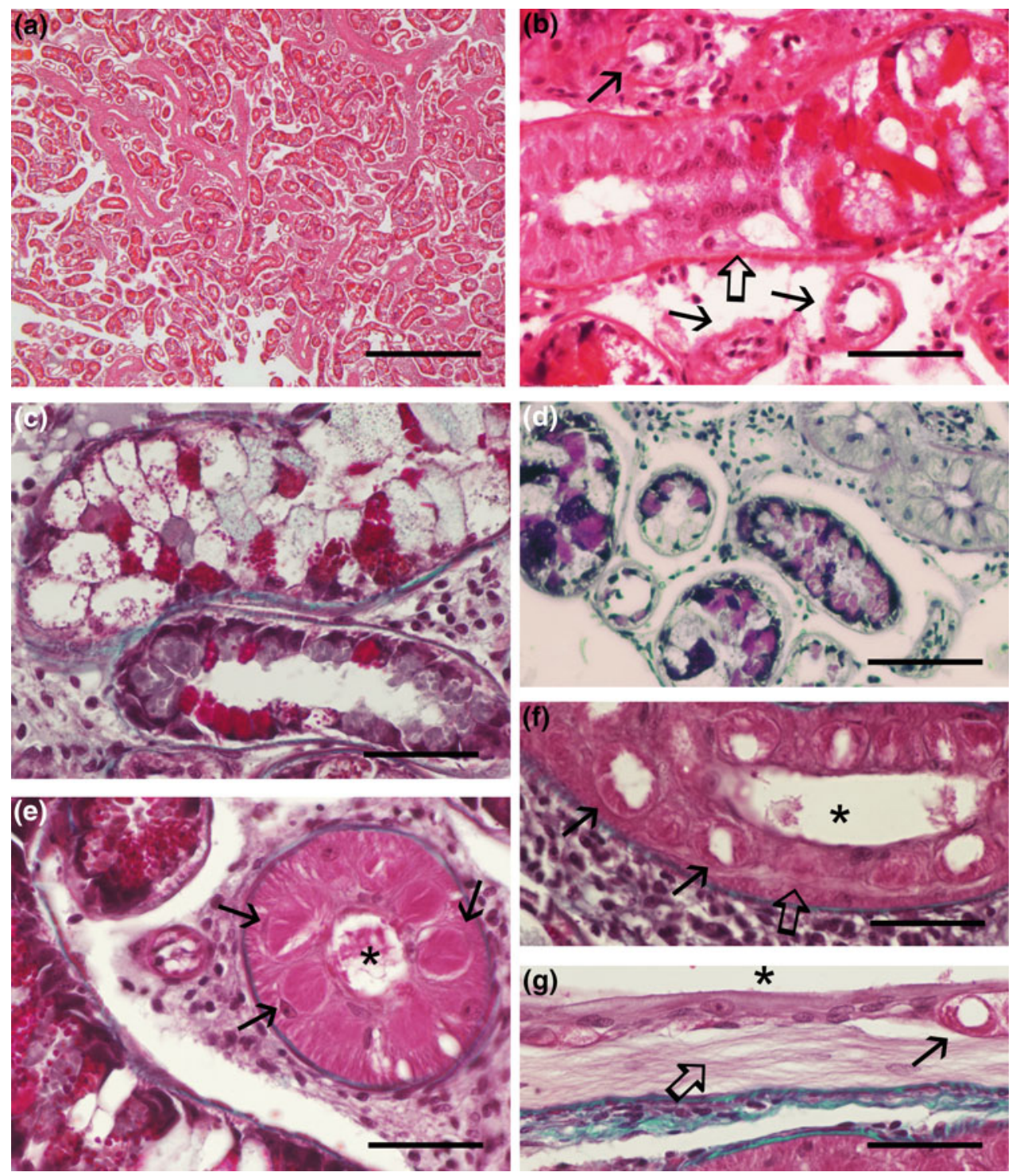

\subsubsection{The Salivary Glands (Figs. 4.8 and 4.9)}

Three types of salivary glands secrete different substances in the buccal mass region contributing to the first phases of feeding including killing preys. These are the submandibular gland and the paired anterior and posterior salivary glands.

The submandibular gland consists of a series of invaginated glandular tubules separated by connective-vascular septa that form a rather compact mass around a central canal lined by the same type of epithelium. In section of octopus glands stained with $\mathrm{H} \& \mathrm{E}$, the glandular tubules show differentiated apical and basal (terminal) regions. The apical part consists of a columnar epithelium formed of large mucous (goblet) glandular cells with basal nuclei and cytoplasm mostly filled of pale granules and, among goblet cells, slender supporting epithelial cells with the nucleus in subapical location. In the basal part of glandular tubules, goblet cells are replaced by shorter glandular cells filled of eosinophilic granules in the supranuclear cytoplasm. Supporting cells are also found among glandular cells. In cuttlefish, the submandibular gland also exhibits goblet cells and granular eosinophilic cells, together with supporting cells, but goblet cells do not form a massive layer.

\subsubsection{Anterior Salivary Gland}

In octopus, the paired anterior salivary glands are located just behind the buccal mass. These glands produce abundant mucus. In H\&E-stained histological sections, the gland appears as a compact mass formed of numerous epithelioglandular tubules with a thin connective-vascular layer 
Fig. 4.10 D3. Transverse sections of esophagus and crop. a Section of the squid esophagus showing the thick muscle layers surrounding the folded mucosa. b, $\mathbf{c}$ Details of the muscular wall and the low prismatic epithelium showing a thick cuticle-like layer.

d Esophagus of octopus stained with the Masson's trichrome. Note the abundant connective tissue and scarcity of muscle fibers in the submucosa and mucosal folds more complex than in squid. e Detail of the mucosa of octopus esophagus showing the tall cylindrical epithelium and the thin cuticle. f Section of the crop of octopus showing the long and complex folds of mucosa. a-c, e-f H\&E stain. Scale bars A, $0.5 \mathrm{~mm} ; \mathbf{b}, \mathbf{d} 200 \mu \mathrm{m} ; \mathbf{c}$, e $50 \mu \mathrm{m} ; \mathbf{f} 1.2 \mathrm{~mm}$
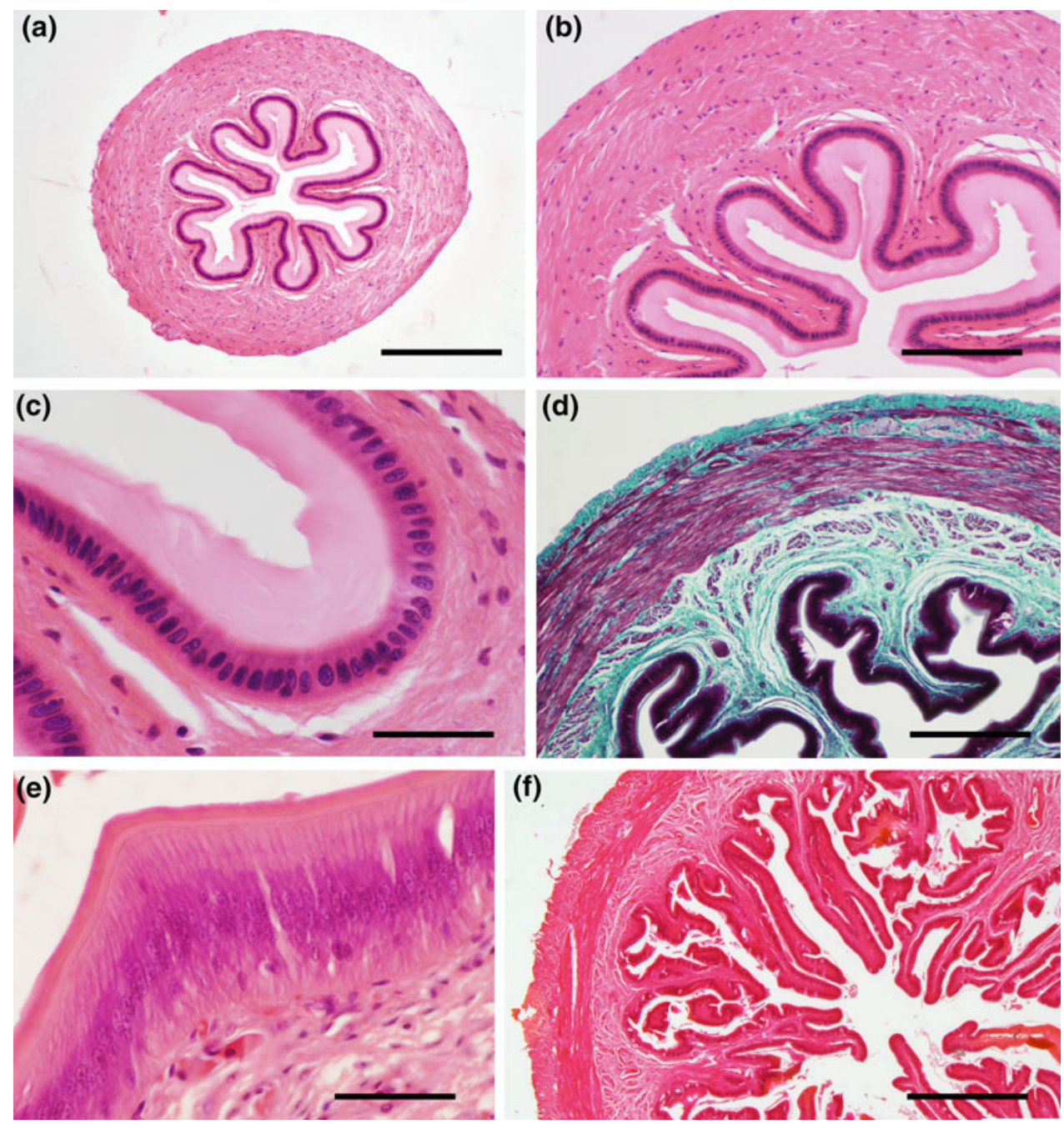

surrounding them. Two types of tubules can be distinguished attending to the appearance of glandular cells. Proximal (toward the ends) parts of tubules show columnar cells with basal rounded nuclei surrounded by basophilic cytoplasm and apical cytoplasm filled of small basophilic granules. Distal tubules are coarser and show a higher glandular epithelium with numerous condensed small nuclei basally and a wide cytoplasm mass filled of eosinophilic granules in which lateral limits between cells are hardly appreciable under light microscopy. The thickest intraglandular ducts show the same type of glandular epithelium.

\subsubsection{Posterior Salivary Glands (Poisonous Gland, Venom Gland)}

The posterior salivary glands of coleoids lie dorsal to the mantle cavity behind the cranium. These glands secrete mixtures of proteins and other substances that are toxic for other animals (Ruder et al. 2013). In cuttlefish, the posterior salivary gland is a massive branched tubular gland with abundant dense connective-vascular tissue among the glandular tubules. Unlike octopus, these glandular tubules show a homogeneous appearance along the gland. The epithelial wall consists of tall columnar glandular cells with basophilic basal cytoplasm including the nucleus and a wide apical region filled of small pale granules, possibly mucous. Among these cells, there are also thin supporting cells with condensed nuclei located subapically. The main duct of the posterior salivary gland of cuttlefish is lined by a short columnar non-glandular epithelium with abundant cell nuclei located at middle heights. This duct is surrounded by abundant circular muscle fibers.

In octopus, the posterior salivary gland consists of branched tubules embedded in a translucent matrix, with two types of tubules, secretory (A) and striated (B), which are continuous. The spaces among tubules are filled of loose connective-vascular tissue. The distal A tubules are clearly 

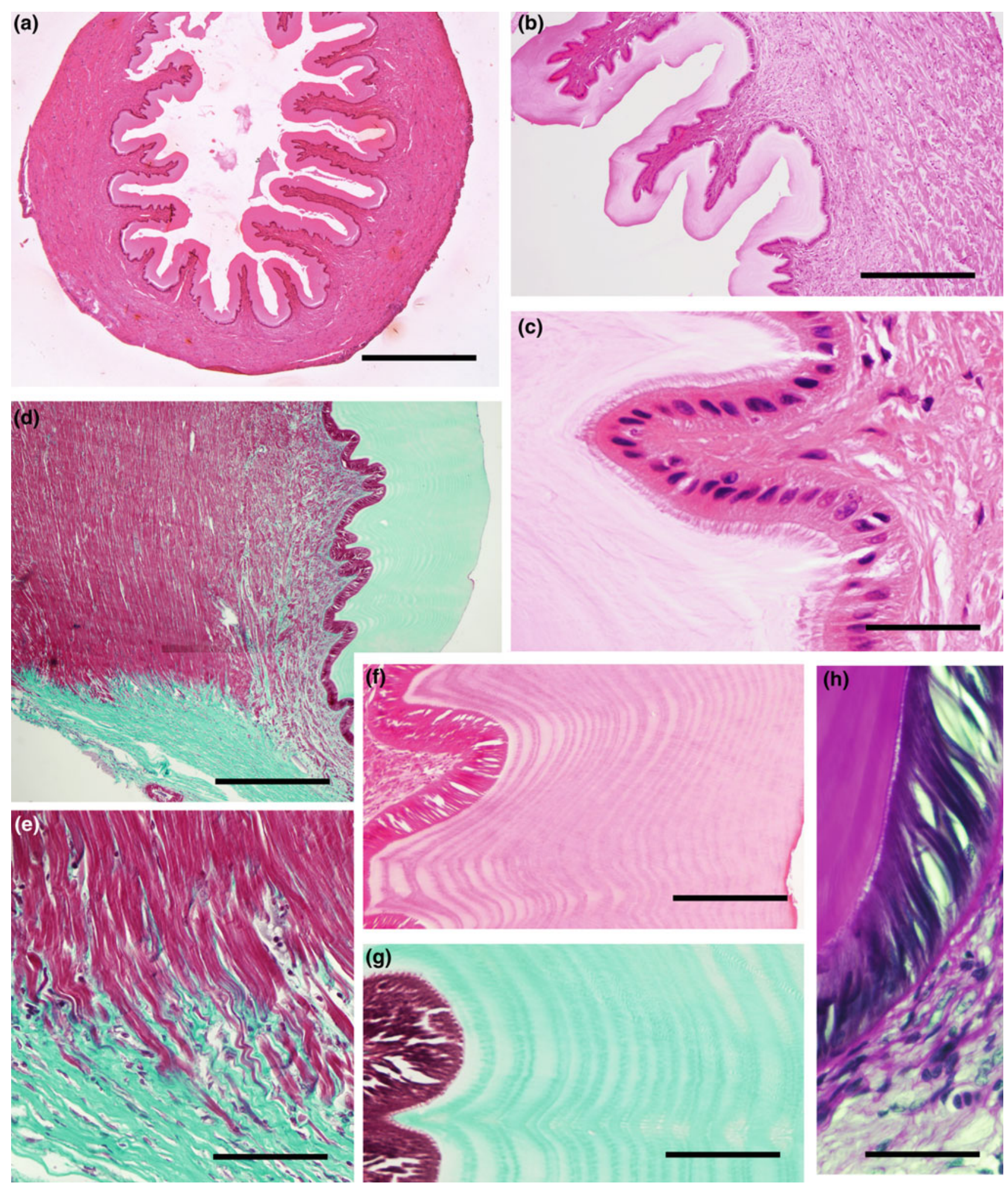

Fig. 4.11 Transverse sections of stomach. a-c Sections of squid stomach showing the muscular wall, the pleated mucosa and the thick cuticle. In c, note long microvillous appendages in the surface of epithelial cells. $\mathbf{d}-\mathbf{h}$ Sections through one of the paired central pads of the octopus stomach showing the insertion of the much thickened

muscle layers in the thick collagenous fascia joining both sides (d and e). Note also in $\mathbf{d}$ the thick submucosa and the small epithelial folds. $\mathbf{f}-$ h Details of the differential staining showing the multilayered cuticle. a-c and $\mathbf{f}$ H\&E staining, d, e, $\mathbf{g}$ Masson's trichrome, h PAS method. Scale bars a $1 \mathrm{~mm}$; b $500 \mu \mathrm{m} ; \mathbf{c}, \mathbf{g}, \mathbf{h} 50 \mu \mathrm{m} ; \mathbf{d} 0.7 \mathrm{~mm} ; \mathbf{f} 100 \mu \mathrm{m}$

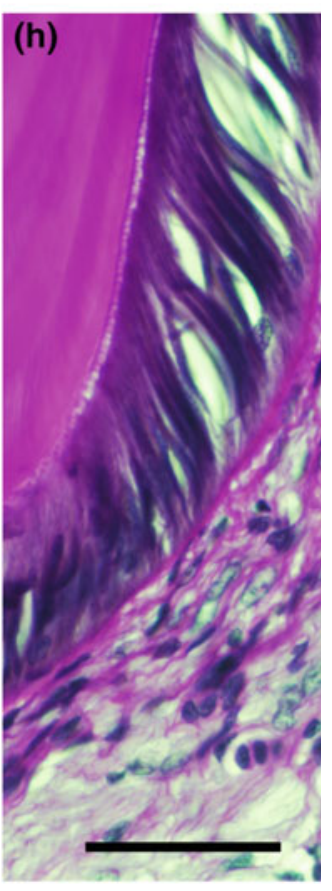


Fig. 4.12 Sections of the caecum of octopus (a-d) and cuttlefish $(\mathbf{e}, \mathbf{f})$. a Panoramic view of a transverse section showing the spiral organization of primary and secondary caecal leafs around the columella (outlined arrow). Note the counterclockwise diminution of the size of leafs and the alternate arrangement of long and short lamellae. b Detail of lamellae of the caecum showing the lateral leaflets mostly consisting of high ciliated epithelium. c Section passing through the apex of a primary lamella showing the mucous tubular glands and the tall epithelium. $\mathbf{d}$ Detail of the base of a leaf showing muscle fibers entering in the axis. e Section of the caecum of cuttlefish showing leafs with leaflets. f Detail of the tall ciliated epithelium covering the leaflets. a, b and e, f H\&E; c, d Masson's trichrome. Scale bars a, e $500 \mu \mathrm{m}$; b $200 \mu \mathrm{m} ; \mathbf{c}, \mathbf{d}$, f $100 \mu \mathrm{m}$
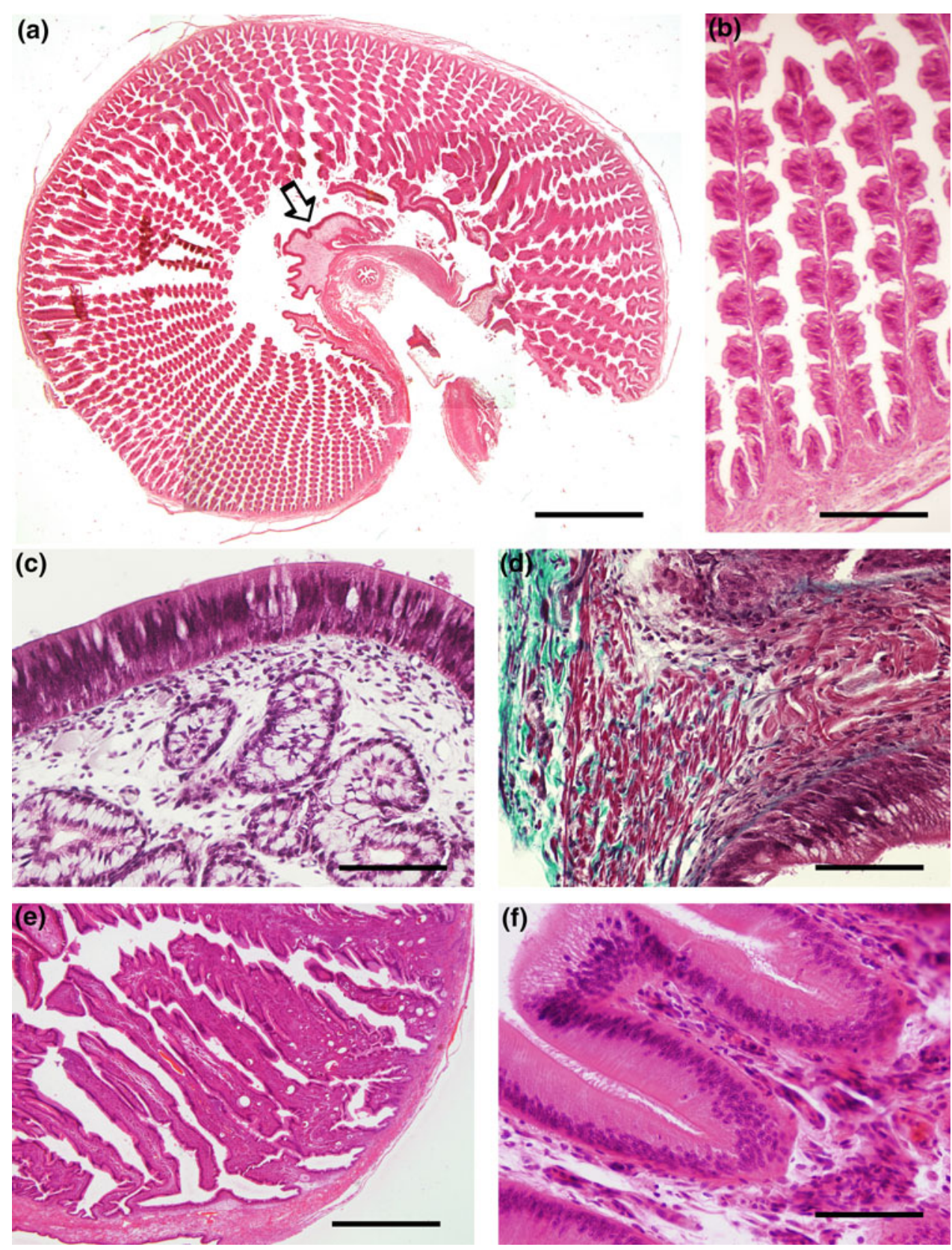

glandular and show at least two types of glandular cells whose cytoplasm appears either bluish (basophilic) or orange (strongly eosinophilic) with the H\&E-staining method. Distal A tubules mostly consist of eosinophilic columnar gland cells that are short or very short in the thin terminal regions, whereas more proximally the epithelium consists of mixed basophilic and eosinophilic cells. The glandular epithelium is continuous with the striated tubules, with a sharp transition between them. In the striated tubules, three types of cell were reported using electron microscopy, striated cells, cistern cells and lumen-lining cells (Matus 1971). The striated cells show a wide basal eosinophilic cytoplasm of striated appearance with nuclei inside. The cytoplasmic striations are better observed in transverse sections of these tubules. Ultrastructural studies in octopus reveal numerous basal infoldings of these cells containing mitochondria and canaliculi, as well as an apical brush border, which reminds the striated ducts of mammalian salivary glands. Cistern cells are rather conspicuous in light microscopy sections, because of their spherical shape, striated cytoplasm and hollow apical region. These cells are surrounded apically by flattened supporting (lining) cells with nuclei located apically. This glandular portion is thought to be involved in active ion transport and excretion. In tangential sections to the two types of tubules, it can be appreciated the presence of a layer of flattened thin muscle fibers surrounding the epithelial tubules, 
Fig. 4.13 Sections of the digestive gland of squid $(\mathbf{a}, \mathbf{b})$ and octopus $(\mathbf{c}-\mathbf{g})$. a panoramic view showing branched glandular tubules open to a large conduct. b Section showing the complex appearance of the digestive gland cells, which appear to form extensions of cytoplasm toward the central region. c Panoramic view showing the two sectors of the octopus digestive gland, main and accessory (limit indicated by arrows). In the low right corner, the accessory gland tubules are open to the branched duct of the gland (asterisks). d-e Portions of the main digestive gland stained with Masson's trichrome showing the complex appearance of gland cell cytoplasm, with granules of various appearances. Note also the vasculo-connective cords among acinar units. f Section of the accessory digestive gland showing the branched system of tubules converging on larger ducts. g Detail of the secretory units of the accessory digestive gland showing the complex star-shaped aspect of the inner cavity and the homogeneous appearance of gland cell cytoplasm. Note the vasculo-connective cords. ac and $\mathbf{f} \mathrm{H} \& \mathrm{E} ; \mathbf{d}$, e, $\mathbf{g}$ Masson's trichrome. Scale bars a $0.8 \mathrm{~mm}$; b, e, g $50 \mu \mathrm{m}$; c $1.2 \mathrm{~mm}$; d $100 \mu \mathrm{m} ; \mathbf{f} 300 \mu \mathrm{m}$
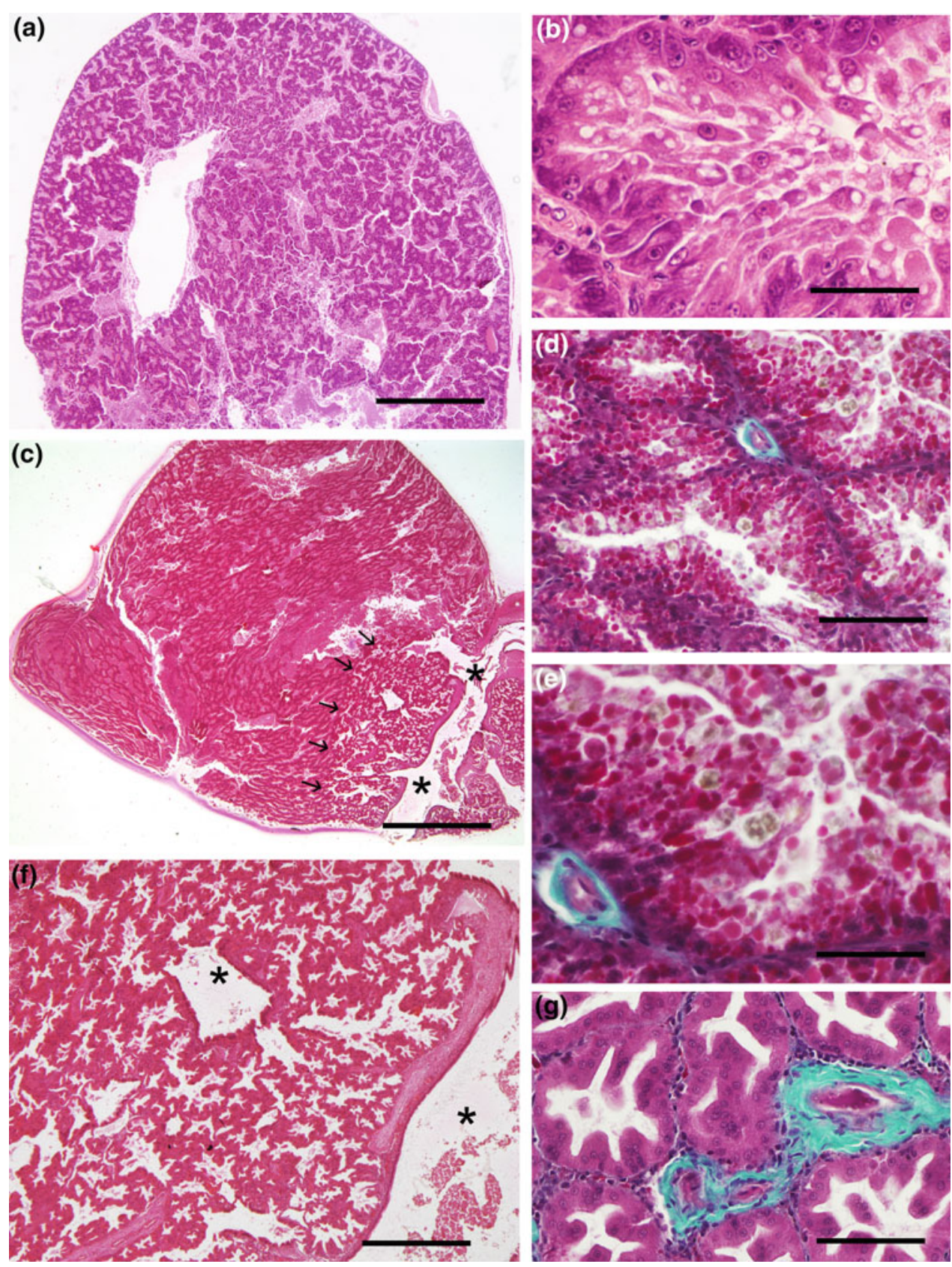

which reminds the myoepithelial cells in mammalian glands. The gland receives rich nerve supply from the superior buccal lobe whose integrity is necessary to poison a crab after catching it (Young 1965). Nerve bundles enter the wall of proximal striated tubules and can be observed coursing along the basal region of the epithelium (Matus 1971).

\subsubsection{Esophagus and Crop (Fig. 4.10)}

The pharynx is continuous with the esophagus that, at the level of the cranium, is surrounded by the brain masses, and that is accompanied by large vessels. In cuttlefish and squid, the esophagus shows a pleated mucosa and submucosa surrounded by muscular layers. The epithelium consists of columnar cells covered of a thick cuticle layer. The mucosa lays over a thick submucosa and three muscle layers with different fiber orientations. The inner muscular layer is thin and consists of longitudinally oriented muscle fibers, whereas the outer layer is thicker and consists of circular muscle. In octopus, the folds of the wall of esophagus are long and thick, and its epithelium is much thicker than in squid and cuttlefish, showing taller and thinner cells. The octopus esophagus only exhibits a thin cuticular layer. 
Fig. 4.14 Transverse sections of the octopus (a-d) and squid intestine (e-f). a Panoramic view showing the folds of the mucosa including the two pairs of typhlosoles flanking the bilateral plane of symmetry (outlined arrow). b Detail of a fold of the mucosa showing the rich vasculo-connective submucosa. c Detail showing the layers of circular and longitudinal muscle fibers between the submucosa and the outer connective layers. $d$ The PAS method stains numerous mucous goblet cells in the intestine mucosa. e Section of the squid intestine. Note the lack of typhlosolis. f Detail of a fold of the mucosa. Note the scarce submucosa. a, e, f H\&E; b, c Masson's trichrome; d PAS. Scale bars a $0.8 \mathrm{~mm} ; \mathbf{b}, \mathbf{d}$, f $50 \mu \mathrm{m}$; c $100 \mu \mathrm{m}$; e $500 \mu \mathrm{m}$
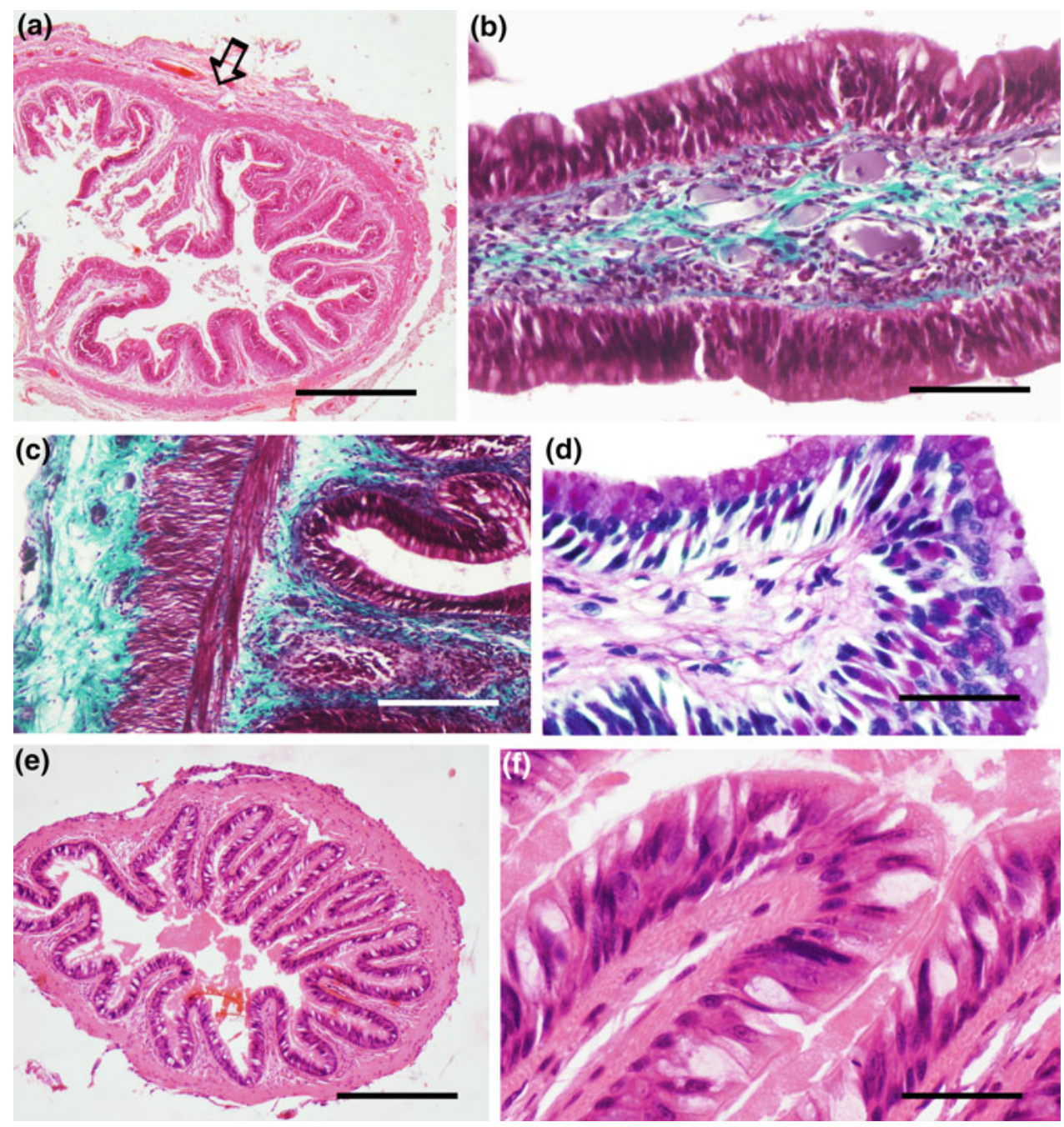

The submucosa is thick and the three muscular layers are looser arranged than in the other two species.

In octopus, but not in cuttlefish and squid, a dilated crop follows the postcranial esophagus. The crop histology is similar to that of the octopus esophagus, but the folds of the inner wall are longer and often branched. It is covered of a similar thick epithelium with thin cuticle, without glandular cells, but the submucosa and muscle layers are thicker than in the esophagus. Thus, the octopus crop forms a very expandable part of the esophagus. Peristaltic movements of the crop have been reported "in vivo" with ultrasound sonographic scannings.

\subsubsection{Stomach (Fig. 4.11)}

The void stomach of squid and cuttlefish shows a deeply folded inner surface, whereas the outer surface is rather smooth. The folds of the stomach wall consist of a mucosa covered by a very thick chitinous cuticular layer and the submucosa. Unlike the esophagus, the epithelium of the squid and cuttlefish stomach shows a tortuous profile and consists of a single type of cell. The short columnar epithelial cells have their nuclei at intermediate levels and apical and basal cytoplasm with different appearances. The basal cytoplasm has a striated appearance, which is typical of transporting epithelia. The apical cytoplasm is homogeneous and is covered of a conspicuous microvillous-like layer (brush border) and the thick cuticle. These cells secrete a chitinous cuticle that is PAS positive and consists of a number of thin lamellae parallel to the epithelium surface. The submucosa contains both connective and muscular tissues and is continuous with the inner layer of the muscular tunica, which consists of longitudinal muscle fibers. The thicker outer layer of the muscle tunica consists of circular muscle fibers. The outer surface is covered of thin and pleated epithelium that lays over connective tissue. The organization of the different layers allows the dilation of the 
stomach during feeding and suggests that the chitinous cuticle is highly flexible.

In octopus, the stomach is a very muscular grinding organ, reminding one of the gizzards of a bird (Isgrove 1909). Its central region consists of paired thick dorsal and ventral pads formed from outer to inner of a thick muscle layer and a columnar epithelium covered of a very thick cuticle. The lateral walls of this central region are thinner and lack muscle layers but exhibit thick collagenous dense connective layers to which the lateral wall muscles are inserted. Transitional regions join this central part of the stomach with the esophagus and the vestibule.

\subsubsection{Vestibule}

The vestibule is a dilatable small chamber that forms the link between the stomach, spiral caecum and intestine. The mucosa of the vestibule of cuttlefish consists of tall columnar cells with cilia in the apical surface and long glandular (goblet) cells interspersed with columnar cells. In octopus, the vestibule epithelium is cuticularized toward the stomach and the cuticle disappears suddenly next to the caecum.

\subsubsection{The Caecum (Cecum, Accessory Stomach, Spiral Stomach, Caecal Sac) (Fig. 4.12)}

The caecum has been considered the main absorptive organ. It is a thin-walled large sac spirally coiled around a columella that is connected with the stomach, the digestive gland and the intestine. The partially digested food passes from the stomach to the caecum and is filtered in it, discarding gross particles that pass directly to the intestine and allowing food to enter the digestive glands through the hepato-pancreatic ducts. The caecum has a complex internal structure that consists of numerous leafs and leaflets covered of ciliated epithelium extending from the outer surface and converging toward the columella without reaching it. In octopus, the outer border of the caecum forms three types of leafs, long (primary), intermediate (secondary) and short. Primary leafs alternate with secondary ones, and both types of leaf are flanked on both sides by very short unfolded lamellae allowing a regular organization. The primary and secondary leafs exhibit short lateral leaflets coursing longitudinally along leafs and giving them a comb-like appearance in cross section. The axis of leafs and leaflets is thin and continuous with the tissue of the border of the sac. The leaflets exhibit a clear alternate arrangement in squid and cuttlefish, but not in octopus where is irregular and leaflets often are opposite. In the octopus caecum, too, there is a clear gradient in the thickness of leafs/leaflets, largely diminishing toward the tip of the spiral. A thick ciliary epithelium covers the crests and valleys of leaflets, and also the region of the columella (typhlosole) that lacks leafs. A large number of goblet cells are scattered in the ciliary epithelium mainly in secondary crests. Similar goblet cells are observed in the folds of epithelium lining the columella. The folds of the columella and leafs of the caecum have a central axis with highly vascularized connective tissue (or chorion). Along the elongated apical border of primary folds, there are rows of simple acinar mucous glands called caecal glands that open directly into the lumen. These caecal glands are formed by secreting cells with a basal flattened nucleus and a light vacuolated cytoplasm. In the columella of the octopus caecum, there is abundant loose connective tissue, as well as dense connective tissue surrounding the hepato-pancreatic ducts.

In squid, the caecum is less coiled than in octopus although the appearance of leafs and leaflets is similar. As in octopus, the thick folded epithelium near the columella (typhlosole) contains numerous goblet cells. In cuttlefish, caecal leafs are poorly organized by comparison with those of octopus and squid, and have a thick connective axis. In cases of heavy infestation by coccidia (Aggregata), caecal folds are thickened and partially disorganized.

\subsubsection{The Digestive Gland and Accessory Digestive Gland (Fig. 4.13)}

The digestive gland (hepatopancreas, midgut gland) is the largest gland of cephalopods. The digestive enzymes are mainly supplied by the digestive gland in alternating phases of synthesis and release. It consists of a highly branched system of glandular tubules covered of a thick epithelium of uniform appearance. Basal conducts have a prominent lumen, but most tubules show a reduced lumen. The epithelium mainly consists of large columnar cells with basal nuclei, an apical region with a brush border and central regions with numerous large rounded pale granules (lipid droplets, lysosomes) and protein spherules ("boules"). The tubules are separated by thin vasculo-connective septa containing some muscle fibers. Electron microscopic studies suggest the presence of two main types of cell, basal (replacement) cells and chief (columnar) cells (Budelmann et al. 1997), but this is hardly distinguishable with light microscopy. Chief cells are polymorphic and may exhibit different appearances during the digestive cycle, with secreting and absorptive periods (see Costa et al. 2014). In some phases of digestion, proteins are secreted as "boules" from the apical cytoplasm of the cells in an apocrine way or even the whole cell passes to the lumen. In these phases, basal cells with abundant basophilic material can be easily observed. Mitotic cells are found often in the epithelium, to replace the tall cells that are probably short-lived. 
The histological appearance of the digestive gland varies very considerably from sample to sample, even in individuals sacrificed at the same time after a meal, which has lead to conflicting reports on its function.

Associated with the main digestive gland, the octopus has a different part of the gland that is known as the accessory digestive gland (pancreatic appendages). This posterior portion of the digestive gland is located around the digestive gland (hepato-pancreatic) duct to which opens through wide ducts and shows an appearance very different from the main glandular region. The main gland duct branches in a number of wide secondary and tertiary ducts ending in a network of closely packed tubules or alveoli with striking angled luminal profiles. This appearance is produced by the large variations in the height of the pleated epithelium of adjacent alveoli, which are separated by a thin vasculo-connective lamina. Cell limits are not resolved by light microscopy, and cell nuclei appear irregularly distributed in the eosinophilic cytoplasm. The apical cytoplasm shows numerous pale round structures that may correspond to lipidic droplets. Ultrastructural observations in octopus reveal cells with a large number of longitudinal folds of the plasma membrane, which explains the difficulty for seeing cell limits with light microscopy. Electron microscopy of these cells also reveals numerous mitochondria, small vacuoles and large lipid droplets in cytoplasm lamellae (see Budelmann et al. 1997). These cells are in contact with the chyme, from which they absorb different nutrients. In the limit with the main part of the digestive gland, tubules of the two glands entering in contact are separated by a thin connective-vascular layer. In cuttlefish and squid, pancreatic appendages are not enclosed in the digestive gland or surrounded by a common capsule, but tubules arising from the hepato-pancreatic duct are in contact with the epithelium of the renal sac.

\subsubsection{Intestine (Fig. 4.14)}

The intestine shows longitudinal folds protruding into the lumen. In octopus, but not in squid or cuttlefish, the presence of large paired folds (typhlosoles) in opposite (dorsal and ventral) regions delineates a bilateral symmetry plane in the intestine. The typhlosolis epithelium has tall ciliated cells with nuclei in basal or intermediate levels, and mucous cells intercalated among them that secrete neutral and acid mucopolysaccharides (proteoglycans). In other intestinal folds, the epithelium mainly consists of numerous gland cells that secrete neutral and acid mucopolysaccharides (proteoglycans) and non-ciliated epithelial cells. Toward the anus, the thickness of the epithelium diminishes, but its features are similar. This epithelium is presumably involved in absorption. The connective tissue is abundant in the submucosa, extending along the axis of epithelial folds, only occasionally branched, and surrounding the muscular layers. The organization of the muscular wall of the intestine comprises an internal layer of longitudinal muscle and an external layer of circular muscle, better observed in octopus because of its large intestine. In octopus and cuttlefish, too, numerous blood vessels are observed in connective regions. The end part of the intestine that opens to the anal pore is similar in structure to other intestinal parts.

\subsubsection{Ink Sac Complex}

The ink sac of cephalopods is the most characteristic gland of these animals. The ink sac originates from an evagination of the intestinal primordium. The ink sac complex consists of the ink gland, a large ink sac or reservoir, and the short ink duct (Girod 1881; Williams 1909). The glandular epithelium consists of immature proliferating cells in the inner portion, whereas the outer glandular portion consists of a series of connected chambers lined by a cubical glandular epithelium. The gland cells are very active in melanogenesis (Palumbo 2003). Submicrometric small melanin granules are secreted by gland cells and accumulate as ink in the ink sac, being ejected (ink-jet) on demand. The wall of the squid ink sac is formed of an outer sheet of connective tissue, a middle sheet of circular and longitudinal muscle fibers and an inner sheet of pavement epithelium (Williams 1909). The reservoir has an additional layer situated between the epithelium and the muscular layer. This layer is about as thick as the other layers combined and is formed of iridiocytes which reflect light and give the ink sac its silvery appearance (Williams 1909). The ink sac opens into the anal chamber, being separated by two sphincters, and the chamber opens into the mantle cavity through the anus (Girod 1881; Williams 1909). The released ink is a complex mixture receiving also contributions of the funnel organ (Derby 2014).

\subsection{Blood and Circulatory System (Figs. 4.15, 4.16, 4.17 and 4.18)}

Cephalopods have a closed circulatory system with arteries and veins joined by a capillary bed. Two branchial hearts pump blood to the gills (branchial circulation) and one systemic heart to the remainder body (systemic circulation), in a double circulation way that reminds the double circulation (pulmonary and systemic) of land vertebrates. The blood is a viscous fluid that mainly consists of plasma with a high content in hemocyanin, a copper-containing respiratory protein, and also contains hemocytes (amebocytes). Hemocyanin and hemocytes are produced in the branchial glands and the white body, respectively. 

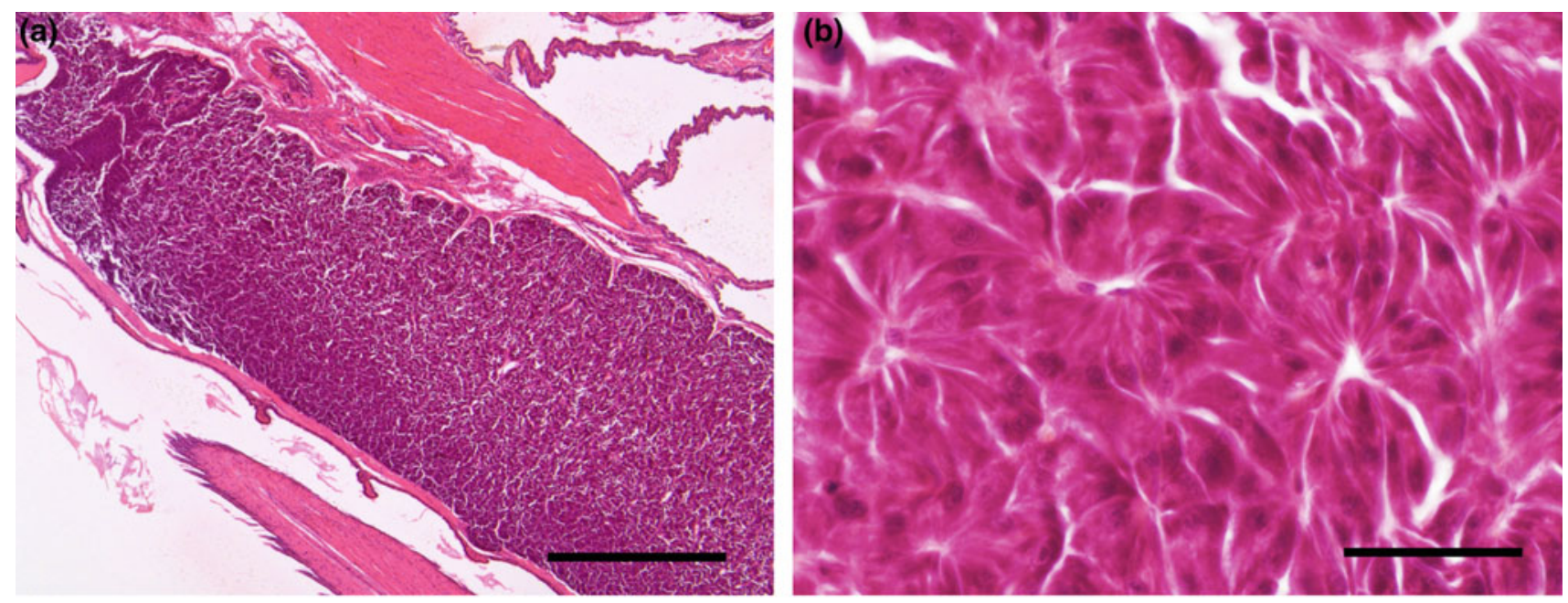

(c)
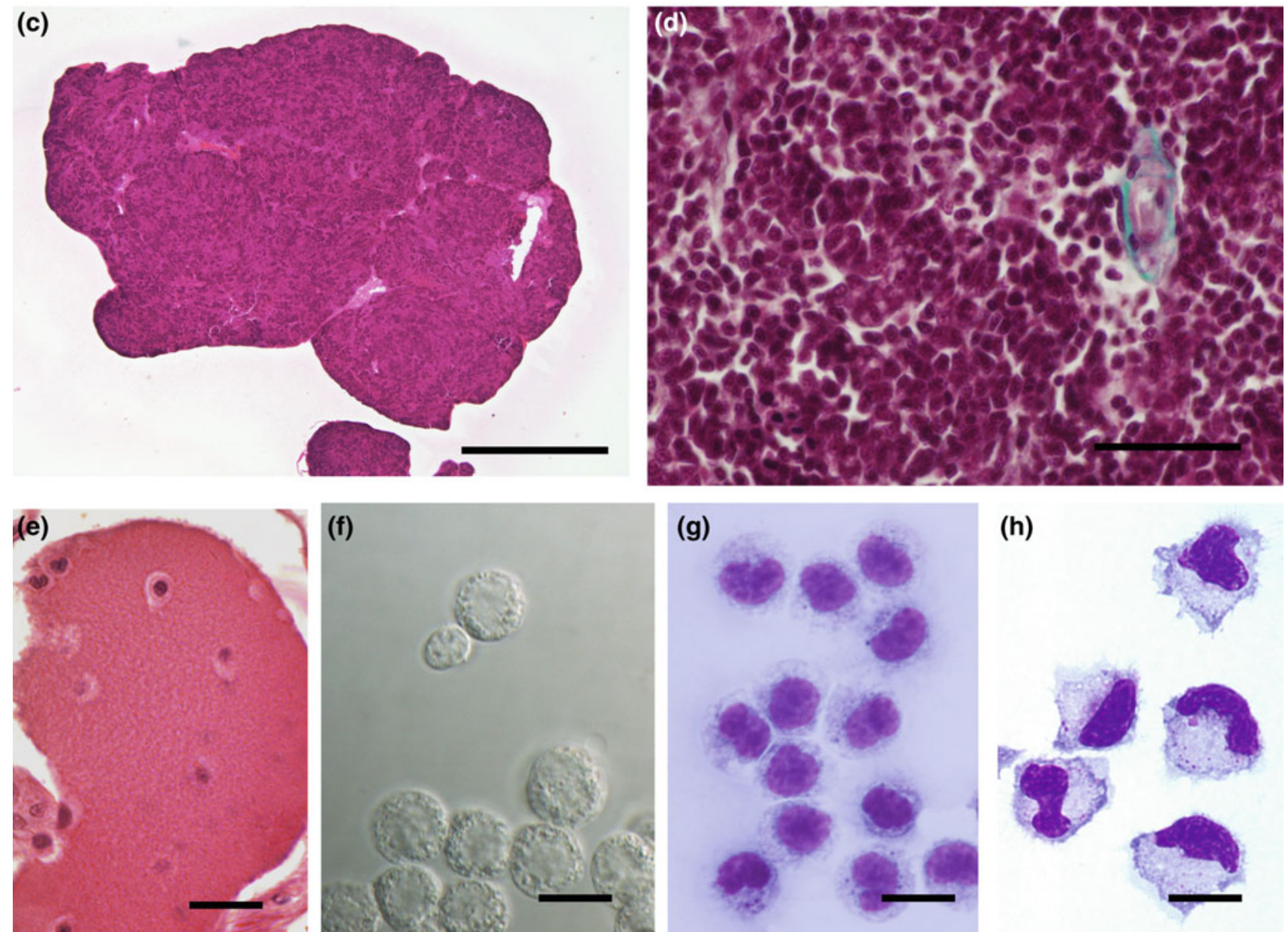

(g)

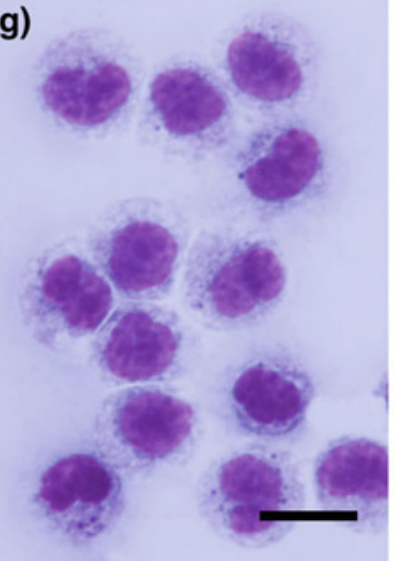

(h)
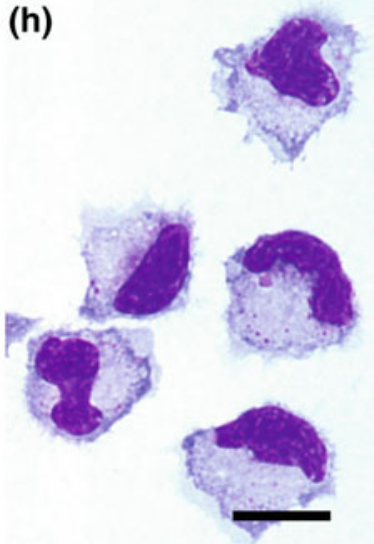

Fig. 4.15 Blood-forming organs and blood. a Branchial gland of cuttlefish showing a dense appearance. b Detail of the branchial gland showing cell cords that synthesize hemocyanin. Spaces among cords are continuous with blood vessels. c Lobe of the white body of cuttlefish. $\mathbf{d}$ Detail of the white body of an octopus showing the large number of blood cells (hemocytes) included in a loose connective-vascular meshwork. Note the vasculo-connective trabecula.

e Section of an octopus vessel showing coagulated plasma containing some hemocytes. f Photomicrograph of live octopus hemocytes showing large cells and a small hemocyte. $\mathbf{g}$, h Photomicrographs of monolayers of fixed hemocytes. a-c, e H\&E stain; d Masson's trichrome; f Nomarski's differential interference contrast (DIC); g, h staining with Hemacolor ${ }^{\circledR}$ (see Castellano-Martínez et al. 2014). Scale bars a $1 \mathrm{~mm}$; b, d $50 \mu \mathrm{m}$; c $1.2 \mathrm{~mm}$; e $25 \mu \mathrm{m}$; f-h $10 \mu \mathrm{m}$ 
Fig. 4.16 Sections of the systemic heart of octopus $(\mathbf{a}-\mathbf{c})$. a Section of the heart showing the very thick myocardium with crossed orientations of fibers and the lumenal spaces at right. b Detail of the superficial layers of myocardium showing in cross-orientation superficial myocardial fiber layers. Note the epicardium (at the left) and the dense connective meshwork surrounding muscle fibers. c Longitudinal view of myocardial fibers and accompanying connective meshwork. $\mathbf{d}$ and $\mathbf{f}$ panoramic views of systemic hearts of squid (d) and cuttlefish (f) showing the very thick muscle layers. e Detail of the squid myocardium. a-c Masson's trichrome; d-f H\&E stain. Scale bars a $0.8 \mathrm{~mm} 500 \mu \mathrm{m}$; b $100 \mu \mathrm{m}$; c, e $50 \mu \mathrm{m} ; \mathbf{d}, \mathbf{f} 1.2 \mathrm{~mm}$ (a)
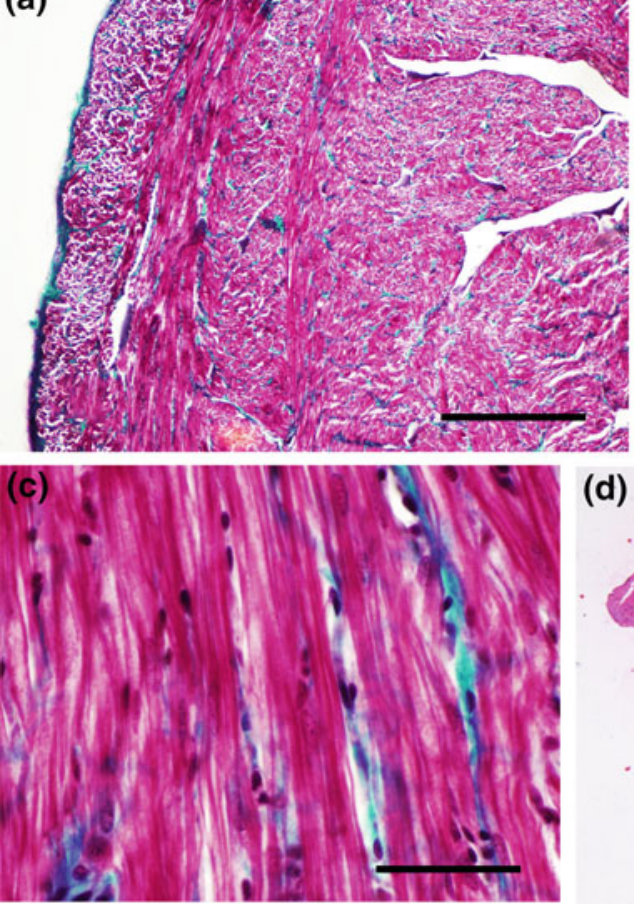

\section{(e)}

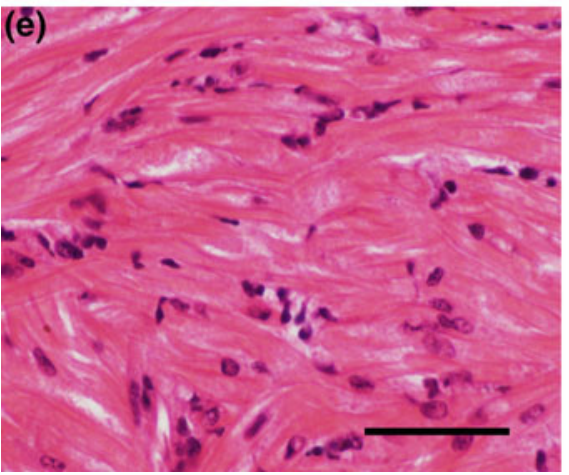

(f) (b)

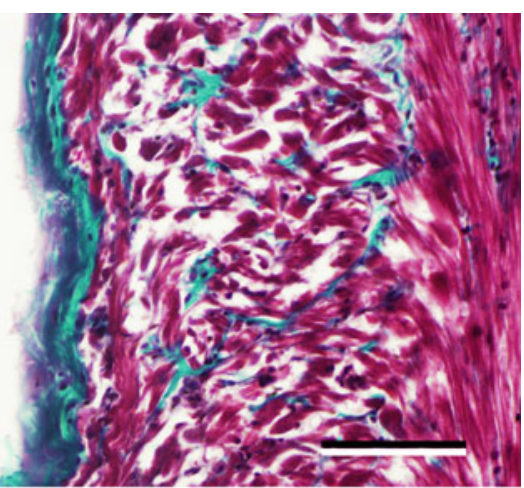

(d)

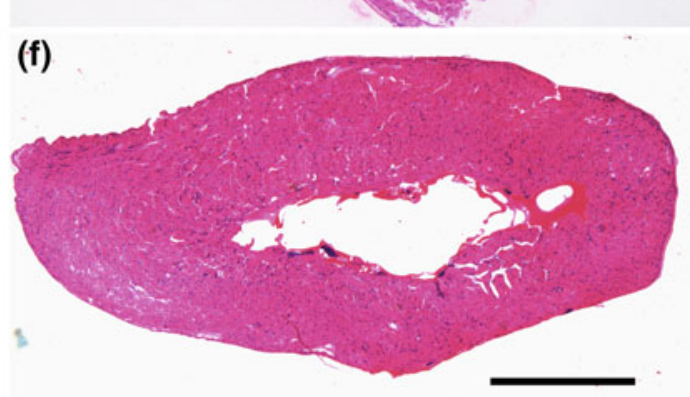

\subsubsection{Branchial Gland}

In Coleoids, a pair of branchial glands accompanies the branchial ligaments through the whole length of the gills. Each gland is contained in a capsule and is profusely vascularized. Under light microscopy, the branchial gland presents a dense appearance with numerous cords of basophilic cells interspersed with blood-filled capillaries. Studies using electron microscopy reveal a dense cytoplasm in these cells with numerous cisterns of rough endoplasmic reticulum. The secretory cells of branchial glands synthesize subunits of hemocyanin, a copper-containing protein that forms high-molecular-weight complexes in circulating blood of cephalopods and other mollusks. This cephalopod "hematopoietic" glands provide the plasma with an oxygen-transport protein, the most abundant protein of the blood (5-10\% of blood volume), being responsible for the blue appearance of oxygenated blood. This abundant protein is also responsible for the eosinophilic staining of the content of blood vessels with the H\&E stain. Capillaries of the branchial gland join to efferent vessels that are brightly red-stained with $\mathrm{H} \& \mathrm{E}$.

\subsubsection{White Body (Hematopoietic Organ)}

There is general agreement that blood hemocytes of coleoids are mainly produced in the white bodies. White bodies are dense masses of small cells enclosed in sinuses that are organized in lobes located around the optic nerves between the optic lobe and the eye orbit. In light microscopic sections, the white body appears as a very dense mass of small cells mostly consisting of a round nucleus. A close inspection reveals islands of cells with lighter nuclei (differentiating hemocytoblasts) among areas of smaller cells with denser nuclei (mature hemocytes). Numerous mitotic cells 

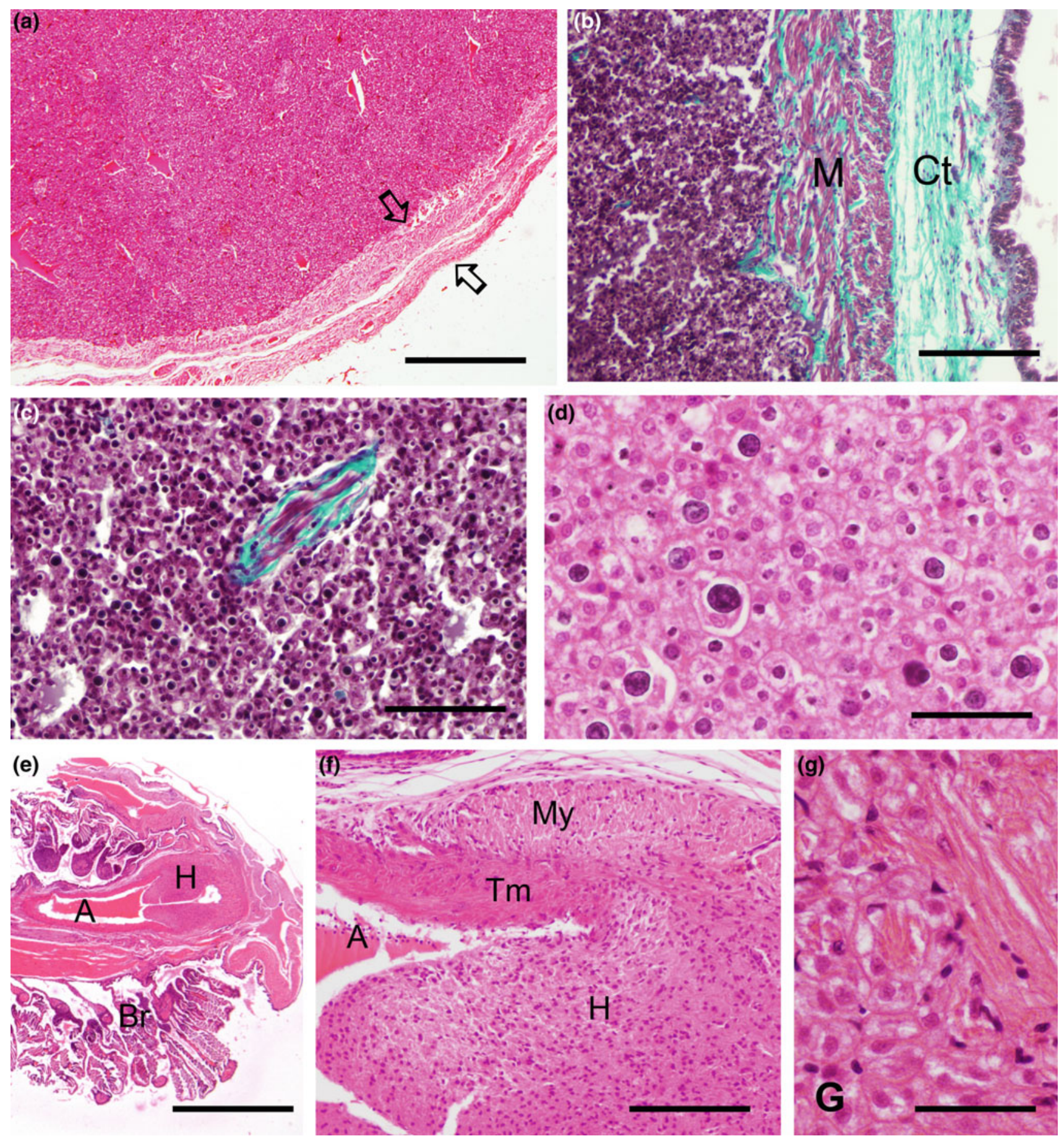

Fig. 4.17 Sections of the branchial heart of octopus (a-d) and squid $(\mathbf{e}-\mathbf{g})$. a Section showing the large mass of cells that appears to fill most of the heart cavity, surrounded by thin muscle and connective layers (outlined arrow). b Detail of the heart wall showing from outer to inner the thick coelomic epithelium, the connective $(\mathrm{Ct})$ and muscular (M) layers and the inner cell mass. c Detail of a musculo-connective trabecula crossing the inner cell mass. d Detail of the inner cell mass showing cells with large spherical cytoplasmatic inclusions. e Section of the branchial heart $(\mathrm{H})$ of a squid at the junction with the branchial arteria (A). Br, gill. f Detail of the junction showing the transition between the thick myocardium (My) to the arterial tunica media (Tm). g Detail of the cardiac muscle. a, d-g H\&E stain; b-c, Masson's trichrome. Scale bars a $0.8 \mathrm{~mm} ; \mathbf{b}, \mathbf{f} 200 \mu \mathrm{m}$; c $100 \mu \mathrm{m}$; d, g $50 \mu \mathrm{m}$; e $1.2 \mathrm{~mm}$ 
Fig. 4.18 Transverse sections of blood vessels of octopus $(\mathbf{a}-\mathbf{d}, \mathbf{f})$ and squid (e). a Section of the octopus aorta showing the thick muscle wall (tunica media) surrounded by abundant collagen connective tissue (tunica adventitia). b Detail of the muscle layer showing muscle fibers surrounded of a dense network of thin connective fibers. $\mathbf{c}$ Section of a medium-sized arteria showing the thin tunica intima of endothelial cells on the elastic lamina stained pink with the PAS method (outlined arrow). The thin meshwork around muscle fibers is also PAS positive. d Section of a small arteria showing the elastic lamina separating the intima and the thin tunica media. e Section of an efferent branchial vessel (vena) of squid. f Collapsed large vena of octopus surrounded by abundant of collagen fibers but scarce muscle fibers. The outlined arrow points to the collapsed lumen. a, b, f Masson's trichrome; $\mathbf{c}, \mathbf{d}$ PAS method; e H\&E. Scale bars a $500 \mu \mathrm{m}$; b $16 \mu \mathrm{m} ; \mathbf{c}, \mathbf{d}, \mathbf{f} 50 \mu \mathrm{m}$; e $100 \mu \mathrm{m}$
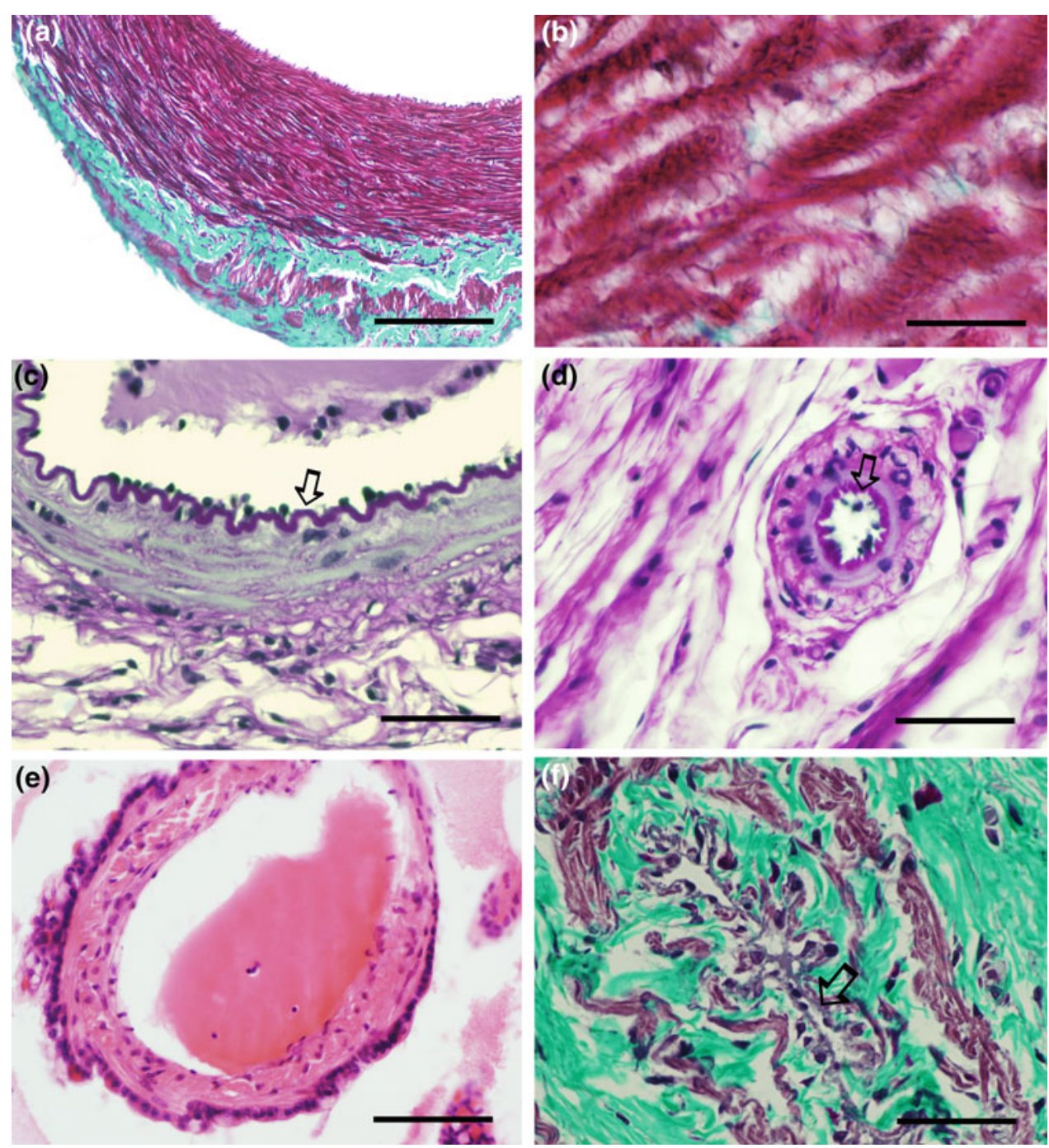

are observed in the white body, indicating it is a highly proliferating organ. As indicated above, respiratory pigments are located in the blood plasma, and no cells similar to vertebrate red blood cells are present in cephalopods.

\subsubsection{Blood}

The blood of coleoid cephalopods is a transparent liquid, turning blue in color when oxygenated. It is about as viscous as the vertebrate plasma, and its osmolarity is similar to that of the seawater although proportions of $\mathrm{Na}^{+}$and $\mathrm{K}^{+}$differ from seawater (lower and higher, respectively). It mostly contains plasma bearing the respiratory pigment, hemocyanin, which is mainly synthesized by the branchial glands, whereas blood is poor in cells. The efficiency of cephalopod blood as an oxygen carrier compares poorly with that the blood of vertebrates. The major circulating blood cells of cephalopods are referred to as leucocytes, amebocytes, or hemocytes. These are small ovoid cells are able to migrate to tissues. In histological sections, they are observed in scarce numbers inside blood vessels. These cells are better demonstrated in fresh hemolymph or in hemolymph smears stained with Romanovsky-type stains (Wright, Giemsa, May-Grünwall, Hemacolor, etc.), similar to blood cells of vertebrates. Flow cytometry, phagocytosis assays and enzymatic histochemistry, together with electron microscopy, have been employed to study cephalopod hemocytes. The major hemocytes identified in octopus are described as granulocytes and are phagocytic cells (Castellanos-Martínez et al. 2014). Small hemocytes are also present. Other authors have recognized haemoblast-like cells, hyalinocytes and granulocytes, hyalinocytes being the most abundant (Troncone et al. 2015). A single type of granulocyte population with variable internal complexity is described in the blood of cuttlefish (Le Pabic et al. 2014). 


\subsubsection{Systemic and Branchial Hearts (Figs. 4.16 and 4.17)}

The systemic heart consists of a large thick-walled ventricle joined to the branchial efferent vessels through a pair of auricles. Two large arteries, the cephalic and posterior aorta, arise from the ventricle. A lacunar system extends in the walls from its inner surface to the periphery. The myocardium consists of a large mass of cardiomyocytes with abundant sarcoplasm that are united among them by intercalary discs in a way analogous to the vertebrate cardiomyocytes, as shown in electron microscopic studies (Schipp and Schäfer 1969). Blood capillaries enter through the myocardium. The myocardium of the systemic and branchial hearts is innervated by nerves from ganglia of the visceral system. Among the neurotransmitters released by cardiac nerve fibers are catecholamines or cardioactive peptides of the FMRFamide family. The heart is enclosed in a pericardial cavity that is closely related to the renal system (see below).

In coleoid cephalopods, a pair of branchial hearts that lies in the gill ligament pumps blood to the gills via the afferent branchial vessel to generate part of the circulatory pressure. These hearts are elongated and appear to be filled partially by a large mass of cells among which numerous blood branching spaces and interstices extend, recognizable by their eosinophilic staining. Most abundant cells are large polygonal or round cells that are grouped in parenchymalike masses. These cells show a round pale nucleus and abundant cytoplasm including dark, often very large round lysosomal inclusions in the cytoplasm. These branchial heart cells are responsible of the glandular consistency of the heart and appear involved in catabolic processes eliminating hemocyanin and blood debris (Beuerlein and Schipp 1998; Beuerlein et al. 1998). In addition, blood cells enter among these cells and may attach them. No well-organized vessels are observed into this cell mass. The walls of branchial hearts consist of layers of cardiomyocytes similar in structure to these found in the systemic heart. At the output side, the transition from the heart to the branchial artery is sharp and the wall of cardiomyocytes is substituted by the thick musculo-connective layer of the arterial wall.

\subsubsection{Blood Vessels (Fig. 4.18)}

The vascular system of coleoids is double, closed and almost symmetrical. The anatomy of the cephalopod circulatory system, including the distribution of main arteries and veins, has been described in detail many times and the interested reader is referred to Williams (1909), Isgrove (1909) and Wells (1978). Here, only the histology of arteries and veins is described. Arteries are easily recognizable in sections by the organization of walls. Three layers or tunicae are distinguishable in the walls of large blood vessels of cephalopods, a thin intima, a thick media and a thin adventitia, analogous to that of large vertebrate vessels. The tunica intima consists of small endothelial cells attached to a thick basal lamina (inner lamina elastica) that in histological sections has a pleated appearance. The conspicuous tunica media of large arteries contain numerous circular and longitudinal muscle fibers included in an abundant connective matrix. The thickness of the media diminishes in smaller arteries. Small arteries usually appear contracted in sections. Veins resemble arteries but generally have thin walls lacking an inner lamina elastica and showing often dilated lumen filled of blood (Figs. 4.18e-f and 4.22f). Contractile veins as branchial efferents and large veins show a thin tunica media. The cephalopod organs are richly supplied of a number of small vessels forming series of different diameters, which is easily appreciable in sections of nervous tissue (Figs. 4.24b and $4.25 \mathrm{e}$ ). The smallest (capillaries) are surrounded only by pericytes enclosing the thin, often discontinuous endothelium (see Budelmann et al. 1997). The largest vessels are often accompanied of nerves and its walls receive abundant innervation.

\subsection{The Respiratory System (Fig. 4.19)}

The two feathery gills of dibranchiate cephalopods protrude within the mantle cavity allowing the pass of the active respiratory water flow created by mantle movements through their folds (Wells and Wells 1982). The branchial organization is similar in cuttlefish and squid. The gill is sustained by the gill ligament that contains a large afferent vessel (branchial artery), muscles and a ganglionic nerve cord that innervates the gill. From this axis, numerous secondary branchial lamellae or primary filaments extend into the cavity and appear as finely meandering (tertiary lamellae) increasing in this way the exchange surface of the gill. Each secondary lamella receives by its proximal side collaterals of the afferent vessel that extends between the two flattened layers of epithelium (respiratory epithelium) that cover the lamella, and some perpendicular cells (pillar cells) join these epithelia. At the distal end of lamellae, blood spaces join to 
Fig. 4.19 Panoramic views and details of sections of gills of squid $(\mathbf{a}, \mathbf{b})$ and cuttlefish (c, d) and octopus (e, f). Note the similar appearance of gill primary and secondary lamellae of squid and cuttlefish, and the muscular axis of the gill (star in a). The branchial gland is also appreciable in a and c. e, f Panoramic view and detail of gill lamellae of octopus. Note the different branching pattern (e) and the thickness of the gill epithelium (f), by comparison with decapods. a-e H\&E stain; f Masson's trichrome. Scale bars a $1 \mu \mathrm{mm}$; c, e $500 \mu \mathrm{m}$; b $50 \mu \mathrm{m}$; d, f $100 \mu \mathrm{m}$
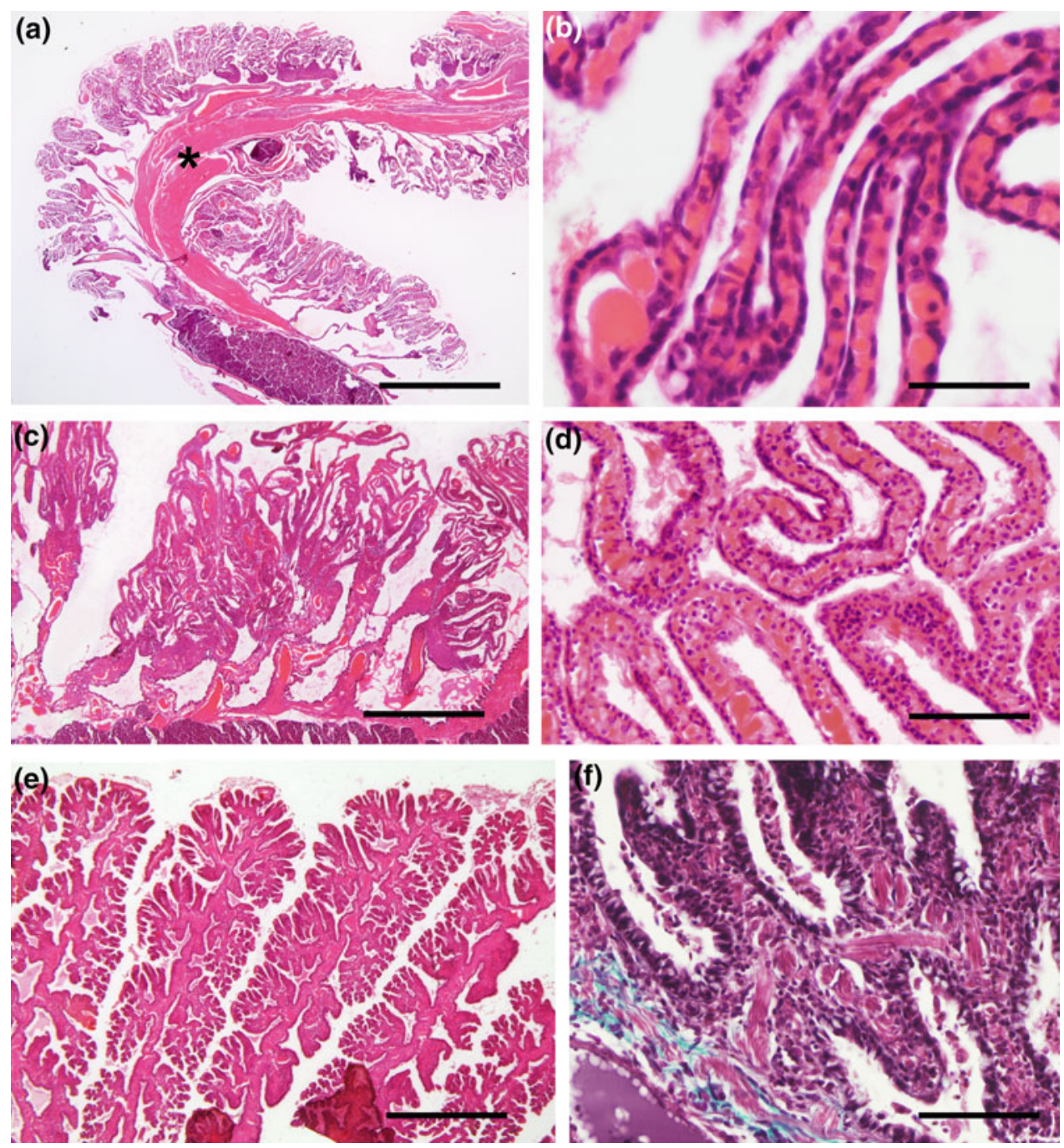

coarse vessels that, together, form the efferent branchial vessel. In octopus, the gills differ dramatically from those of cuttlefish and squid, because the secondary lamellae are branched and tertiary lamellae have the appearance of small trees rather than laminae. The vascularization also differs from that of the other two species (see Young and Vecchione 2002). In octopus, too, the respiratory epithelium is thicker than in these species. A thinner epithelium appears to favor the gaseous interchange in most active species. The thin branchial epithelium also allows direct elimination of substances from blood, such as ammonium and other wastes.

\subsection{The Excretory System (Fig. 4.20)}

The coleoids have a complex excretory system consisting of different organs with various functions. The proper excretory organs are the renal and pericardial (branchial heart) appendages, though the gills, pancreatic appendages and other structures also contribute to excretion and homeostasis of the internal milieu. The renal and pericardial appendages are gland-like structures protruding in the renal and pericardial coelomic sacs, respectively. In octopus, the renal appendages consist of highly branched structures protruding in the renal sac. They are formed of continuous sheets covered of two layers of cuboid epithelial cells separated by blood sinuses derived of the vena cava system. The epithelial cells show a central rounded nucleus and abundant cytoplasm. Ultrastructural studies reveal the complex organization of these cells, with a microvillous apical border and a lobulated basal region directly contacting blood (see Budelmann et al. 1997), which are inappreciable in conventional light microscopy sections. In octopus, the renal sac is a unique habitat for parasites and the coelomic surface of the renal appendages appears generally colonized by numerous dicyemids. 
Fig. 4.20 a Panoramic view of the renal appendages of octopus. b Section showing the renal appendages associated with the pericardial surface. c Detail of the octorpus renal epithelium showing the luminal surface of the epithelium facing faintly stained parasites (dicyemids). d Renal appendages of cuttlefish. e Detail of the renal epithelia showing two different papillar appearances, lower facing the renal sac filled of dicyemids (bottom) and taller in the opposite surface. f Detail or the complex pericardial epithelium shown in b. a, d, e H\&E stain; b, f Masson's trichrome. Scale bars a $0.8 \mathrm{~mm} ; \mathbf{b} 500 \mu \mathrm{m} ; \mathbf{c}, \mathbf{e}$, f $50 \mu \mathrm{m} ; \mathbf{d} 200 \mu \mathrm{m}$
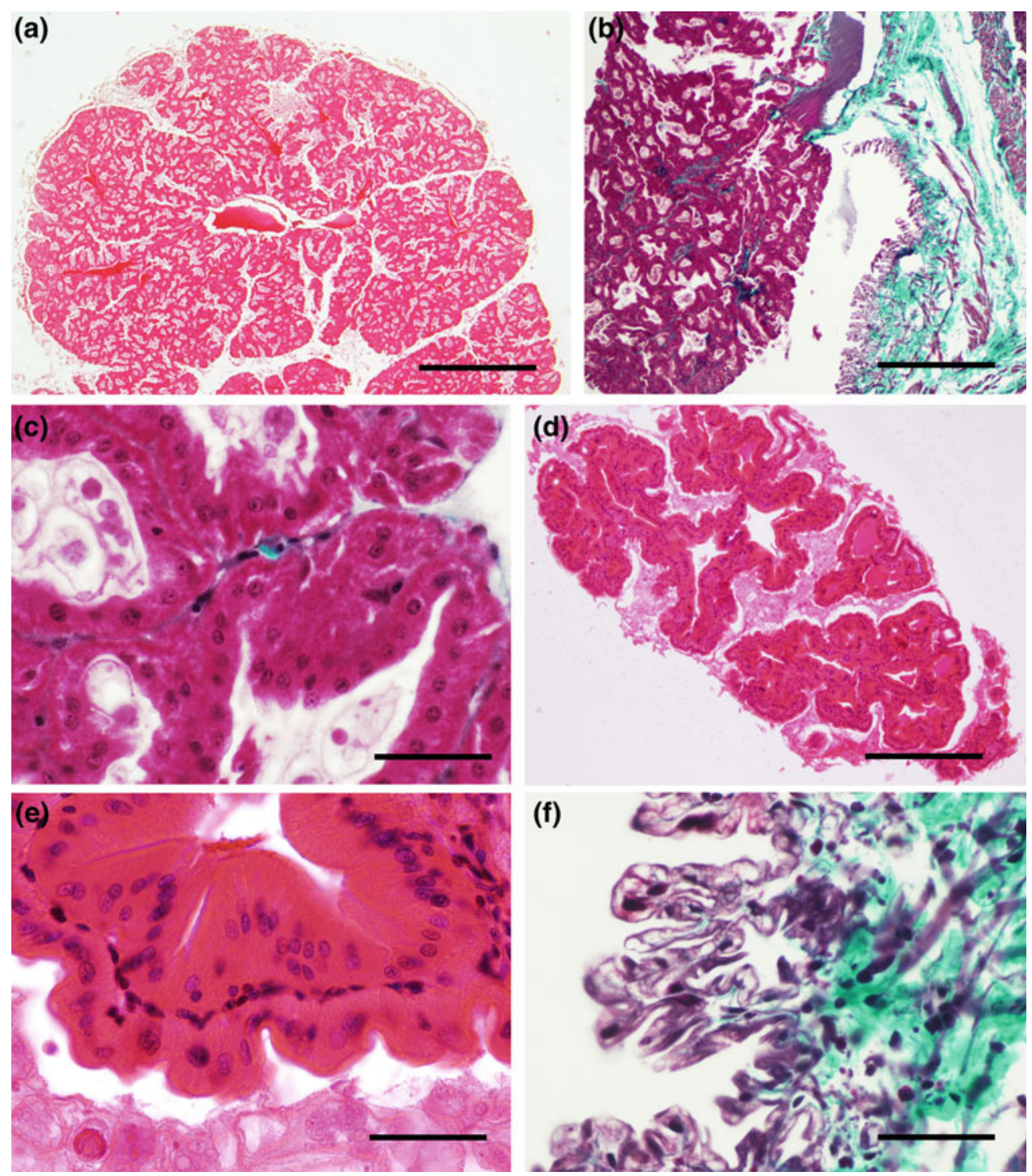

\subsection{The Visual System (Figs. 4.21 and 4.22)}

The visual system of coleoid cephalopods is highly developed. It consists of a pair of big camera-type eyes connected with paired optic lobes (ganglia) through the optic nerve (Hensen 1865; Young 1971). The parts of the cephalopod eye are strikingly similar to those of vertebrate eyes, although they differ in its origin and organization, being considered a notable example of convergent evolution. The inner surface of the eye consists of a neural retina that continues anteriorly with a simple pigment epithelium extending to the lens-producing "ciliary papillae." More anteriorly, this epithelium is continuous with that of the iris. The iris lines a pupil circular (squid), horizontal (octopus), or irregular in shape (cuttlefish), and is outwardly followed by a transparent cornea. External eyelids are found in many cephalopod species as the octopus and cuttlefish. The retina is covered with connective tissues, and in the equatorial region of the eye, there is a lamina of cartilage that shows a different organization in octopus and cuttlefish/squids (Fig. 4.2). A connective fascia is also present in the posterior pole of the eye except at the exit of the optic nerve bundles. Several extra-ocular muscles (both rectus and oblique muscles) formed of muscle fiber fascicles allow eye movements with a surprising similarity with those found in vertebrate eyes, though its number and organization largely vary among cephalopod species, unlike in vertebrates.

The retina (Fig. 4.21) is a bilayered structure in the three species illustrated here, with long photoreceptor cells of a single type, with perikarya located in the deep (inner) layer and photoreceptor processes extending in the superficial (outer) layer. Note that this convention is different than that used for vertebrate eyes. In the outer layer, photoreceptor processes bear two opposite rhabdomeres (formed of long, densely packed microvilli perpendicular to the axis of the 
(a)

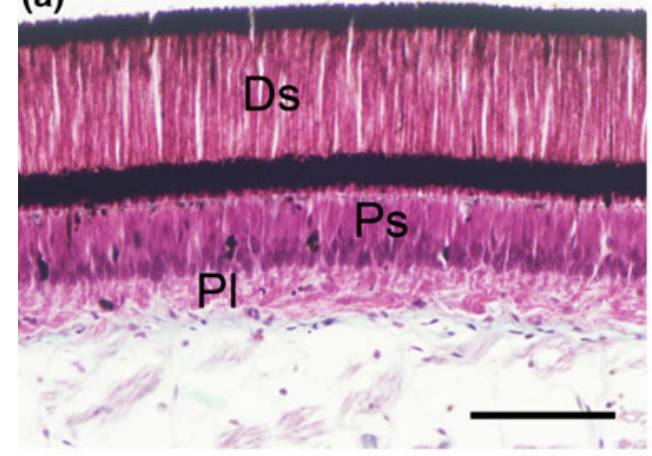

(c)
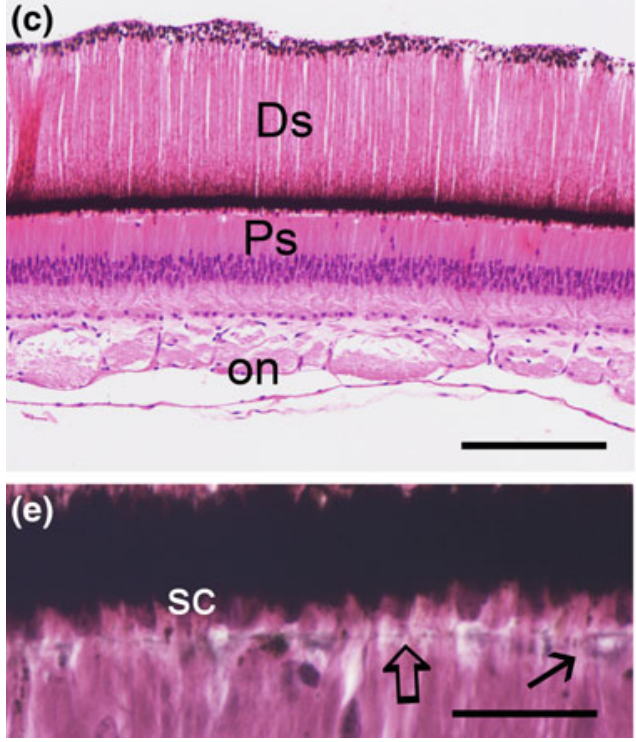

Fig. 4.21 Vertical sections through the retina of an octopus (a, b) and a squid (c, d), showing the layers of distal photoreceptive segments bearing the rhabdomeres and pigment granules (Ds), the layer of proximal photoreceptive segments (Ps) and nuclei $(\mathrm{N})$ of photoreceptors, and the basal plexiform layer with axonal processes of photoreceptors and efferent fibers. Note that the distribution of pigment granules shown here is typical of light-adapted retinas. Outlined arrows in $\mathbf{b}$ and $\mathbf{d}$ point to the basal lamina separating proximal and distal

process bearing the visual pigment or rhodopsin), contacting laterally with rhabdomeres of adjacent photoreceptors. Using light microscopy, rhabdomeres appear as a fuzzy layer, but these structures can be resolved using transmission electron microscopy (Young 1971). This latter technique allows differentiating numerous filamentous mitochondria in the axis of the process, a well as pigment granules that cyclically migrate along the photoreceptor segment depending on light/darkness conditions. In the outer layer, there are also supporting (glial) cells with somata located basally and a long apical process extending till and forming part of the outer limiting membrane. Numerous blood capillaries are observed between the inner and outer retinal layers. The orientation of photoreceptor segments facing toward the light entering through the pupil (direct retina) is the opposite
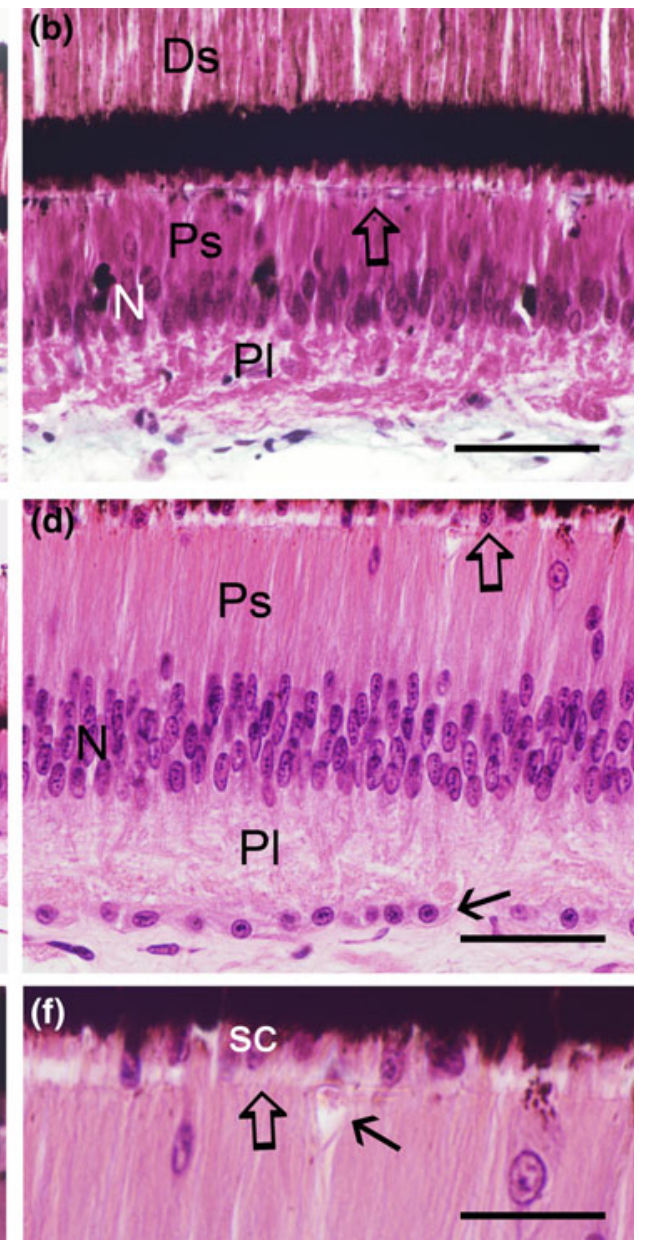

segments. The thin arrow in $\mathbf{d}$ points to a defined layer of basal ("epithelial") cells below the plexiform layer in the squid retina. e and f Detail of the basal membrane (outlined arrows) separating distal and proximal segments in octopus and squid, respectively. Note capillaries in the basal lamina (thin arrows), and nuclei of supporting cells (sc) that are obscured by the accumulation of pigment granules. On, optic nerve (in c). a, b, f Masson's trichrome; c, d, f H\&E stain. Scale bars a, c $200 \mu \mathrm{m} ; \mathbf{b}, \mathbf{d} 100 \mu \mathrm{m} ; \mathbf{e}, \mathbf{f} 50 \mu \mathrm{m}$

to that of vertebrate retinas (inverted retina). Inner processes of photoreceptor cells give rise to collaterals forming part of an inner plexiform layer before entering in the optic fiber bundles. Note that to observe these collaterals and their contacts with efferent axons from the optic lobes, it is necessary the use of Golgi methods or transmission electron microscopy.

The numerous optic nerves (bundles) of cephalopods do not form a single nerve as in vertebrates, but exit the eye orbit at its posterior pole and course toward the first optic center, the optic lobe, in such a way that bundles arising from the dorsal retina, course toward the ventral optic lobe, those ventral ones toward the dorsal region of the lobe and the central ones toward the central region of the lobe, i.e., inverting their relative positions along the dorso-ventral and 

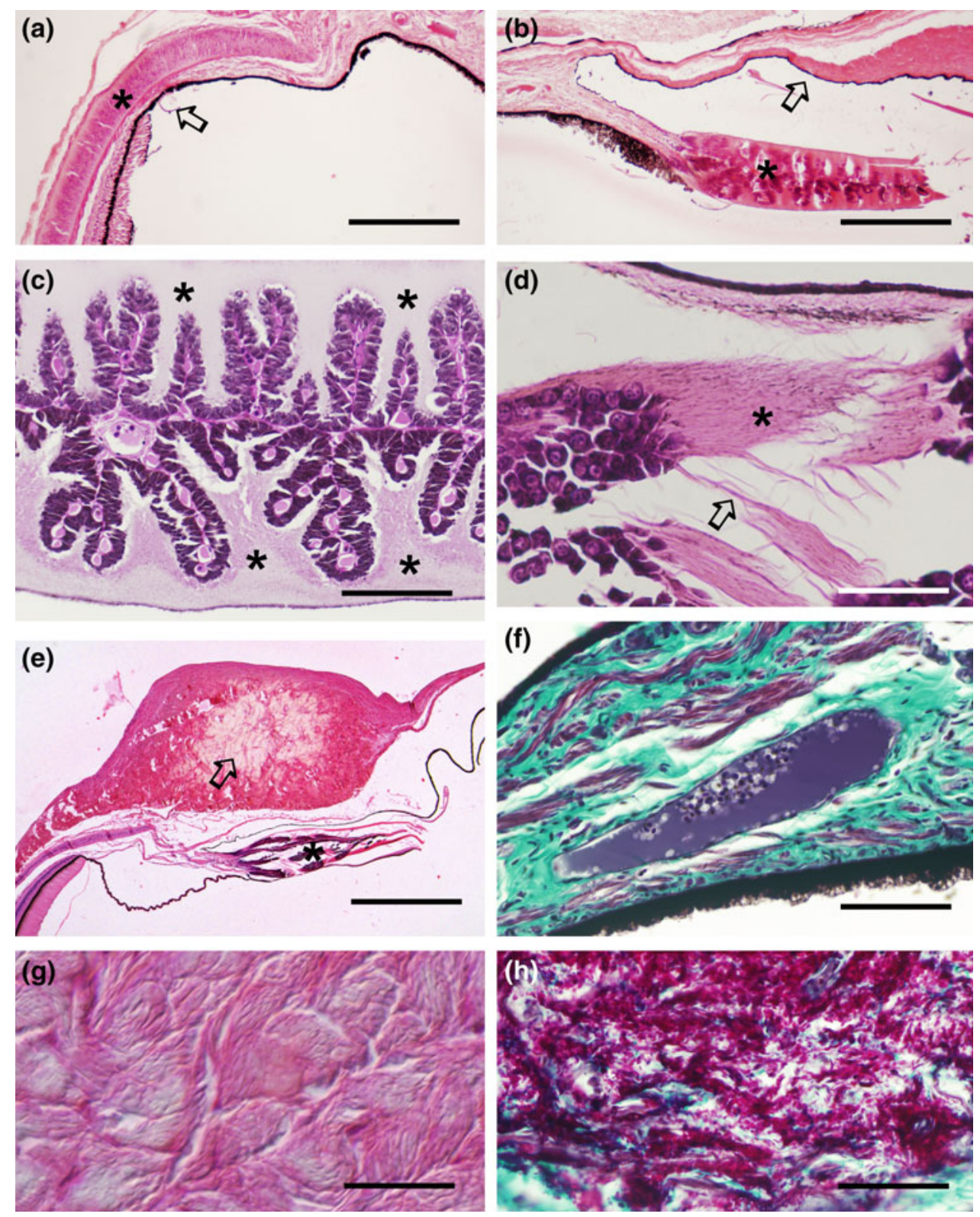

Fig. 4.22 Sections through anterior structures of cephalopod eyes. a Section of the octopus eye showing the transition between the retina and the ciliary region ("ora serrata"-like; outlined arrow). Star indicates the equatorial scleral cartilage. b Section of octopus eye showing the ciliary papillae (star) and the base of the iris (outlined arrow). c Transverse section of the lens-forming ciliary papillae, the upper and lower halves giving rise to the outer and inner hemilenses, respectively. The homogeneous pale material that surrounds papillae (stars) consists of innumerable cell processes of papillary cells. Note also abundant blood vessels in the axes of papillae. d Tangential

rostro-caudal axes (see below). This cross of bundles was named optic chasm by Cajal (1917). The bundles consist of numerous thin axons accompanied of glial cells and blood capillaries.

The ciliary proximal part of the retina is a simple epithelium formed of cuboidal-prismatic cells with the

section of a papilla showing lens cells with dense cytoplasm forming long, thin eosinophilic processes (outlined arrow, star) that form the lens. e Section showing the irideal angle of a squid eye, with a thick iris (outlined arrow) and ciliary papillae (star) below. f Proximal region of the iris of an octopus showing inner and outer pigment epithelia and a stroma with abundant collagen, small muscular bundles and blood vessels. $\mathbf{g}, \mathbf{h}$ The granule-filled iridophores of octopus iris appear colorless in H\&E stains but pink with the Masson's trichrome. Scale bars a, b, e $500 \mu \mathrm{m} ;$ c $200 \mu \mathrm{m}$; d, $\mathbf{f}-\mathbf{h} 50 \mu \mathrm{m}$

nucleus in basal location, large amounts of black pigment in the middle and an eosinophilic apical cytoplasm. This epithelial layer is continuous with that of supporting cells of the retina. The abrupt change from the neural retina to the ciliary epithelium reminds the ora serrata of vertebrates. More distally, this epithelial layer transforms toward the lens 
forming a numerous series of radial folds covered of characteristic epithelial cells and a vasculo-connective axis (ciliary papillae and ciliary ring). The shape and size of the papillary epithelial cells vary from small cells proximally to tall cell with large nucleus and highly basophilic cytoplasm sometimes with melanic granules that give rise to a thin process that extends in parallel with those of neighbor cells toward the lens. The accumulation of these long and thin cytoplasmic processes (crystalline processes) gives rise to the layers of the spherical lens, which is formed of two unequal halves, a small external and a large internal separated by a septum. Two series of papillary folds are responsible of these portions. A muscular ring joins the scleral cartilage to the ciliary ring, its contraction allowing eye accommodation by displacing the lens perpendicularly to the eye axis (Schaeffel et al. 1999).

Externally to the ciliary papillae, the pigment epithelium continues and covers the inner surface of the iris. In octopus, cuttlefish and squid, the iris is much thickened toward the pupil and contains a number of large iridophores filled of reflecting platelets (reflecting tissue, silver layer) in a central location. These platelets are unstained in H\&E sections but appear brightly red-stained with the Masson's trichrome method. Iridocyte platelets contain condensed proteins of the reflectin family (Crookes et al. 2004; Andouche et al. 2013; DeMartini et al. 2015).

For the organization of statocysts, olfactory organs and other sensory structures, readers are referred to Young (1971), Wells (1978), Budelmann et al. (1997) and Polese et al. (2015).

\subsection{The Nervous System (Figs. 4.23, 4.24, 4.25 and 4.26)}

\subsubsection{Brain}

The nervous system of coleoid cephalopods (squid, cuttlefish and octopus) is very complex compared to other invertebrates, its level of complexity being comparable to those of fishes despite their very different designs. The cephalopod nervous system supports a number of complex behavioral traits with multiple dedicated systems for memory, learning and control of body movements, dynamic camouflage, reproductive behavior and visceral function (Young 1971, 1995; Wells 1978; Huffard 2013). The ganglionic nervous system of cephalopods has evolved from a more generalized mollusk organization as that observed in present-day gastropods. This nervous system is composed of cerebral ganglia joined by connectives and commissures with different pairs of ganglia: pallial, pedal, visceral and buccal. In coleoid cephalopods, the number of ganglia has increased by growth, condensation and subdivision of ancestral ganglia, forming a large mass ("brain") around the esophagus composed of numerous ganglia and lobes. This brain is partially encased by cartilage (cranial cartilage) and dense connective tissue. Here, only a brief description of selected ganglia, nerve cords and nerves stained with general methods will be provided. For further histological details, readers are directed to specialized monographs as that of Young (1971) on the nervous system of octopus.

In octopus, the different brain lobes (Fig. 4.23) exhibit a cortex of cell perikarya that surrounds an extensive neuropil and tract region. Large differences are noted among lobes in the number and size of perikarya, which is easily appreciable in sagittal sections of the brain. In some lobes, cords of cells enter the central neuropil, forming networks. The location, cell size and histological organization allow distinguishing lobes, although wide intermediate neuropil areas make difficult to trace boundaries between lobes. In the supraesophageal mass of the brain, the vertical lobes are most easily recognizable centers because the large amounts of small granule cells forming columns in the cortex and its superficial dorsal location. Rostral to it in superficial locations, the superior and inferior frontal lobes and the subfrontal lobe exhibit different cortical organization. Just rostral to the inferior frontal and subfrontal lobes, the superior buccal lobe exhibits a characteristic cortex with large neurons. Coarse labial nerves extend from this lobe rostrally. By comparison with these lobes, deeper regions of the supraesophageal mass appear as poorly delimited regions, including the subvertical lobe and several regions in the basal lobe system.

The optic lobes (Fig. 4.24) are easily recognizable in the three species by their lateral location with regard to the brain and relation with the eye, as ganglia that receive fibers of the optic nerves. The optic lobe is covered by a layered superficial region (cortex) that by analogy with deep layers of the vertebrate retina is named retina profunda, and a central region that shows a non-laminar organization with islands of neurons intermingled with extensive neuropil areas. The cortex is three-layered, with two dense bands of small neurons (granules) flanking an elaborated middle layer or plexiform layer. Optic nerve fibers end in this plexiform layer contacting with neurons of the granular layers. In both granular layers, some larger neurons can be distinguished among small cells, indicating a complex neuronal organization. Small axonal bundles cross these layers, giving them a columnar appearance. Below the inner granular layer, groups of neurons become arranged in radial columns 

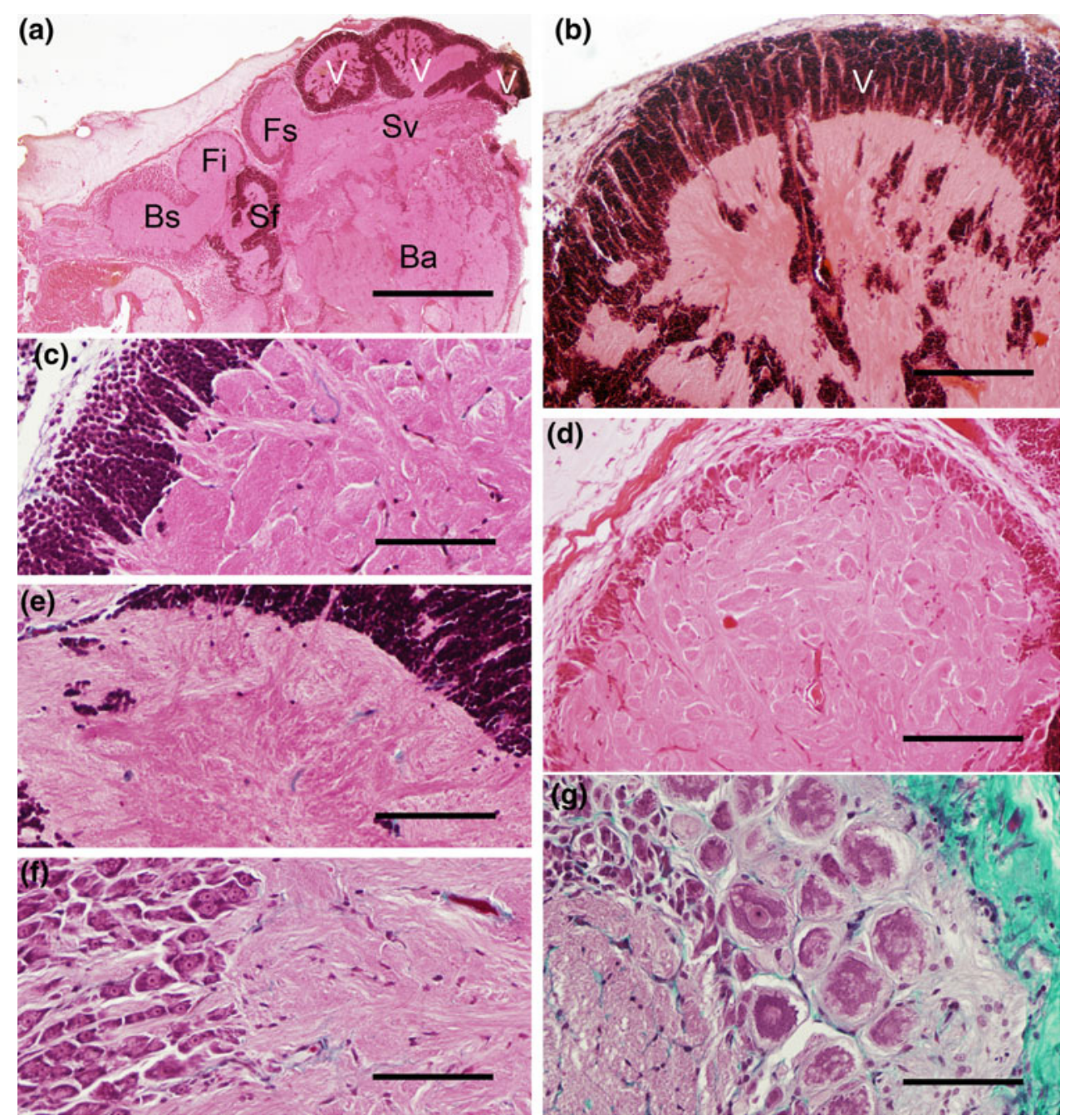

Fig. 4.23 a Photomicrograph of a parasagittal section of supraesophagic cerebral mass of octopus showing the different appearance of the main lobes. Rostral is at the left. Ba, Basal lobe; Bs, Superior buccal lobe; cb, cerebro-brachial connective; $\mathrm{Fi}$, inferior frontal lobe; Fs, superior frontal lobe; Sf, Subfrontal lobe; V, vertical lobe. b Detail of the vertical lobe showing the cortex with small-celled columns extending cell cords to the central neuropil or medulla. c Detail of the frontal superior lobe showing the thick small-celled cortex and the

separated by abundant neuropil. In more central regions of the lobe, the cords appear more heterogeneous forming a network and exhibiting large neurons. The optic lobes are among the most complex centers of the cephalopod central nervous system. The medial region of the optic lobes lacks the three-layered cortex and is joined with the basal complex of the supraesophagic mass via conspicuous optic tracts coursing in the optic peduncle, which includes small peduncle and olfactory lobes. In coleoids, the olfactory lobes receive sensory information of a peripheral chemosensory structure located in the skin behind the eye. Closely associated with the optic peduncle, there is a conspicuous optic

central neuropil with glomerular appearance. d Detail of the inferior frontal lobe showing its glomerular neuropil. e Subfrontal lobe showing the small-celled cortex and a central region with numerous fiber bundles. $\mathbf{f}$ Detail of the buccal superior lobe showing large neurons in the cortex. $g$ Detail of the magnocellular chromatophoric lobe of the palliovisceral complex showing big and small neuronal perikarya in the cortex. The connective layer covering the lobe is seen at right. a-f H\&E stain; f Masson's trichrome. Scale bars a $1 \mathrm{~mm}$; b-g $200 \mu \mathrm{m}$

gland that consists of endocrine cells and is innervated by a tract bearing fibers from peptidergic neurons of the posterior dorsal basal ganglion. These peptidergic neurons express the neuropeptides FMRFamide and/or GnRH, which appears to inhibit secretion (Di Cosmo and Di Cristo 1998). The secretion of gonadotropic mitogenic factor by this gland varies throughout the sexual cycle and is involved in the control of gametogenesis, being regulated by the axo-glandular innervation.

Most lobes of the subesophageal mass exhibit a simple histological organization with neuronal perikarya segregated to the cortex and a massive central region occupied by 

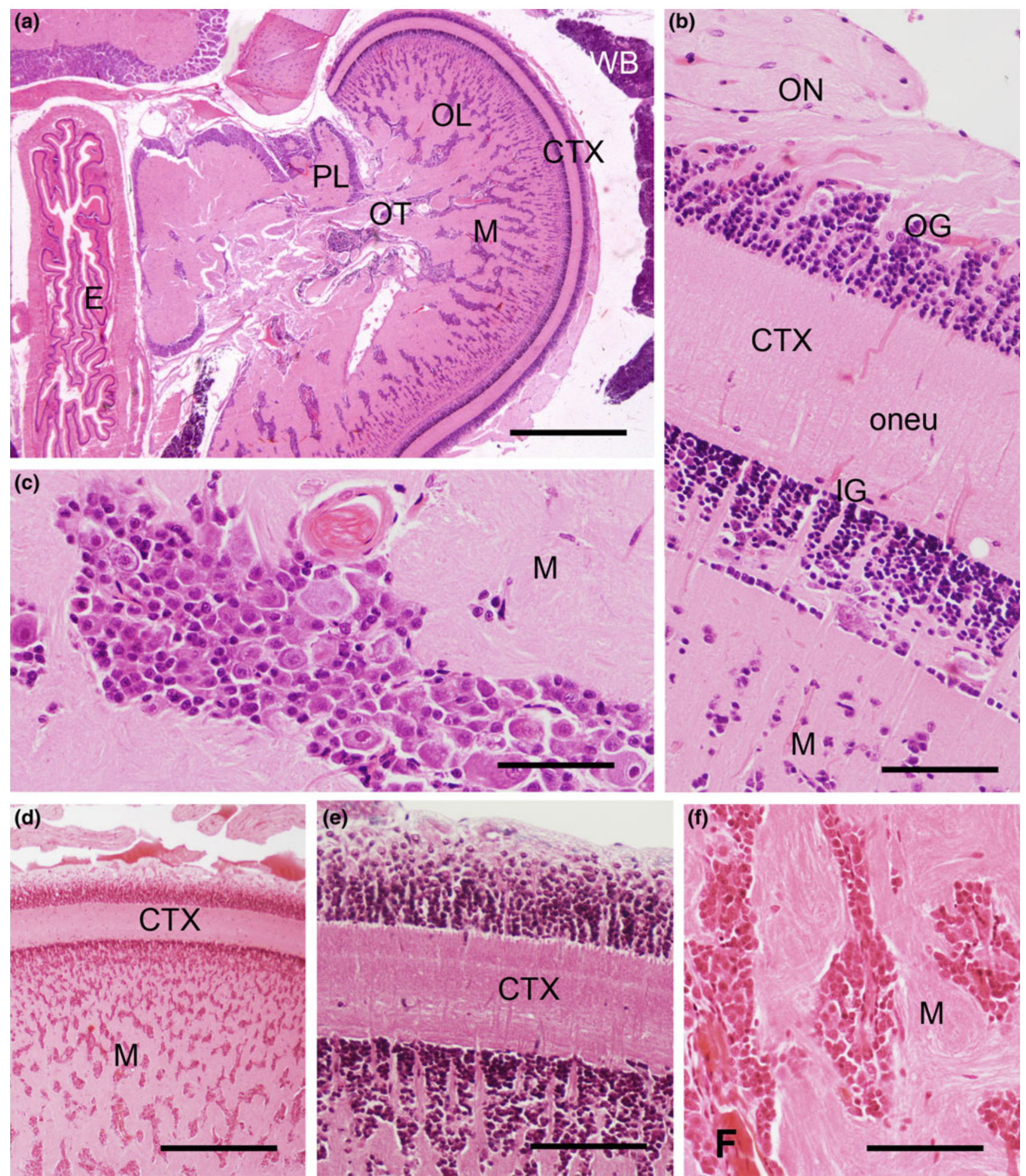

Fig. 4.24 Section of the cerebral mass of a squid showing the optic lobe (OL) and the optic tracts (OT) connecting with other lobes. Note the cortical laminas (CTX) embracing the core or medulla $(\mathrm{M})$ of the lobe. Note also the esophagus (E) surrounded by cerebral masses and the white body (WB). PL, peduncular lobe. b Detail of the cortex of the squid optic lobe showing outer (OG) and inner (IG) granular layers and the thick outer neuropil (oneu). Note also the entrance of optic nerve $(\mathrm{ON})$ bundles. $\mathbf{c}$ Detail of a cell cord of the medulla (M) with large and small neurons surrounded by neuropil. d-f Sections of the octopus optic lobe, showing similar organization as in squid, with small differences. Same abbreviations as used for squid. H\&E stain. Scale bars $\mathbf{a} 1 \mathrm{~mm} ; \mathbf{d} 500 \mu \mathrm{m} ; \mathbf{b}, \mathbf{c}, \mathbf{e}, \mathbf{f} 200 \mu \mathrm{m}$ 
Fig. 4.25 Transverse section of the nerve cord of club $(\mathbf{a}, \mathbf{b})$ and tentacle (c, d) of a squid. a, b Panoramic view and detail showing the mantle of neuron perikarya that surround the central neuropil (neu). Glial and vascular processes are the better stained structures in the neuropil. Note the cerebral-tentacular tract (btt). c, $\mathbf{d}$ In the squid tentacle cord, the cerebro-tentacular tract is prominent exhibiting numerous coarse axons. With regard to the club, the cord neuropil is more scarce and the perikarya (N) small. e Section of octopus arm nerve cord showing the peripheral mantle of perikarya and the central neuropil.

Masson's trichrome stains in green the vascular net entering the cord and the connective surrounding the cord. Scale bars a, c $200 \mu \mathrm{m} ; \mathbf{b}, \mathbf{d}, \mathbf{e} 100 \mu \mathrm{m}$
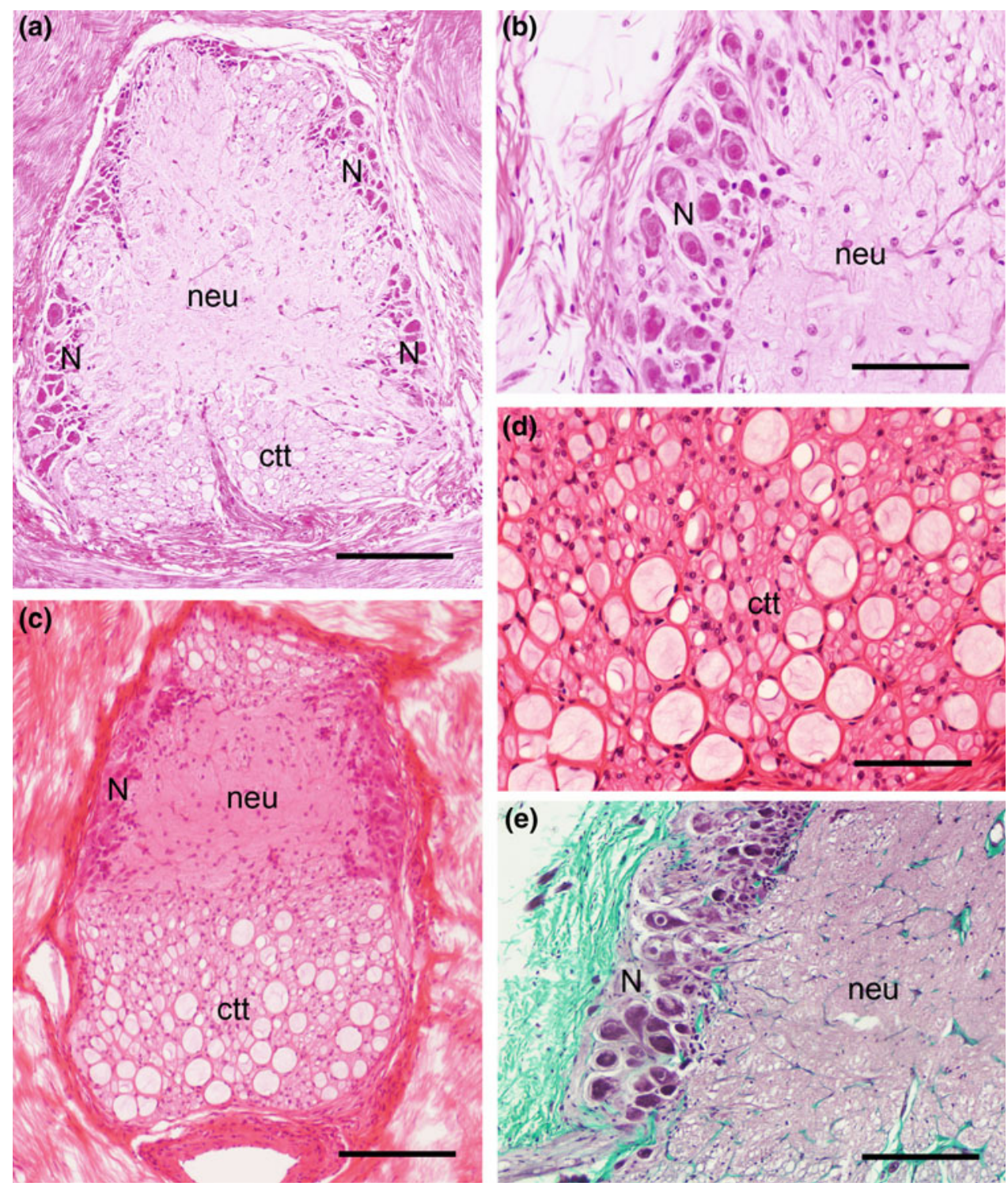

neuropil with glial cells and capillaries. The size of neurons in the cortex varies from small to large or very large in the different ganglia. Some tracts of thickened fibers can be observed passing through the neuropil. These conspicuous tracts interconnect the different ganglia. Different nerves connect these ganglia with other structures. The subesophageal mass of cephalopods has evolved by fusion and specialization of several ganglia that are present in other mollusks. The anterior subesophageal mass of octopus gives rise to the eight thick arm nerves (ten in squid and cuttlefish), to large tracts joining the mass with the supraesophageal lobes (buccal, frontal) and to a large dorsal commissure. The arm nerves course toward the arms and to some distance of the brain acquire ganglionic cells and form the axial nerve cord that extends all along the center of the arms. The middle subesophageal mass receives the statocyst nerves. The subesophageal mass includes several conspicuous lobes dedicated to chromatophore control (chromatophoric lobes), as well as lobes dedicated to skin, vascular and body movements. The histological appearance of the chromatophoric lobes of octopus is unusual, with a very thick cortical layer with very numerous large neurons and a small core of cells and neuropil.

\subsubsection{Ganglionic Nerve Cords of Arms and Tentacles (Fig. 4.25)}

The control of the complex muscular system and coordination of arms and suckers, and the integration of sensory information, is provided by the brachial nerves and by additional arm ganglionic structures (Young 1971). The center of the arms and tentacles contains a ganglionic nerve cord that extends along the entire length and is continuous 
Fig. 4.26 Sections of nerves of octopus (a-c) and squid (d-f). a, b Transverse sections of nerves passing through the cranial skeleton showing the close arrangement and large diameter of non-myelinated fibers. Star, cartilage. c, Tangential section of the large-celled stellate ganglion (G) of octopus showing the exit of a stellar nerve (outlined arrow). d, e Mantle nerves of squid showing thin axons (d) and a giant axon (e), respectively. Thin arrows point to the profile of the giant axon. f, Branchial nerve cord with ganglion cells (outlined arrow). a, c-f H\&E stain, b Masson's trichrome. Scale bars a, b, d-f $100 \mu \mathrm{m} ; \mathbf{c} 200 \mu \mathrm{m}$
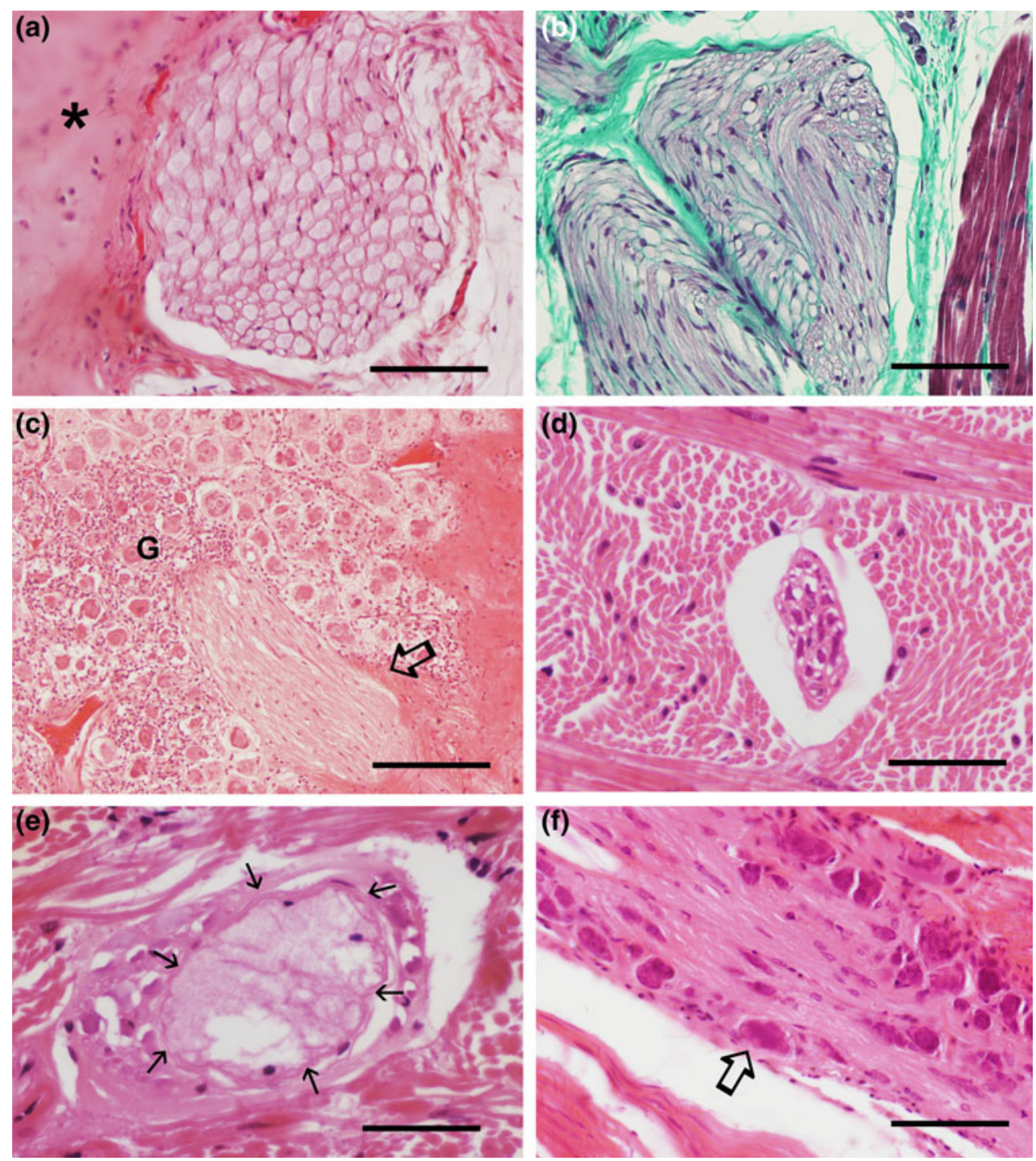

with the brachial nerve. The cord consists of a cortical region with perikarya mainly located at its lateral surfaces, a central region of neuropil and bundles of longitudinal fibers (cerebro-brachial tracts) on the oral and aboral sides. The cord innervates the complex musculature of the arms and suckers through numerous nerves, and also receives sensory fibers. The histological organization varies between arms and tentacles. In octopus arms, which bear two alternate lines of suckers, an alternate concentration of perikarya that innervate the suckers is noted along the cord (ganglionic cord). In squid tentacles, the shaft lacks suckers. In the nerve cord, almost a half of the oral side is occupied by thick fibers of the cerebro-brachial tract; those of the aboral side are smaller and scarcer. The lateral bands of neurons and central neuropil are located between tracts. Numerous glial cells are also observed. The cord is surrounded by connective tissue and accompanied of large blood vessels. In the tentacular club, the nerve cord is displaced toward the oral surface. The nerve cord organization is similar in cuttlefish tentacles.

\subsubsection{Nerves, the Stellate Ganglion and the Giant Fiber System (Fig. 4.26)}

Numerous nerves innervate the different parts of the cephalopod body. These consist of fibers of different diameters distinguishable from other tissues (muscle, connective) by its characteristic appearance. Some nerves consist of thick fibers, others of thin fibers and some of a mixture of thick and thin fibers. In the mantle of cuttlefish and squid, nerves containing a single giant nerve fiber are also recognizable.

The stellate ganglion is one of the larger peripheral ganglia of the coleoid nervous system. By its superficial location in the mantle, it is an accessible ganglion for experimentation. In octopus, it consists of a peripheral cortex with numerous 
large perikarya and a core neuropil that receives fibers from the palliovisceral lobe of the subesophageal mass through a coarse pallial nerve. The ganglion connects with the mantle through about 20 radial stellar nerves. This ganglion provides the motor fibers that innervate the mantle musculature. In cuttlefish and squid, the processes of some perikarya of this ganglion fuse to form the third-order giant fibers that innervate the mantle in these species. Most motor fibers arising in this ganglion, however, are not gigantic. In cuttlefish and squid, too, a pair of first-order gigantic neurons receiving statocyst fibers is situated in the magnocellular lobe of the subesophagic mass. These cells mediate the fast escape reflex in a way analogous to that of Mauthner neurons in many fishes. These first-order giant neurons contact second-order ganglion neurons located in the palliovisceral lobes that directly innervate some fast retractor muscles or contact the third-order giant axons in the stellate ganglion. Stellate nerves control respiratory movements of the mantle, jetting and the expansion of the mantle which causes water to be inhaled (Packard and Trueman 1974).

\subsection{Reproductive System (Figs. 4.27, 4.28, $4.29,4.30,4.31,4.32,4.33,4.34$ and 4.35)}

\subsubsection{Females}

The female reproductive system of coleoid cephalopods consists of an ovary and one (squid and cuttlefish) or two (octopus) oviducts with associated oviducal glands, which opens in the gonopore to the pallial cavity (Wells 1978).
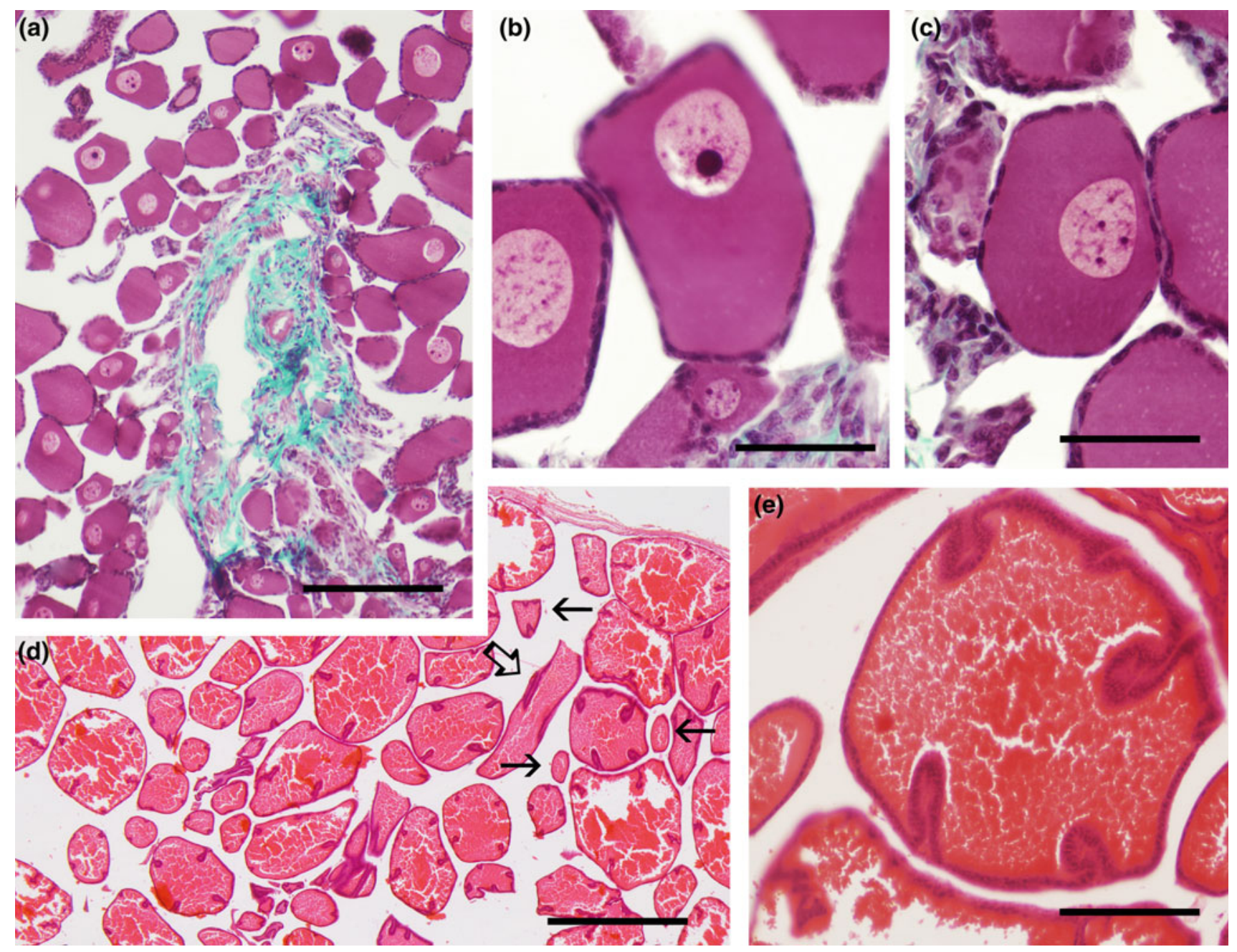

Fig. 4.27 Sections of ovaries of immature (a-c) and mature (d, e) female octopus. a Section of showing numerous oogonia and early oocytes attached to an ovarian cord. b, c Detail of an oogonia and oocytes in early folliculogenesis. Note in $\mathbf{b}$ a big nucleolus, and in $\mathbf{b}$ and $\mathbf{c}$ the meiotic chromosomes. d Section of a vitellogenic ovary showing abundant yolk inside oocytes and the follicular epithelium infolds forming elongated crests. Octopus follicles are elongated and pear-shaped, so that in sections of the long stalks show small diameter (arrows; most follicles are sectioned transversely). The outlined arrow points to an obliquely sectioned follicular stalk. e Detail of a vitellogenic follicle. a-c Masson's trichrome; d, e H\&E stain. Scale bars a $200 \mu \mathrm{m} ; \mathbf{b}$, c $50 \mu \mathrm{m} ; \mathbf{d} 800 \mu \mathrm{m}$; e $100 \mu \mathrm{m}$ 

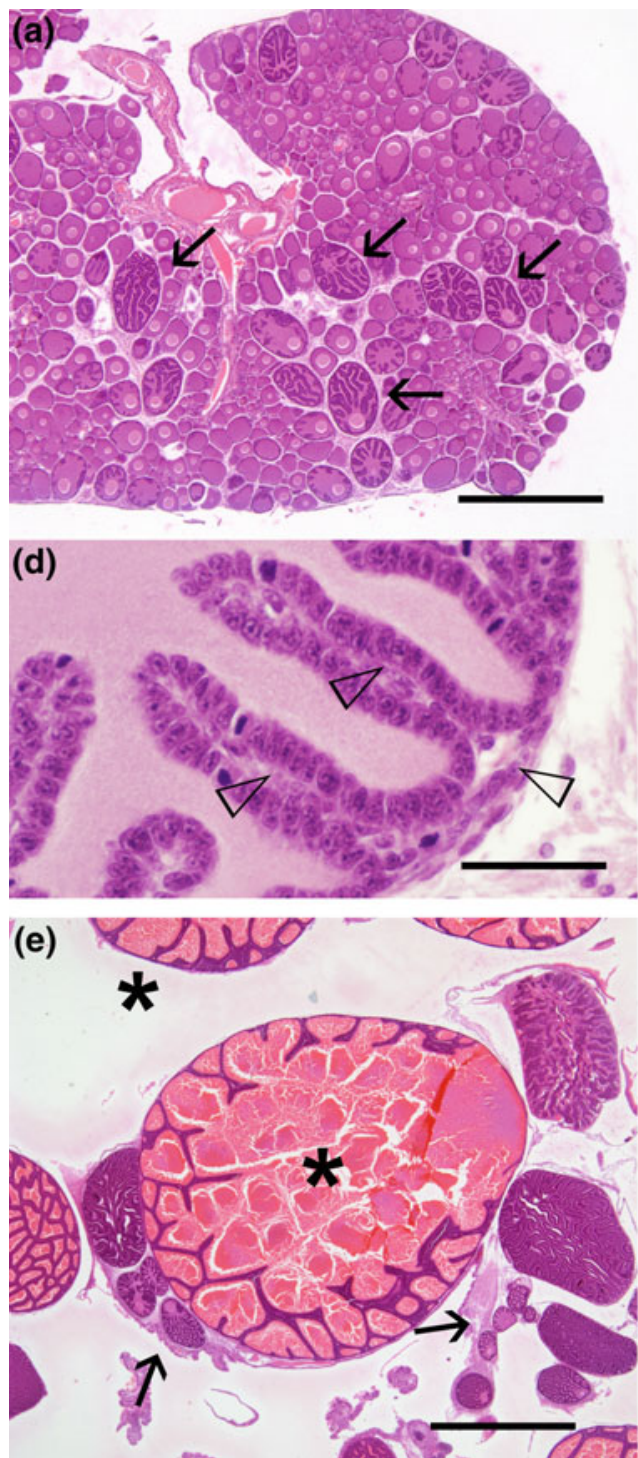

Fig. 4.28 Sections of ovaries of squid (a-d) and cuttlefish (e-g). a Panoramic view of an immature squid ovary showing some previtellogenic follicles (arrows) and a number of oocytes in early folliculogenesis. b Detail of a small oogonia (outlined arrow) and oocytes in early stages of folliculogenesis with a pole of follicular cells (arrowheads). Note that oocytes are in meiotic prophase (zygotenepachytene) judging from the nuclear appearance. c Detail of previtellogenic follicles (thin arrows) and oocytes in folliculogenesis (arrowheads) of the same ovary. d Wall of a previtellogenic follicle showing
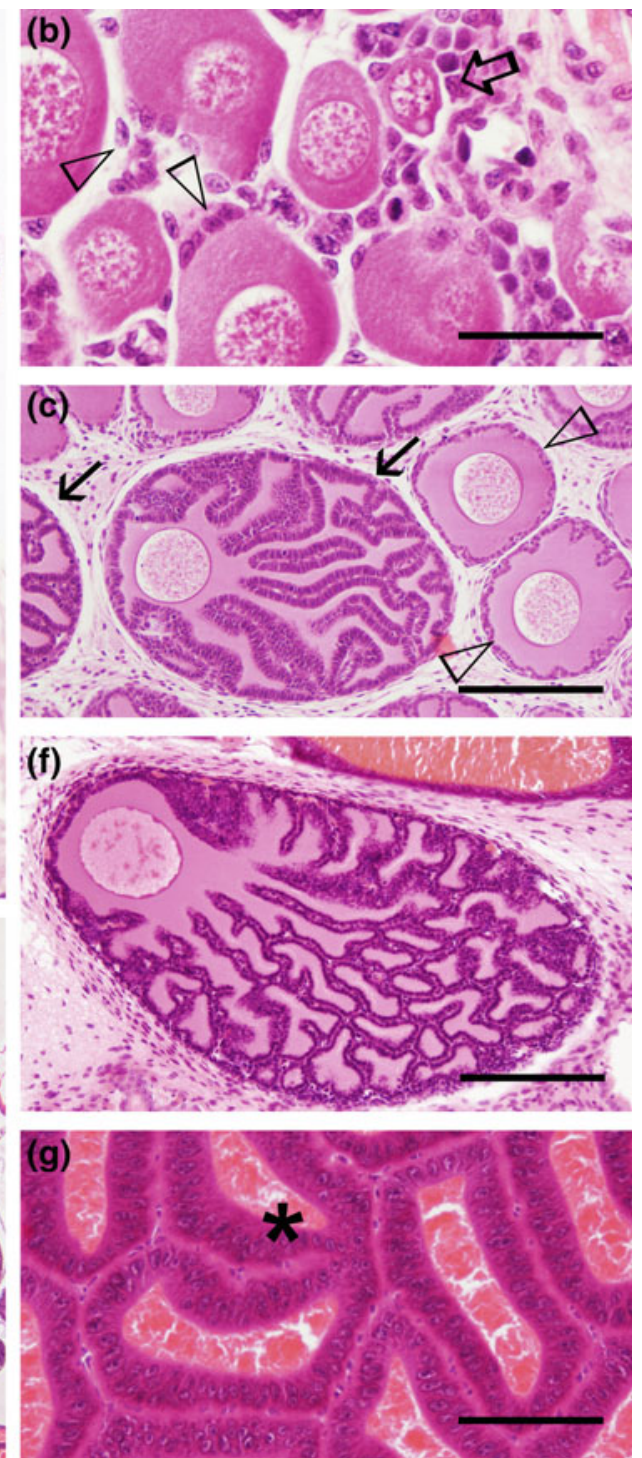

deep infolds of the follicular epithelium accompanied of vasculo-connective tissue (arrowheads). Note frequent mitotic figures in the follicular epithelium. e Section of a mature cuttlefish ovary showing large vitellogenic follicles (stars) and smaller follicles in previtellogenic stages (arrows). Note the yellow-stained yolk inside the cytoplasm of large oocytes. f Previtellogenic follicle of cuttlefish showing the reticular appearance of follicular infolds. e Detail of the follicular infolds of a large vitellogenic follicle. H\&E stain. Scale bars a $0.8 \mathrm{~mm}$; b, d, g $50 \mu \mathrm{m} ; \mathbf{c}, \mathbf{f} 200 \mu \mathrm{m} ; \mathbf{e} 1.2 \mathrm{~mm}$
Spermatophore receptacles or spermathecae of octopus are part of the oviducal gland, whereas receptacles of cuttlefish and squid females are located in the head. In decapods, a pair of large nidamental glands and accessory nidamental glands opens directly in the pallial cavity near the gonopore. These accessory glands lack in octopus. Oviducal and nidamental glands form the egg case that is essential in the reproductive strategy of cephalopods (Boletzky 1986).

\subsubsection{The Ovary of Octopus (Fig. 4.27)}

The ovary has the appearance of a racemose gland with numerous ovarian follicles surrounded by the gonadial coelom. A comparison of the ovaria of immature and mature octopus illustrates the huge changes occurring in ovarian follicles (Di Cosmo et al. 2001). In sections of an octopus immature ovary sac, a large number of small developing follicles can be appreciated. These follicles are pear-shaped, 

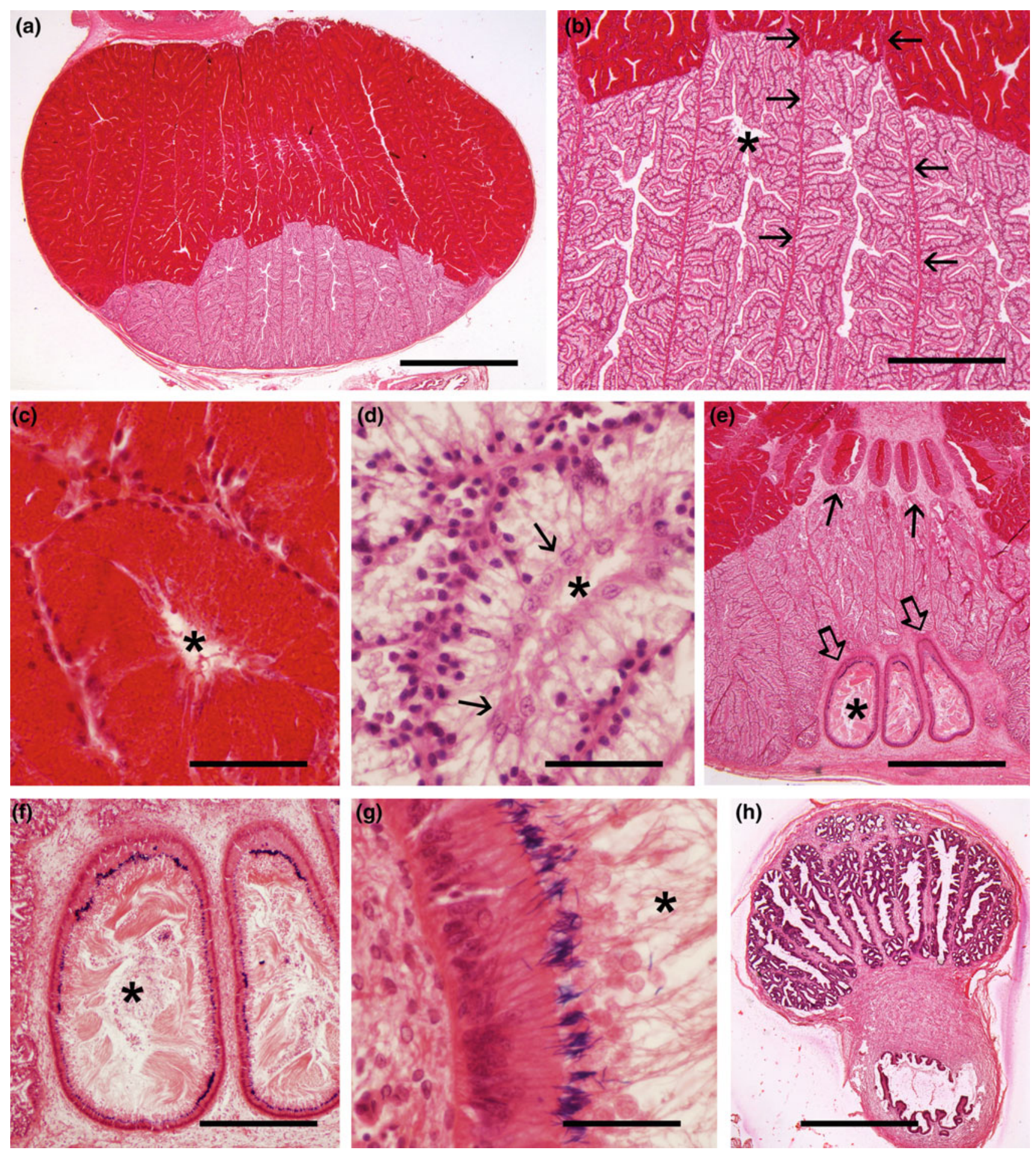

Fig. 4.29 a, b Longitudinal tangential section of the oviducal gland of a mature female octopus shows the organization in sectors consisting of glandular units of two types, proximal and distal with respect to the ovary. Distal units stain brightly red and the proximal units pale pink. Note the sharp limit between the units extending in each gland sector (arrowed) (b). Star, lumen of mucous region. c Detail of the distal glandular epithelium showing gland cells filled of red-stained secretory granules. Note the basal location of cell nuclei. Star, lumen. d Detail of proximal secretory units filled of pale mucous granules. Note pale nuclei of cells lining the lumen (arrows) and dense nuclei of gland cells. e Section passing more centrally showing secretory ducts of the distal portion (arrows) and sections of three spermathecae (outlined arrows). f Spermathecae with sperm released from spermatophores waiting for egg fertilization. g Detail of the spermatheca tall epithelium with attached sperm heads and long sperm tails directed to the lumen (bundles of tails are appreciable in $\mathbf{f}$ ). $\mathbf{h}$ Tangential section of the oviducal gland and oviduct (ov) of an immature female octopus showing sectors of branching tubules that are broadly separated by connective stroma. Star, lumen. H\&E stain. Scale bars a, e $1.2 \mathrm{~mm}$; b $400 \mu \mathrm{m} ; \mathbf{f} 500 \mu \mathrm{m} ; \mathbf{c}, \mathbf{d}, \mathbf{g ~} 50 \mu \mathrm{m} ; \mathbf{h} 1 \mu \mathrm{mm}$ 

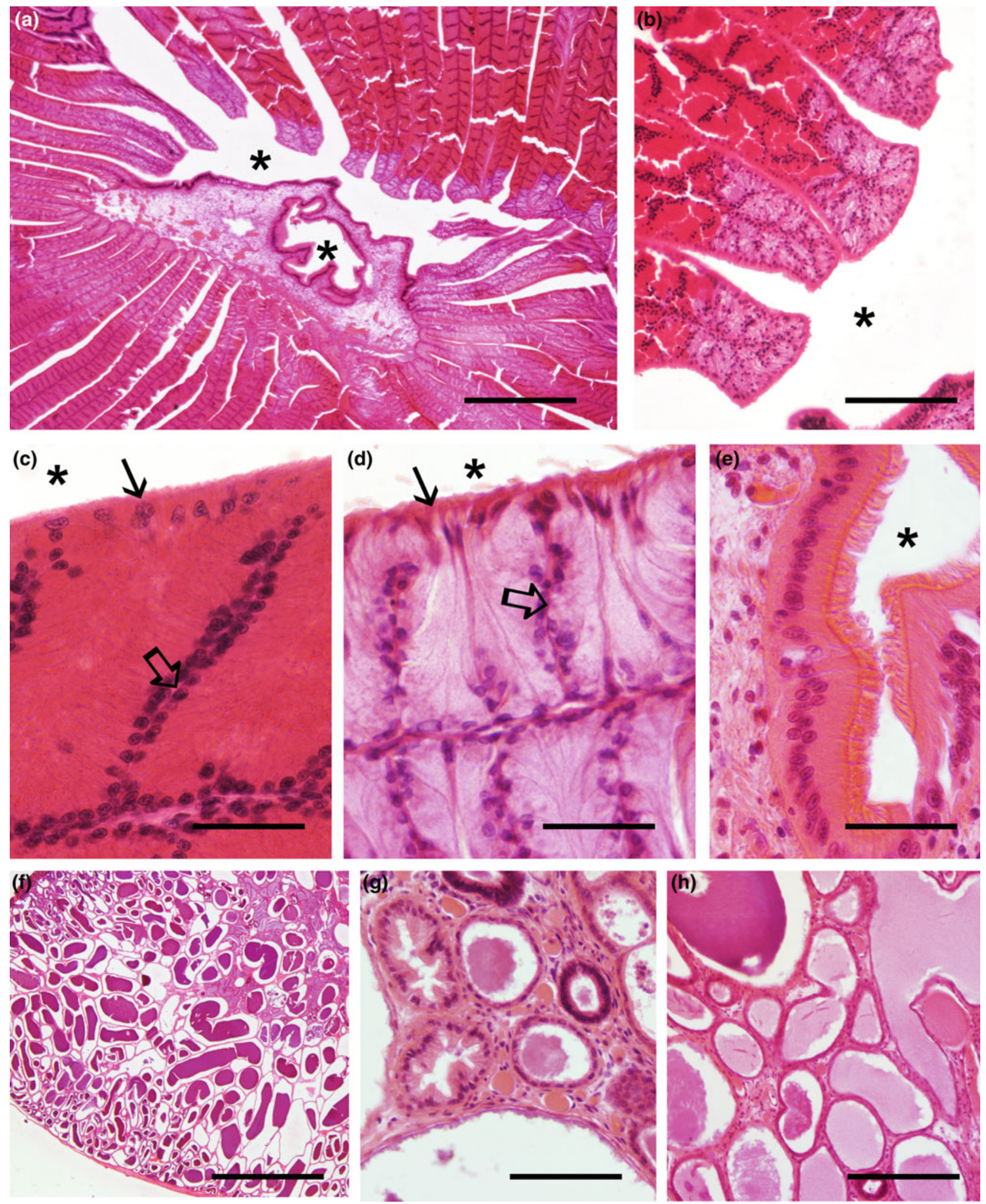

Fig. 4.30 a Section of the nidamental gland of a mature female cuttlefish showing leafs of glandular tissue around a central region showing the gland duct. b Detail of the inner region of leafs showing two different glandular regions. c Detail of the basal region of the leaf showing closely apposed parallel bands of tall glandular cells with cytoplasm filled of red-stained granules and a dense basal nucleus. Note apical non-glandular cells (arrow). d Detail of the apical region of the leaf showing parallel bands of tall mucous cells with basal nuclei and

apical supporting cells (arrow). The outlined arrows in $\mathbf{c}, \mathbf{d}$ point to the thin connective layers separating glandular bands excepting apically. e Section of the nidamental gland duct showing the tall ciliated epithelium. Stars in a-e indicate the glandular and duct lumen. $\mathbf{f}-\mathbf{h}$, Panoramic view and details of the accessory nidamental gland of a mature female cuttlefish showing numerous glandular tubules filled of secretion. H\&E stain. Scale bars a, f $500 \mu \mathrm{m} ; \mathbf{b}, \mathbf{h} 200 \mu \mathrm{m} ; \mathbf{c}-\mathbf{e} 50 \mu \mathrm{m}$; g $100 \mu \mathrm{m}$ 

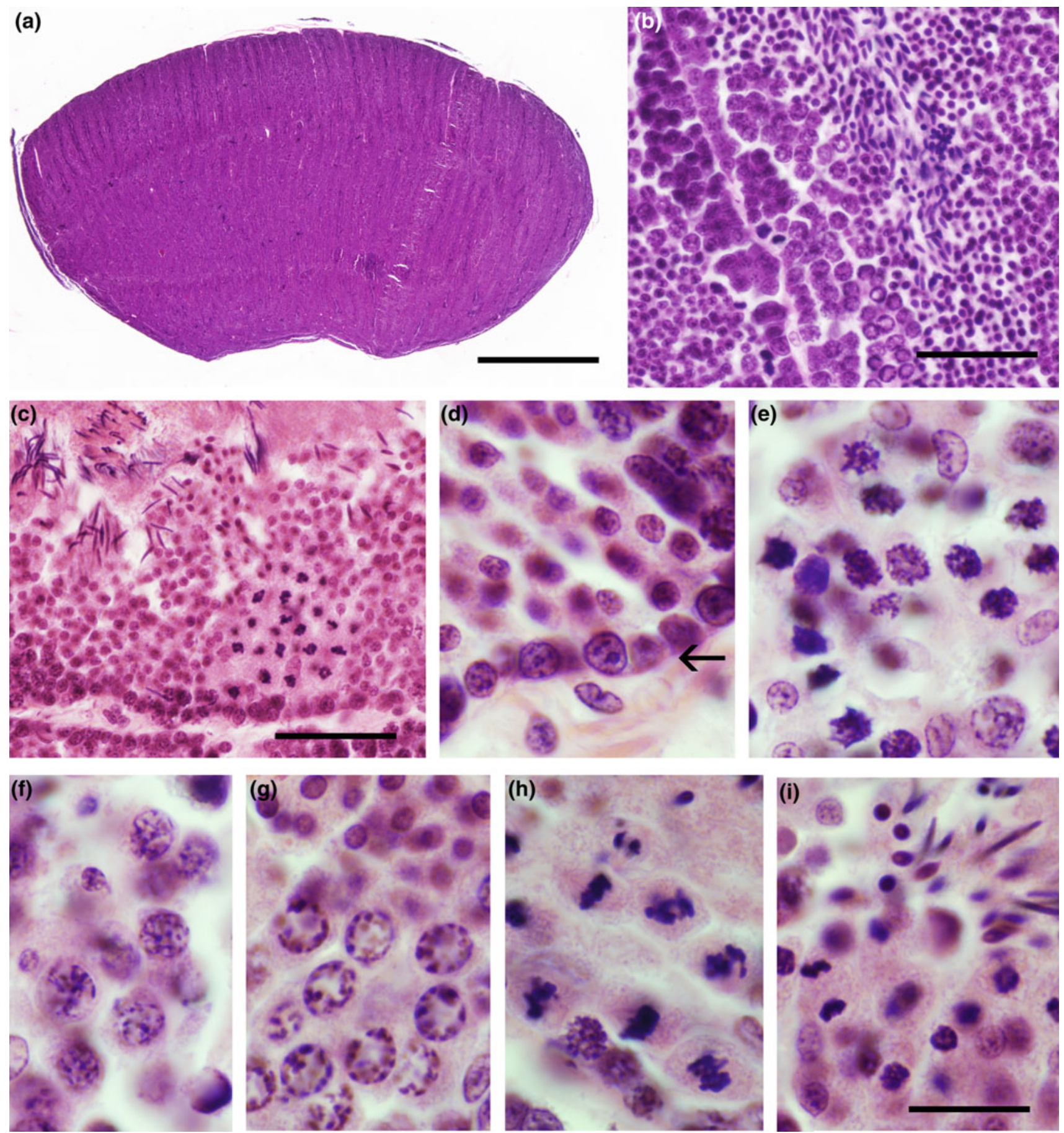

Fig. 4.31 a Section of the testis of an immature squid showing the compact organization of testicular cords. b Detail of adjacent testicular cords (tubules) showing a zonal organization with spermatogonia in the outer layers, followed of cysts of spermatocytes and spermatids in maturation. c Section of the wall of a testicular tubule of a mature octopus showing cysts of germ cells in different maturation stages, including mature spermatozoa. $\mathbf{d}-\mathbf{i}$ Details of spermatogenic cells in different

with a long stalk continuous by its proximal end with the septal ingrowths of the ovary wall and protrude in the ovarian cavity. The octopus oocytes are flask-shaped with a thin part stages of maturation. d Layer of spermatogonia (arrow) in the tubule border. b Cluster of spermatocytes in leptotene (prophase $\mathbf{I}$ of meiosis). f Cluster of spermatocytes $\mathbf{I}$ in zygotene. f Cluster of spermatocytes in pachytene (bottom) and early spermatids (top). h Cluster of spermatocytes in metaphase I. i Spermatocytes in telophase I (bottom), and spermatids with elongating nuclei (top). H\&E stain. Scale bars a $1 \mathrm{~mm}$; b $40 \mu \mathrm{m}$; c $50 \mu \mathrm{m}$; i $16 \mu \mathrm{m}$, this bar also applies to $\mathbf{d}-\mathbf{h}$

entering the stalk and a thicker distal region. The oocyte is covered by an inner follicular epithelium surrounded by a flattened ovarian epithelium with thin blood vessels that enter 
in the stalk between these layers. The nucleus of immature oocytes is rounded and exhibits a large nucleolus and a granular appearance. In mature octopus, the ovary contains very large yolk-filled oocytes, which are covered by a thick follicular epithelium that shows some longitudinal infoldings. The number of follicular cells covering each oocyte is enormous. These follicular cells synthesize among others the main protein of yolk, vitellogenin and other substances as lipids that form this egg reserve material. With high magnification, a number of yolk platelets are appreciable in the otherwise homogeneous yolky region. Nuclei are very infrequently observed in sections of these big oocytes.

\subsubsection{The Ovary of Squid and Cuttlefish}

(Fig. 4.28)

The pictured sections of squid ovary were from an immature female. In this ovary, a large number of immature, previtellogenic oocytes of several sizes, are observed. Smaller oocytes only present very flattened follicular cells and may appear to contact other oocytes, whereas in larger oocytes a thicker follicular epithelium was clearly appreciable. Only a few oocytes show infolds of their surface accompanied of a pleated sheet of follicular cells. In larger follicles, numerous mitotic figures are appreciable in the follicular epithelium. The nucleus of oocytes shows chromatin with granular appearance but not a conspicuous nucleolus.

Sections of ovaries of mature female cuttlefish show ovarian follicles in different stages of development, the most advanced being in vitellogenic stages. The presence of follicles in different stages of development indicates that cuttlefish females may breed at different times. Small previtellogenic oocytes are surrounded by a layer of follicular cells whose height increases with development. In more advanced vitellogenic follicles, the follicular epithelium becomes pleated accommodating in the infolds of the oocyte surface, having a meandering appearance. These infolds are anastomosed forming a complex network. The follicular cells are short and are mostly occupied by a round condensed nucleus. In some sections, the large and round oocyte nucleus can be appreciated with uncondensed chromatin showing an appearance similar to that of lampbrush chromosomes (uncondensed bivalents), and the cytoplasm becomes slightly basophilic. In large vitellogenic follicles, the follicular cells are tall and intensely basophilic, with a granular nucleus that occupies the middle of the cell. The entire follicle is surrounded by connective tissue (follicular theca), and connective tissue and blood vessels enter in the axis of infoldings of the follicular epithelium. This is unlike octopus, where the covers of follicles are inconspicuous. The oocyte is filled of eosinophilic yolk that by places appears formed of rounded platelets. The follicle diameter increased considerably from early vitellogenic stages. Atretic follicles can also be observed in the ovary.

\subsubsection{The Oviduct}

The oviduct of female cuttlefish is a duct with folded inner surface that consists of a high ciliated epithelium that lies on a thick connective-vascular tissue. The thin and tall epithelial cells show basal nuclei. Muscular layers surround externally the connective tissue.

\subsubsection{The Oviducal Gland and Seminal Receptacle of Female Octopus} (Fig. 4.29)

The oviducal gland of mature female octopus is a compact ovoid-shaped gland that exhibits two different sectors, an outer sector consisting of highly eosinophilic gland cells and an inner one with light gland cells, with a clear limit between. These sectors produce cement (a mucoprotein) and mucopolysaccharides that act as a polymerizer of the cement, to form an egg string for its fixation to appropriate substrates. The gland appears organized in compact lobes separated by thin connective septa that extend through both sectors, and it is covered with a thin connective-muscular capsule. The lobes consist of branched glandular epithelial tubules with thick walls and small lumen that are separated by very thin septa, giving the gland a quite compact appearance. The tubules branch from the central region of the lobe, where the lumen of the tubules is larger. The tubules of the eosinophilic sector consist of two types of cell, glandular and supporting, the glandular cells showing the abundant cytoplasm filled of round secretory granules that are highly eosinophilic, whereas the small and condensed nucleus is located basally close to the septa. The supporting cells have larger nuclei located apically and basal processes coursing among glandular cells, but they are masked by the large amount of secretory granules. The non-eosinophilic sector is also formed of closely apposed thick branched epithelial tubules with small lumen. In this sector, the supporting cells show clearly their apical nuclei and the basal processes because the light glandular cells do not mask them. The light gland cells exhibit condensed nuclei in the basal region. No continuity between eosinophilic and light tubules was observed in the sections examined. In the central region of the eosinophilic lobes, some short tubules showed regions without gland cells covered by ciliated epithelial cells, forming a transition toward the gland ducts that are covered by a tall ciliated epithelium with undulated surface. In sections showing the ducts, they appear filled of a mass of eosinophilic granules including condensed nuclei, suggesting that secretion of this gland sector is of holocrine type. 
The seminal receptacle of female octopus consists of the spermathecae, which are closely associated with the oviducal gland. They are elongated sacs of smooth surface covered of a columnar epithelium with nuclei located basally. In mated females, the epithelium is associated with large numbers of sperm cells attached through their head, whereas the long sperm tails fill the sac cavity accompanied of numerous eosinophilic globules. Sperm waits there until oviposition.

Unlike in mature females, the oviducal glands of immature octopus show a very different appearance, with wide ducts of pleated and branched walls, forming numerous alveolar structures. These ducts exhibit a radial arrangement around the oviduct, and each duct and its lobules are separated from those adjacent by abundant connective tissues. The ducts are covered of a tall ciliated epithelium, and the walls do not show the appearance of glandular epithelium.

\subsubsection{Nidamental Glands (Fig. 4.30)}

The nidamental gland of cuttlefish is a large gland of massive appearance formed of a number of laminas extending from the periphery toward the center. The lamina is formed of two closely apposed thick layers of glandularepithelial tissue separated by a thin vasculo-connective axial region with an unusual appearance. The glandular cells are organized in parallel bands partially separated by processes of ciliated epithelial cells. In these bands, the gland cell nuclei are displaced toward the limit of the axial sheet or to the limit between adjacent bands, whereas the abundant cytoplasm with secretory granules is located toward the centro-apical region. This organization produces a characteristic pattern of parallel bands when sections are tangential to the lamina surface. The elongated glandular units may be anastomosed at some points. The covering cells are small cells with nuclei located mostly apically in the epithelium and long basal processes coursing mostly among gland cells toward the basis of the epithelium or to the lines between adjacent secretory bands. These cells are ciliated. Toward the tip of the lamina, the epithelium becomes progressively thinner, most glandular cells disappear and the epithelium changes to a thin highly ciliated epithelium similar to that covering the gland duct. Areas of ciliated epithelium can also be observed toward the base of laminas. The outer surface of the gland is formed of connective-vascular layers.

The accessory gland of cuttlefish is a large glandular structure filled of numerous wide tubular and alveolar structures surrounded with layers of connective and vascular tissue. Tubular parts of small diameter are covered with a simple cuboidal epithelium and have reduced lumen, whereas the dilated tubules and alveoli are covered by a flattened epithelium. Abundant amorphous secretory material can be appreciated inside of alveoli and tubules. Among tubules and alveoli run thin sheets of connective-vascular tissue with numerous blood vessels.

In immature female squid, the elongated nidamental gland shows a large number of closely parallel laminas formed of two apposed cuboid epithelia with a thin connective-vascular lamina between them. At the border of laminas, each layer of
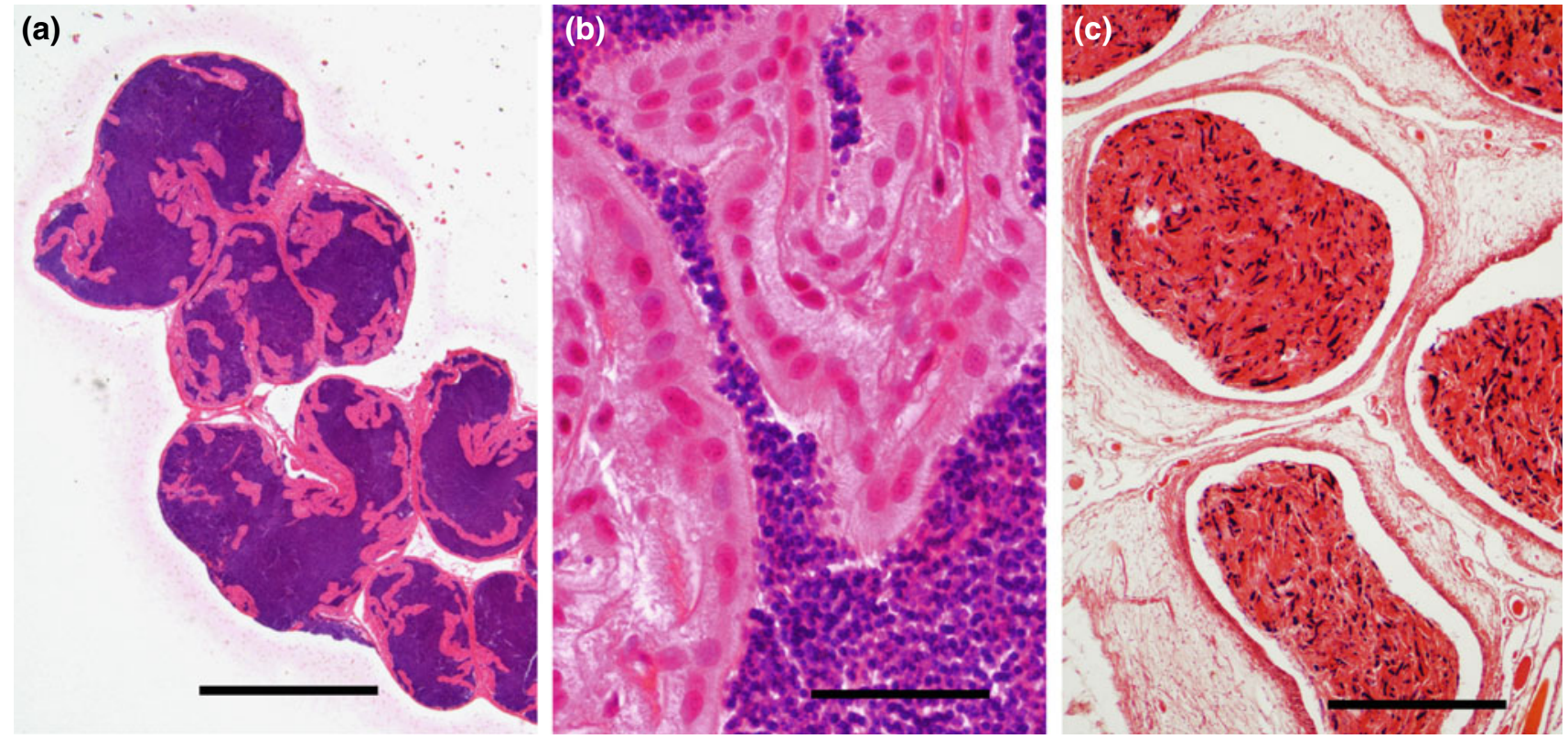

Fig. 4.32 Sections of the ependyme (coiled male duct) of cuttlefish $(\mathbf{a}, \mathbf{b})$ and octopus $(\mathbf{c})$. Note large amounts of spermatozoa and in $\mathbf{b}$, the thick epithelium covering the trabeculas that are characteristic of cuttlefish and squid. H\&E stain. Scale bars a $1 \mathrm{~mm} ; \mathbf{b} 50 \mu \mathrm{m} ; \mathbf{c} 500 \mu \mathrm{m}$ 
Fig. 4.33 a Section of the spermatophoric gland of a mature male octopus showing different parts, including a convoluted glandular region (1; Section 1), a thick-walled secretory part (3; Section 3) and a part of the proximal vas deferens with a sperm rope inside (outlined arrow) abutting Section 1. b Detail of the ciliated epithelium of the vas deferens. Star, lumen. c Detail of the convoluted glandular epithelium in Section 1. d, e Detail of glandular epithelia of Section 3 covering the convex wall (d) and the thicker outer region (e). Note the different appearance of basal regions, with solid invaginations in $\mathbf{d}$ and smooth in e. The apical epithelial cells are ciliated, as better shown in e. Stars, duct lumen.

f Section of the thick glandular epithelium of the spermatophoric gland of a cuttlefish, with an appearance similar to that octopus. The outlined arrow points to superficial epithelial (supporting) cells. g Detail of basal columns of gland cells that form most of the epithelium.

H\&E stain. Scale bars a $1 \mathrm{~mm}$; d, e $50 \mu \mathrm{m} ; \mathbf{b}, \mathbf{c}, \mathbf{f} 100 \mu \mathrm{m} ; \mathbf{g} 30 \mu \mathrm{m}$
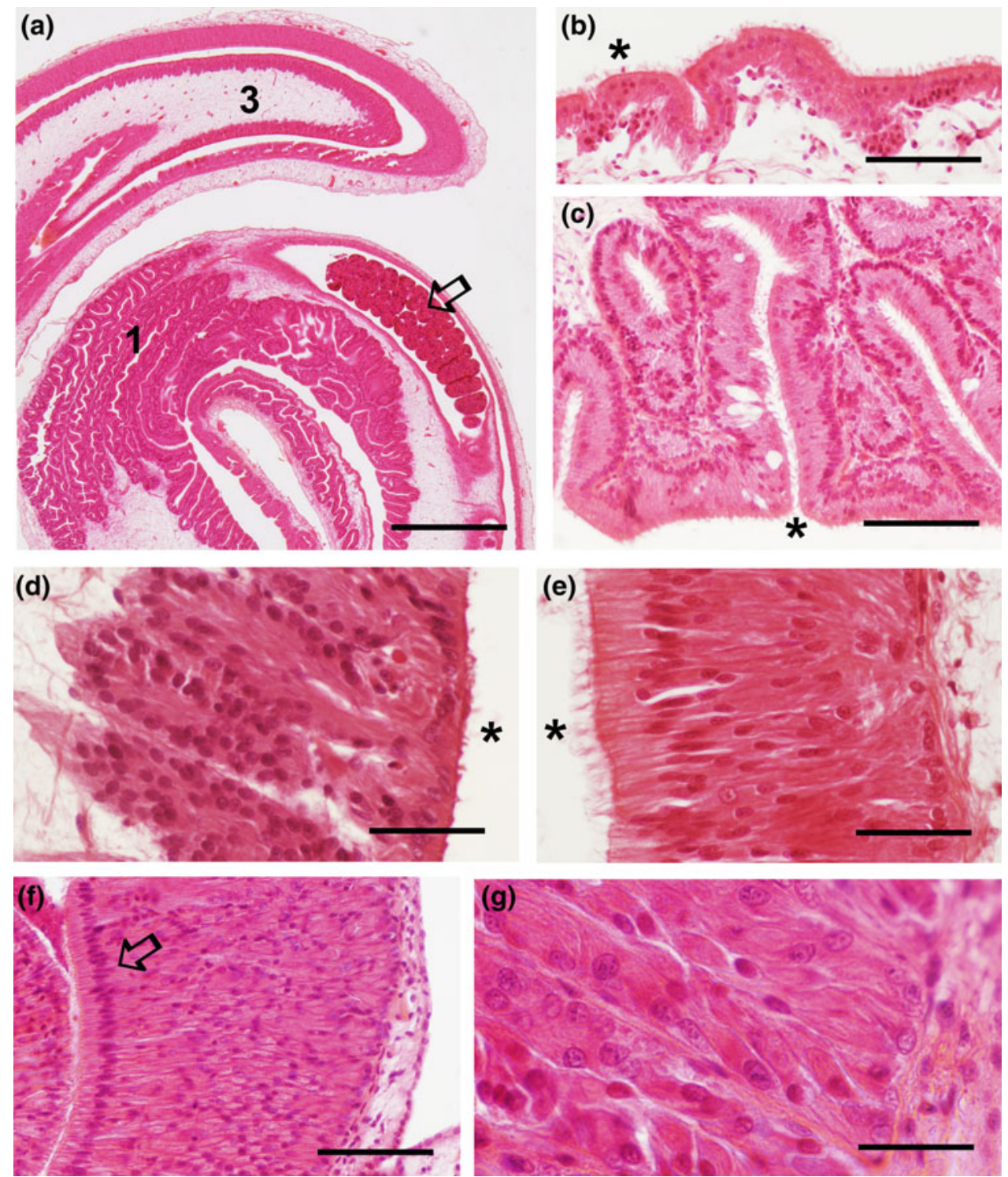

epithelium is continuous with that of the adjacent lamina. The epithelium shows frequent apical mitosis and lacks any glandular appearance at this immature stage.

\subsubsection{Male Reproductive Organs (Figs. 4.31, $4.32,4.33,4.34$ and 4.35 )}

The male reproductive system of coleoid cephalopods consists of a single testis and the gonoduct, which comprises the proximal deferent canal (male duct, spermiduct), blind-end seminal vesicles (spermatophoric glands) and associated accessory gland, the distal deferent canal and a dilatation that, in mature animals, contains spermatophores, the Needham's sac. It opens into the pallial cavity through the gonopore (Mann et al. 1970; Wells 1978).
The Testis (Fig. 4.31)

In immature males of cuttlefish, the testis is massive and formed of closely apposed testicular cords or tubules. The cords show a large number of germinal cells in different phases of maturation. In a mature male octopus, the massive testis consists of a number of thick-walled testicular tubules with maturing spermatozoa inside the lumen. The tubules are separated by a thin connective-vascular space. The walls of tubules show a sequence of stages of spermatogenesis from gonial stages outside to spermiogenesis near the lumen. Cysts of cells are easily recognized because they show the same appearance. The outermost cell layer is formed of spermatogonia attached to a connective membrane that at some places look like an epithelium. Mitosis is occasionally 
Fig. 4.34 a Transverse section of the accessory spermatophoric gland (spermatophoric gland system II, prostrate) of a mature male octopus showing numerous glandular tubules abutting the central duct. b Detail of the junction of tubules with the duct (star). c Section of tubules showing the secretory cells with nuclei in the outer region and supporting cells close to the lumen (arrow). d Section of the accessory spermatophoric gland of cuttlefish showing the glandular tissue. H\&E stain. Scale bars a $800 \mu \mathrm{m} ; \mathbf{b} 100 \mu \mathrm{m}$; c, d $50 \mu \mathrm{m}$
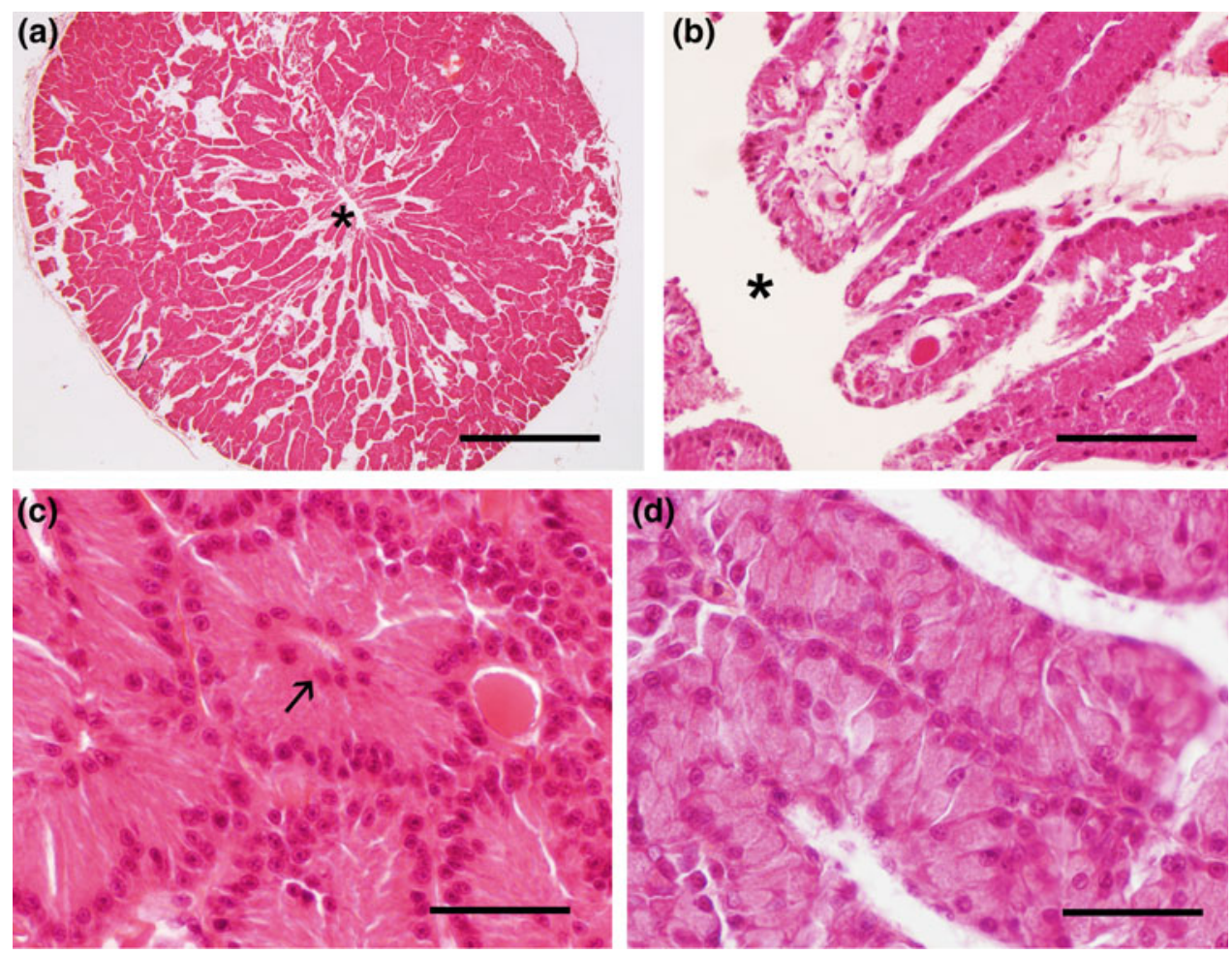

observed in this layer. In other areas, groups of secondary spermatogonia with fine chromatin are prophasic cells. Primary spermatocytes are numerous occupying next locations. These cells are characterized by their large size (they are the largest cells in the testis) and characteristic chromatin inside the nucleus that reveals that cells of each group are in the same phase of the long first meiotic prophase (leptotene, zygotene, pachytene and diplotene). Some cysts also appear in metaphase I showing paired chromosomes with a lozenge shape. This is the longest phase of the first meiotic division, and the anaphase I and telophase I are rarely observed. Most cells over the region of primary spermatocytes are small spermatids with small round nuclei, because spermatocytes II and second meiotic division are short-lived stages. Cysts of spermatids changing its nuclear shape (elongating) in various stages of transformation to spermatozoa can also be observed close to the lumen. Clumps of spermatozoa with long filamentous nucleus and tangles of long sperm flagella occupy the lumen of the tube.

\section{Proximal Vas Deferens and Ependymus (Fig. 4.32)}

In male cuttlefish, the ependymus appears as a tortuous dilated tube filled of spermatozoa, which in sections appears to consist of a pale cubic or flattened epithelium over a thin vasculo-connective lamina. In cuttlefish, the tube exhibits sparse meandering infolds of the epithelium, which is unlike the octopus. The large amounts of spermatozoa preclude a clear observation of the apical surface of these epithelial cells.
The spermatozoa leaving the octopus testis pass into the proximal vas deferens (Mann et al. 1970). In mature octopus, this highly convoluted duct consists of a ciliated epithelium surrounded by connective tissue. The duct is dilated by the presence of large masses (rope) of spermatozoa and has a rather smooth inner surface with opposite indentations. Numerous blood vessels enter the axis of the tubular complex.

\section{Spermatophoric Gland I (Seminal Vesicle) (Fig. 4.33)}

This complex part of the spermiduct follows the proximal vas deferens containing a beaded rope of spermatozoa in Fig. 4.33a. It is a convoluted structure in which three sectors can be distinguished from proximal to distal (Mann et al. 1970). A proximal region is characterized by the labyrinth formed by its finely pleated walls. Its inner walls consist of a high ciliated epithelium showing two layers of nuclei, those of ciliated cells in the apical region, and those of the numerous glandular cells in the basal region of the epithelium. The epithelium is finely pleated and a thin basal vasculo-connective layer separates its different folds. The third sector shows a C-shaped lumen because a side of the tube wall protrudes toward it. In this third region, the ciliated glandular epithelium is very thick and shows a striking appearance. Differences are noted between the thicker epithelium covering the outer, concave lumen surface and the thinner convex inner surface. In the outer lumen surface, a large number of nuclei are distributed through most of the epithelium thickness. Several rows of dense spindle-shaped 

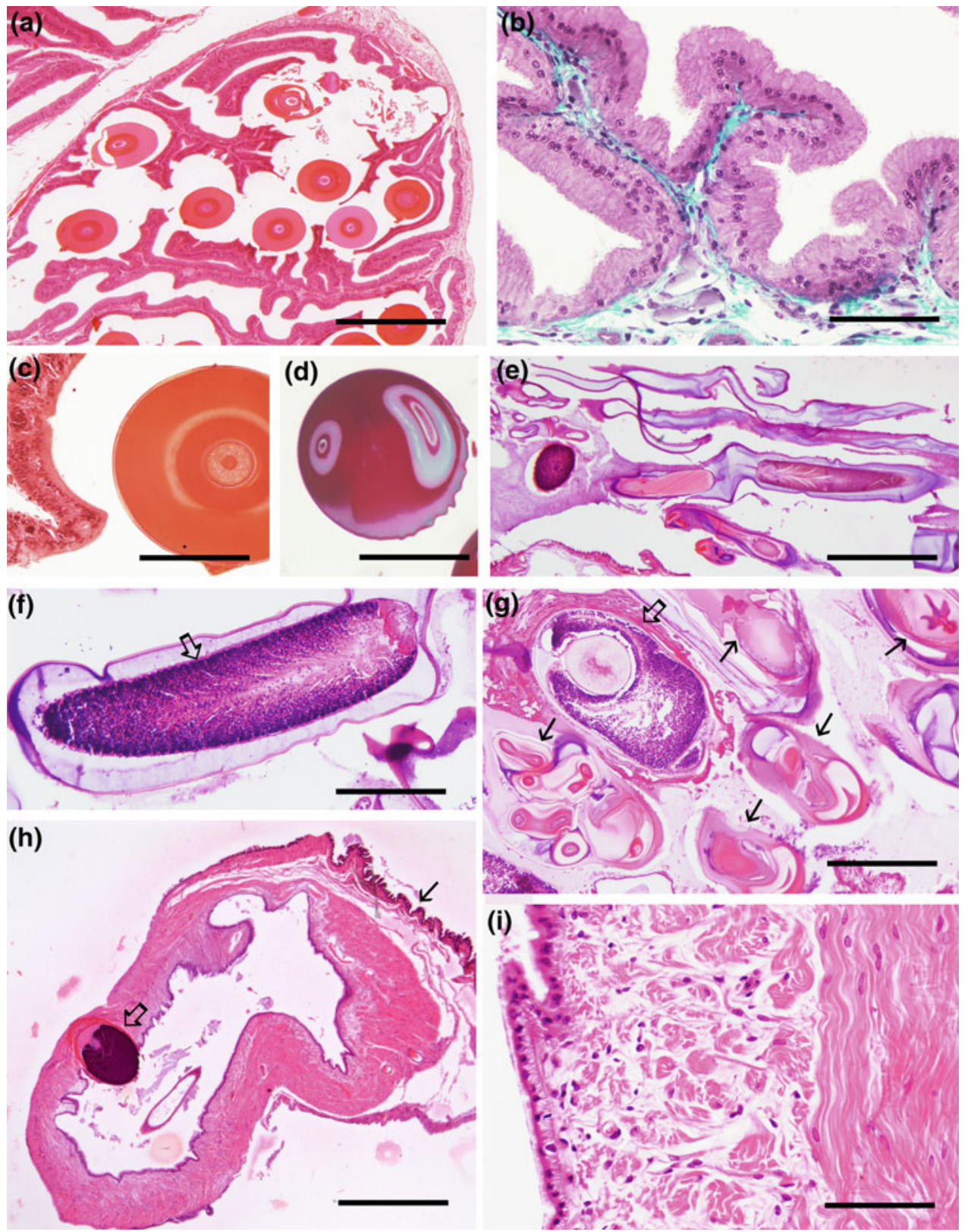

Fig. 4.35 a Transverse section showing a part of the octopus Needham's (spermatophoric) sac with spermatophores among extensive wall folds. $\mathbf{b}$ Detail of the simple thick epithelium covering the branched folds and the connective-vascular axes. c, $\mathbf{d}$ Sections of the "female oriented" ejection apparatus of octopus spermatophores showing the secretion spiral in $\mathbf{d}$. Note the layered organization of the ejaculatory apparatus. e Section of cuttlefish elongated spermatophores in Needham's sac showing different regions. f Section passing trout the cuttlefish spermatophore "male-oriented" pole containing the coiled rope of

nuclei are located apically, corresponding to nuclei of ciliated epithelial cells and apical mucous cells. Other glandular cells with larger and less-condensed nuclei are distributed along most of the thickness. Deep glandular cells appear grouped forming vertical columns corresponding with the lobes of the basal border of the epithelium. The distribution

spermatozoa. g Sections of spermatophores passing through the transition between the rope and the ejaculatory apparatus (outlined arrow) and through different levels of this apparatus (thin arrows). Note the complex spermatophore organization. $\mathbf{h}$ Transverse section of the terminal organ (penis) of a squid showing a spermatophore (outlined arrow) lodged in one of the longitudinal grooves of the wall. Note skin papillae (thin arrow). i Detail of the covering epithelium and the longitudinal and circular muscle layers. a, c, e-i H\&E stain; b, d Masson's trichrome. Scale bars a $500 \mu \mathrm{m} ; \mathbf{b}$ I, $50 \mu \mathrm{m} ; \mathbf{c}, \mathbf{d}, \mathbf{f}, \mathbf{g}, 100 \mu \mathrm{m} ; \mathbf{e}, \mathbf{h} 200 \mu \mathrm{m}$

of glandular cells in the convex surface of this sector is clearly lobular, with basal lobes extending in the loose connective submucosa. Deep glandular cells show an eosinophilic cytoplasm but do not show secretory granules. In tangential sections through the apical part of the epithelium, a mosaic of necks of glandular cells of two types is 
appreciable. In some parts of the thick epithelium, there are large cells with large nuclei often showing a conspicuous nucleolus. These cells probably correspond to intraepithelial sensory neurons. In the region containing these cells, small intraepithelial nerve bundles are also seen coursing horizontally near the base of the epithelium. Below the epithelium, there is a layer of loose connective tissue that links the major turns of the glandular conduct.

In mature male cuttlefish, the thick epithelium of the spermatophoric sector 3 appears quite similar to that of octopus. The lobed appearance of the basal glandular region is more pronounced than in octopus, and thin connective laminas ascend among lobes till the subapical region.

\section{Spermatophoric Gland II (Accessory Gland, Prostrate)}

\section{(Fig. 4.34)}

This is a massive gland that in octopus consists of a highly branched system of thick-walled convoluted glandular tubules that radiate from a central canal. The gland is surrounded by a thin connective capsule, whereas thin laminas of vasculo-connective tissue extend from it inside the gland and branch separating glandular tubules. Blood vessels are numerous. The tubules consist of two types of cell. Most of the thickness of the epithelium is formed of glandular cells with basal nuclei. Other cells are ciliated and show apical nuclei located near the central lumen. The ciliated nature of these cells is better observed in sagittal sections of tubules, since in transverse sections the lumen is narrow or very narrow. At the junction of proximal tubules with the gland duct, the glandular epithelium diminishes its thickness and transforms in a ciliated cuboidal epithelium.

In mature male cuttlefish, the massive accessory gland consists of tubules with glandular and ciliated epithelial cells that are similar to those described in octopus.

\section{Distal Vas Deferens (Transition to the Needham's Sac)} In octopus, this part of the gonoduct consists of a tube with the lumen invaded by long epithelial laminas accompanied of a vasculo-connective axis. Secondary laminas are numerous along the longest primary laminas. The epithelium is formed of cuboidal cells with numerous apical cilia, showing a homogeneous appearance.

\section{Needham's (Spermatophoric) Sac, Spermatophores and Penis (Fig. 4.35)}

The Needham's pouch or sac of mature male octopus is a wide sac of pleated inner walls covered in most parts of a thick glandular epithelium that contains the mature spermatophores waiting for breeding. The epithelium consists of tall ciliated cells with round nuclei. Nuclei of these cells are dense and locate at the basal pole of glandular cells, whereas a granular secretion occupies most of the apical cytoplasm. At the transition of this glandular epithelium to non-glandular regions, the tall glandular cells disappear, whereas covering cells form then all the epithelium. The glandular zone lies over a rich vasculo-connective layer. The folds of the inner wall of the sac in the glandular zone consist of long primary and short secondary folds sometimes bifurcated, whereas the folds are short and simple in non-glandular regions. The folded region surrounds spermatophores that in sections appear as long rods or circles depending on the plane of the section. Surrounding the sac, there is a loose connective wall containing numerous blood vessels, but apparently lacking muscular tissue.

\section{Spermatophores}

Spermatophores of octopus and cuttlefish are very long slender structures bearing large packets of spermatozoa that consist of two moieties, one that bears the rope of spermatozoa at one end and the other, the ejaculatory apparatus, in the other. The spermatophores of cuttlefish were first described in the seventieth century by Swammerdam, who represented five different parts including the long anterior flagellum, the coiled ejaculatory apparatus, a vitreous portion, a white substance and a posterior "perlucida" part. Since spermatophores are very large structures (about $2-3 \mathrm{~cm}$ long in octopus), histological sections provide details of parts but make difficult to understand the whole organization. Here, only some details of cuttlefish spermatophores will be presented. In sections through the posterior region, the coiled rope of spermatozoa shows a thin laminar appearance with thin laminas of eosinophilic material separating turns. The heads of spermatozoa are oriented obliquely toward the walls and the mass of tails and including materials toward the center and anteriorly. This spermatangium is surrounded by a thick slightly basophilic inner tunica and a thin eosinophilic outer tunica. These tunics extend till the tip of the flagellum surrounding the other spermatophore structures. The anterior limit of the spermatangium is a flask-like structure called the cement body of complex shape that after a constriction continues in a coiled layered structure that stains differentially. It disappears in the flagellum. For further data on spermatophores and the spermatophore reaction, see Mann et al. (1970), Marian and Domaneschi (2012) and Marian (2012).

\section{Terminal Organ or Penis}

From the spermatophoric sac, octopus spermatophores enter singly in the terminal spermatophoric duct consisting of the diverticulum and terminal organ or "penis" (Mann et al., 1970). In sections, the duct appears covered with a thick epithelium that consists of ciliated and mucous glandular cells. In the lumen, the single spermatophore is appreciable. The epithelium shows small undulations and invaginations. The epithelial duct is surrounded by connective tissue containing a large number of blood vessels. 


\subsection{Concluding Remarks}

The chapter presents a basic histological and functional study of the various tissues of fascinating cephalopods. For those readers studying aspects of the cephalopod biology, it intends to be a convenient guide on the basic knowledge on the histological organization of their various functional systems. For readers unfamiliar with cephalopods, it may uncover them the strange organization of tissues and systems in these successful soft-bodied carnivorous mollusks, which show both some surprising convergences and most often large divergences with the body organization of vertebrates, including man.

Acknowledgements We thank José Manuel Antonio Durán (IIM-CSIC) for his technical assistance in necropsies and tissue processing for histological analysis.

\section{References}

Andouche A, Bassaglia Y, Baratte S, Bonnaud L (2013) Reflectin genes and development of iridophore patterns in Sepia officinalis embryos (Mollusca, Cephalopoda). Dev Dyn 242:560-571. https:// doi.org/10.1002/dvdy.23938

Beuerlein K, Schipp R (1998) Cytomorphological aspects on the response of the branchial heart complex of Sepia officinalis L. (Cephalopoda) to xenobiotics and bacterial infection. Tissue Cell 30:662-671

Beuerlein K, Schimmelpfennig R, Westermann B, Ruth P, Schipp R (1998) Cytobiological studies on hemocyanin metabolism in the branchial heart complex of the common cuttlefish Sepia officinalis (Cephalopoda, Dibranchiata). Cell Tissue Res 292:587-595

Boletzky SV (1986) Encapsulation of cephalopod embryos-a search for functional correlations. Am Malacol Bull 4:217-227. http:// biostor.org/reference/143198

Boucaud-Camou E, Boucher-Rodoni R (1983) Feeding and digestion in cephalopods. In Saleuddin ESM, Wilbur KM (eds) The Mollusca, vol 5, part 2. Academic Press, New York

Budelmann BU, Schipp R, Boletzky S (1997) Cephalopoda. In: Harrison FW, Humes AG (eds) Microscopic Anatomy of Invertebrates, vol 6A, Mollusca II. Whiley-Liss, New York, pp 119-414

Cajal SR (1917) Contribución al conocimiento de la retina y centros ópticos de los cefalópodos. Trab Lab Invest Biol Univ Madrid $15: 1-82$

Castellanos-Martínez S, Prado-Álvarez M, Lobo-da-Cunha A, Azevedo C, Gestal C (2014) Morphologic, cytometric and functional characterization of the common octopus (Octopus vulgaris) hemocytes. Dev Comp Immunol 44:50-58. https://doi.org/10.1016/ j.dci.2013.11.013

Checa AG, Cartwright JH, Sánchez-Almazo I, Andrade JP, Ruiz-Raya F (2015) The cuttlefish Sepia officinalis (Sepiidae, Cephalopoda) constructs cuttlebone from a liquid-crystal precursor. Sci Rep 5:11513. https://doi.org/10.1038/srep11513

Chun C (1914) The Cephalopoda. 1975 English translation freely available in https://archive.org/details/cephalopoda00chun

Cole AG, Hall BK (2009) Cartilage differentiation in cephalopod molluscs. Zoology (Jena) 112:2-15. https://doi.org/10.1016/j.zool. 2008.01.003

Costa PM, Rodrigo AP, Costa MH (2014) Microstructural and histochemical advances on the digestive gland of the common cuttlefish. Zoomorphology 133:59-69
Crookes WJ, Ding LL, Huang QL, Kimbell JR, Horwitz J, McFall-Ngai MJ (2004) Reflectins: the unusual proteins of squid reflective tissues. Science 303(5655):235-238

Cuvier G (1817) Mémoires pour servir á l'histoire et a l'anatomie des mollusques. Chez Deterville, Paris. Freely available at https:// archive.org/details/mmoirespourser00cuvi

DeMartini DG, Izumi M, Weaver AT, Pandolfi E, Morse DE (2015) Structures, organization, and function of reflectin proteins in dynamically tunable reflective cells. J Biol Chem 290:1523815249. https://doi.org/10.1074/jbc.M115.638254

Derby CC (2014) Cephalopod ink: production, chemistry, functions and applications. Mar Drugs 12:2700-2730. https://doi.org/10. 3390/md12052700

Di Cosmo A, Di Cristo C (1998) Neuropeptidergic control of the optic gland of Octopus vulgaris: FMRF-amide and GnRH immunoreactivity. J Comp Neurol 398:1-12

Di Cosmo A, Di Cristo C, Paolucci M (2001) Sex steroid hormone fluctuations and morphological changes of the reproductive system of the female of Octopus vulgaris throughout the annual cycle. J Exp Zool 289:33-47

Dilly PN, Nixon M (1976) The cells that secrete the beaks in octopods and squids (Mollusca, Cephalopoda). Cell Tissue Res 167:229-241

Ding D, Guerette PA, Hoon S, Kong KW, Cornvik T, Nilsson M, Kumar A, Lescar J, Miserez A (2014) Biomimetic production of silk-like recombinant squid sucker ring teeth proteins. Biomacromol 15(9):3278-3289. https://doi.org/10.1021/bm500670r

Girod P (1881) Recherches sur la poche du noir des Céphalopodes des côtes de France. Typographie A. Hennuyer, Paris. https://archive. $\mathrm{org} /$ search.php?query=recherchessurlap00giro

Guerette PA, Hoon S, Ding D, Amini S, Masic A, Ravi V, Venkatesh B, Weaver JC, Miserez A (2014) Nanoconfined $\beta$-sheets mechanically reinforce the supra-biomolecular network of robust squid sucker ring teeth. ACS Nano 8:7170-7179

Guérin M (1908) Contribution à l'étude des systèmes cutané, musculaire et nerveux de l'appareil tentaculaire des Céphalopodes. Arch Zool Exp Gen 8:1-178. https://archive.org/details/ contributionl00gu

Hanlon R (2007) Cephalopod dynamic camouflage. Curr Biol 17(11): R400-R404

Hensen V (1865) Über das Auge einiger Cephalopoden. Wilhelm Engelmann, Leipzig

Hiew SH, Guerette PA, Zvarec OJ, Phillips M, Zhou F, Su H, Pervushin K, Orner BP, Miserez A (2016) Modular peptides from the thermoplastic squid sucker ring teeth form amyloid-like cross- $\beta$ supramolecular networks. Acta Biomater 46:41-54. https://doi.org/ 10.1016/j.actbio.2016.09.040

Huffard CL (2013) Cephalopod neurobiology: an introduction for biologists working in other model systems. Invert Neurosci 13:1118. https://doi.org/10.1007/s10158-013-0147-z

Isgrove A (1909) Eledone. Williams \& Norgate: London. Freely available in https://archive.org/stream/eledone00isgr\#page/n5/mode/2up

Johnsen S, Kier WM (1993) Intramuscular crossed connective tissue fibres: skeletal support in the lateral fins of squid and cuttlefish (Mollusca: Cephalopoda). J Zool Lond 231:311-338

Kier WM (1985) The musculature of squid arms and tentacles: ultrastructural evidence of functional differences. J Morphol 185:223-239

Kier WM (2016) The musculature of coleoid cephalopod arms and tentacles. Front Cell Dev Biol 4:10. https://doi.org/10.3389/fcell. 2016.00010

Kier WM, Curtin NA (2002) Fast muscle in squid (Loligo pealei): contractile properties of a specialized muscle fibre type. J Exp Biol 205:1907-1916. http://jeb.biologists.org/content/205/13/1907

Kier WM, Smith KK (1985) Tongues, tentacles and trunks: the biomechanics of movement in muscular-hydrostats. Zool J Linn Soc 83:307-324

Kier WM, Stella MP (2007) The arrangement and function of octopus arm musculature and connective tissue. J Morphol 268:831-843 
Kurth JA, Thompson JT, Kier WM (2014) Connective tissue in squid mantle is arranged to accommodate strain gradients. Biol Bull 227:1-6

Le Pabic C, Goux D, Guillamin M, Safi G, Lebel JM, Koueta N, Serpentini A (2014) Hemocyte morphology and phagocytic activity in the common cuttlefish (Sepia officinalis). Fish Shellfish Immunol 40:362-373. https://doi.org/10.1016/j.fsi.2014.07.020

Lee DG, Park MW, Kim BH, Kim H, Jeon MA, Lee JS (2014) Microanatomy and ultrastructure of outer mantle epidermis of the cuttlefish, Sepia esculenta (Cephalopoda: Sepiidae). Micron 58:38 46. https://doi.org/10.1016/j.micron.2013.11.004

Mann T, Martin AW, Thiersch JB (1970) Male reproductive tract, spermatophores and spermatophoric reaction in the giant octopus of the North Pacific, Octopus dofleini martini. Proc R Soc Lond B 175:31-61. https://doi.org/10.1098/rspb.1970.0010

Marian JEAR (2012) Spermatophoric reaction reappraised: novel insights into the functioning of the loliginid spermatophore based on Doryteuthis plei (Mollusca: Cephalopoda). J Morphol 273:248278. https://doi.org/10.1002/jmor.11020

Marian JEAR, Domaneschi O (2012) Unraveling the structure of squids' spermatophores: a combined approach based on Doryteuthis plei (Blainville, 1823) (Cephalopoda: Loliginidae). Acta Zool Stockholm 93:281-307

Matus AI (1971) Fine structure of the posterior salivary gland of Eledone cirrosa and Octopus vulgaris. Z Zellforsch Mikrosk Anat 122:111-121

Messenger JB, Young JZ (1999) The radular apparatus of cephalopods. Phil Trans R Soc Lond B 354:161-182

Meyer WTh (1913) Tintenfishche mit besondere Berücksichtigung von Sepia und Octopus. Verlag von Dr. Werner Kinkhardt, Leipzig. Freely available in https://archive.org/details/tintenfischemitb 00meye

Mommsen TP, Ballantyne J, Macdonald D, Gosline J, Hochachka PW (1981) Analogues of red and white muscle in squid mantle. Proc Natl Acad Sci USA 78:3274-3278

Osorio D (2014) Cephalopod behaviour: skin flicks. Curr Biol 24(15): R684-R685. https://doi.org/10.1016/j.cub.2014.06.066

Owen R (1855) Lectures on the comparative anatomy and physiology of the invertebrate animals: delivered at the Royal College of Surgeons. Longman, London. Freely available in https://archive. org/details/lecturesoncompar1855owen

Packard A (1995) Organization of cephalopod chromatophore systems: a neuromuscular image generator. In: Abbott NJ, Williamson R, Maddock L (eds) Cephalopod neurobiology: neuroscience studies in squid, octopus and cuttlefish. Oxford UP, London, pp 331-367

Packard A, Trueman ER (1974) Muscular activity of the mantle of Sepia and Loligo (Cephalopoda) during respiratory movements and jetting, and its physiological interpretation. J Exp Biol 61:411-419

Palumbo A (2003) Melanogenesis in the ink gland of Sepia officinalis. Pigment Cell Res 16:517-522

Polese G, Bertapelle C, Di Cosmo A (2015) Role of olfaction in Octopus vulgaris reproduction. Gen Comp Endocrinol 210:55-62. https://doi.org/10.1016/j.ygcen.2014.10.006
Rosenbluth J, Szent-Györgyi AG, Thompson JT (2010) The ultrastructure and contractile properties of a fast-acting, obliquely striated, myosin-regulated muscle: the funnel retractor of squids. J Exp Biol 213:2430-2443

Ruder T, Sunagar K, Undheim EA, Ali SA, Wai TC, Low DH, Jackson TN, King GF, Antunes A, Fry BG (2013) Molecular phylogeny and evolution of the proteins encoded by coleoid (cuttlefish, octopus, and squid) posterior venom glands. J Mol Evol 76:192-204. https://doi.org/10.1007/s00239-013-9552-5

Schaeffel F, Murphy CJ, Howland HC (1999) Accommodation in the cuttlefish (Sepia officinalis). J Exp Biol 202:3127-3134

Schipp R, Schäfer A (1969) Vergleichende elektronenmikroskopische Untersuchungen an den zentralen Herzorganen von Cephalopoden (Sepia officinalis). Z Zellforsch 101:367-379

Swammerdam J (1737) Biblia Naturae. Leyden. Freely available in https://archive.org/details/BybeldernatuureISwam

Tan Y, Hoon S, Guerette PA, Wei W, Ghadban A, Hao C, Miserez A, Waite JH (2015) Infiltration of chitin by protein coacervates defines the squid beak mechanical gradient. Nat Chem Biol 11:488-495. https://doi.org/10.1038/nchembio.1833

Tramacere F, Beccai L, Kuba M, Gozzi A, Bifone A et al (2013) The morphology and adhesion mechanism of Octopus vulgaris suckers. PLoS ONE 8(6):e65074. https://doi.org/10.1371/journal.pone. 006507

Tramacere F, Kovalev A, Kleinteich T, Gorb SN, Mazzolai B (2014) Structure and mechanical properties of Octopus vulgaris suckers. J R Soc Interface 11:20130816. https://doi.org/10.1098/rsif.2013. 0816

Troncone L, De Lisa E, Bertapelle C, Porcellini A, Laccetti P, Polese G, Di Cosmo A (2015) Morphofunctional characterization and antibacterial activity of haemocytes from Octopus vulgaris. J Nat Hist 49:1457-1475. https://doi.org/10.1080/00222933.2013. 826830

Uyeno TA, Kier WM (2005) Functional morphology of the cephalopod buccal mass: a novel joint type. J Morphol 264:211-222

Wells MJ (1978) Octopus. Physiology and behaviour of an advanced invertebrate. Chapman and Hall, London

Wells MJ, Wells J (1982) Ventilatory currents in the mantle of cephalopods. J Exp Biol 99:315-330

Williams LW (1909) The anatomy of the common squid Loligo pealii Lesueur. Brill, Leiden. Freely available in https://archive.org/ details/anatomyofcommons00will

Young JZ (1965) The nervous pathways for poisoning, eating and learning in octopus. J Exp Biol 43:581-593

Young JZ (1971) The anatomy of the nervous system of Octopus vulgaris. Clarendon Press, Oxford

Young JZ (1995) Multiple matrices in the memory system of Octopus. In: Abbott NJ, Williamson R. Maddock L (eds) Cephalopod neurobiology: neuroscience studies in squid, octopus and cuttlefish. Oxford UP, London, pp 431-443

Young RE, Vecchione M (2002) Evolution of the gills in the Octopodiformes. Bull Mar Sci 71:1003-1017
Open Access This chapter is licensed under the terms of the Creative Commons Attribution 4.0 International License (http:// creativecommons.org/licenses/by/4.0/), which permits use, sharing, adaptation, distribution and reproduction in any medium or format, as long as you give appropriate credit to the original author(s) and the source, provide a link to the Creative Commons licence and indicate if changes were made.
The images or other third party material in this chapter are included in the chapter's Creative Commons licence, unless indicated otherwise in a credit line to the material. If material is not included in the chapter's Creative Commons licence and your intended use is not permitted by statutory regulation or exceeds the permitted use, you will need to obtain permission directly from the copyright holder. 